\title{
LIFE CYCLES: A RETROSPECTIVE ANALYSIS OF TRANSPORTATION BEHAVIOURS AND ATTITUDES
}

\author{
by \\ Mark D Romeril \\ (BA, Political Science, University of Guelph 2006)
}

\author{
A Major Research Paper \\ presented to Ryerson University \\ In partial fulfillments of the requirements \\ For the degree of \\ Master of Planning \\ in \\ Urban Development
}

Ryerson University, Toronto, Ontario, Canada 2014

(C) Mark Romeril 2014 


\section{Author's Declaration}

I hereby declare that I am the sole author of this major research paper. This is a true copy of the major research paper, including any required final revisions, as accepted by my examiners. I authorize Ryerson University to lend this major research paper to other institutions or individuals for the purpose of scholarly research I further authorize Ryerson University to reproduce this major research paper by photocopying or by other means, in total or in part, at the request of other institutions or individuals for the purpose of scholarly research. I understand that my major research paper may be made electronically available to the public. 


\title{
LIFE CYCLES: A RETROSPECTIVE ANALYSIS OF TRANSPORTATION BEHAVIOURS AND ATTITUDES
}

CMark D Romeril, 2014

\author{
Master of Planning \\ In \\ Urban Development \\ Ryerson University
}

\begin{abstract}
This study seeks to explore the factors that have encouraged people to start cycling more frequently, despite lack of improvements of cycling facilities in Toronto. This study uses a Grounded Theory methodology, and a mixed method approach. A literature review was performed to identify the initial sample, and additional literature was used to make a theoretical sub-sample later in the study. Primary data was collected through a survey, focus group and a follow-up questionnaire. The data was analyzed using open and theoretical coding techniques, memo-writing, and critical case analysis. During the process of answering the research questions, a conceptual model was developed to aid in the visualization of the theoretical complexity involved in mode-choice. These results were discussed in a broader context, including implications for the future of cycling-as-transportation in Toronto, as well as possibilities for future research.
\end{abstract}

\section{Key words:}

Cycling, Transportation Sociology, Behaviour Change Intervention, Transtheoretical Model, Grounded Theory 


\section{ACKNOWLEDGEMENTS}

To Dr. Shelagh McCartney. You're straight up and genuine - I like that. I have a lot respect for the passion and insight that you bring to work every day, even when other things in life don't quite go as planned. After our first meeting, I felt a hunch that I'd to well to work with you during my remaining time at Ryerson. Sure enough, the Black Creek Studio, as well as this MRP, has captivated my mind and shaped the trajectory of my thoughts. Thank you for your efforts in projects past, and for supervising this research project in particular.

The most impactful thing you've instilled in me is the need of a critical filter to promote effective communication. When I would come into your office, and talk about things that send sparks flying in my mind, you seemed receive them with ease and grace, and respond with the cool response "Why are you telling me this?" This was incredibly helpful, as it has refreshed a self-awareness about my approach to communication: When time is scarce, and every second of captive attention is priceless, there can be no chaff - only kernels.

Thank you to all the participants in this project, without you, I would have had a much shorter, and decidedly less interesting paper.

I want to thank Dr. Beth Savan, for her patience, insight and expertise. By extension, thanks to the whole research team at the Cycling Think and Do Tank. The direction and scope of their early work has served as an important theoretical cornerstone, as well as a point of departure for my own research. I hope you find this paper as interesting to read, as I found it to write.

I want to thank Dr. Joe Springer, and Dr. Pamela Robinson; your input on the design of the research, and support during its execution helped, and guided me. Our few meetings were as important as they were brief.

Thanks to Cycle Toronto for providing me with potential opportunities to imagine, and ultimately live-out some of the ideas contained within these pages. This is a partnership to which I look forwards to very, very much.

Finally, a big thank you all the friends and warm spaces, in various places, which served as my refuge. You have all saved me from myself on at least once occasion- especially my housemates, Roddie Ko and Megan Jonk. This last year wouldn't have been the same without you both. 


\section{DEDICATION}

To my mother and father.

Everything that I am today, I owe to you both.

I fear I do not say it often enough...

I love you immensely - forever, and always. 


\section{Table of Contents}

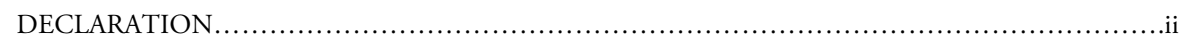

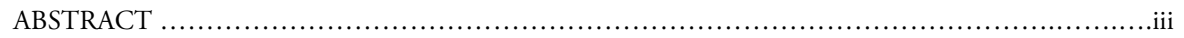

ACKNOWLEDGMENTS.......................................................................

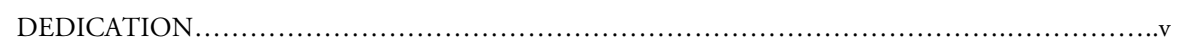

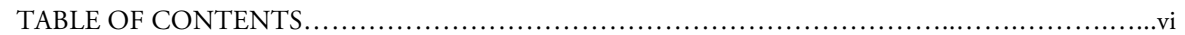

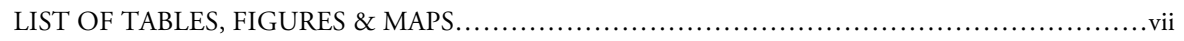

CHAPTER 1. INTRODUCTION 1

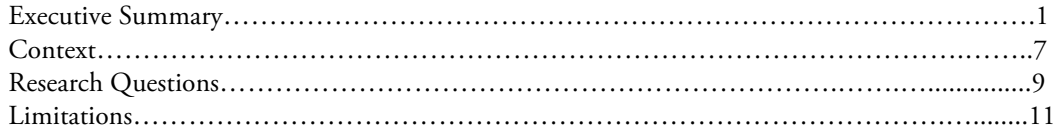

\begin{tabular}{ll} 
CHAPTER 2. LITERATURE REVIEW & 12 \\
\hline
\end{tabular}

Benefits of Riding a Bicycle.......................................................... 12

Built Form, Poverty, Health and Transportation ............................................15

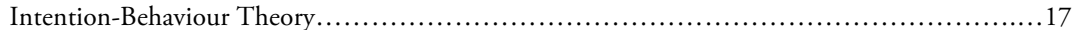

CHAPTER 3. GROUNDED THEORY: METHODOLOGY \& METHODS

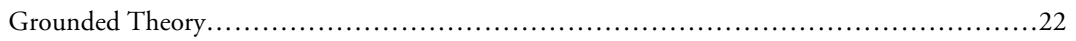

Methods in Grounded Theory............................................................23

CHAPTER 4. RESEARCH METHODS

Ethics Review................................................................. 26

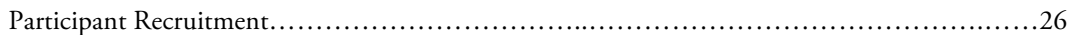

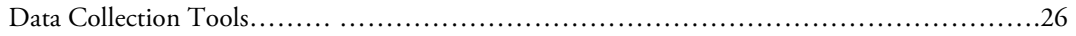

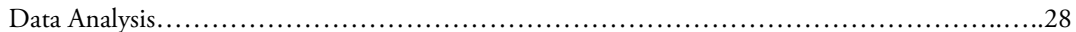

\begin{tabular}{lr} 
CHAPTER 5. RESULTS \& ANALYSIS & 29 \\
\hline
\end{tabular}

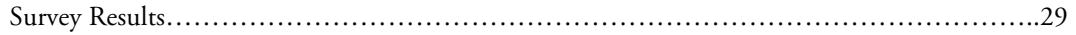

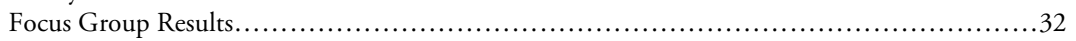

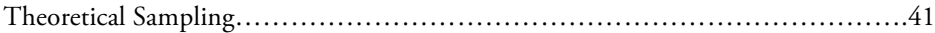

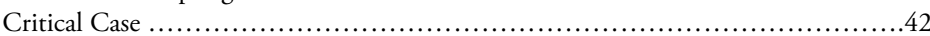

CHAPTER 6. SUMMARY \& REFLECTIONS 51

CHAPTER 7. CONCLUSIONS \& NEXT STEPS

\section{APPENDICIES}

Appendix A - Literature Review - Intention-Behaviour Theory

Appendix B - Survey

Appendix C - Focus Group Questions

Appendix D - Recruitment E-mail

Appendix E - Recruitment Poster

Appendix F - Participant Consent Form

Appendix G - Focus Group Transcripts and Coding

Appendix $\mathrm{H}-\mathrm{Memos}$

Appendix I - Follow Up Questions

\section{WORKS CITED}




\section{LIST OF TABLES, FIGURES AND MAPS}

\section{Tables}

Table $1 \quad$ Selective Sample Demographics..................................2, 29

Table 2 Theoretical Codes for Focus Group................................33

Table 3 Memo Samples, Categories \& Cluster...............................34

\section{Figures}

Figure 1

Figure 2

Figure 3

Figure 4.1

Figure 4.2

Figure 5

Figure 6

Figure 7.1

Figure 7.2

Figure 8

Figure 9

Figure 10

\section{Maps}

Map 1

Map 2

Map 3

Map 4
Participants Reasons for Riding............................... 30

Significant Motivator for Riding More............................ 30

Significant Barrier from Riding More............................. 30

Participant by 'Type of Cyclist' ....................................3, 31

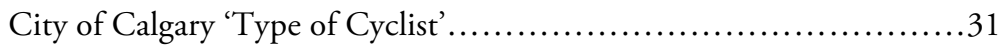

The Psychosocial Dynamic...................................... 35

Psychosocial Dynamic with Physical Factors............................36

Strong and Fearless Dynamic...................................... 36

Interested, but Concerned Dynamic....................................36

TTM and Mode Choice Dynamic................................... 37

Staged Mode Choice Ecosystem.................................4, 35

Sallis Ecological Model....................................... 45

Hulchanski's Three Cities.......................................17, 51

AR's Approximate Commute........................................ 46

Ledsham's Mapping Cycling Behaviour...............................51

Draft Bicycle Priority Framework...................................5 


\title{
Chapter 1. INTRODUCTION
}

\section{Executive Summary}

The City of Toronto Bicycle Plan (2001) had proposed a network of $495 \mathrm{~km}$ of on-street bicycle lanes, with a total planned network of $1000 \mathrm{~km}$ across city by 2011 . Even after three years have elapsed since the end of the Bicycle Plan, progress towards reaching the targets has been slow. At current rate of construction, it will take approximately 158 years to complete the network as outlined 2001 Bicycle Plan (Kolb, 2014). However, there has been a noticeable increase in the number of riders on Toronto's streets. Bicycle counts performed on College St. during afternoon peak on a weekday in the autumn revealed that the traffic volume was over $50 \%$ bicyclists (Kolb, 2013). More importantly, there appears to have been a $67 \%$ increase when compared to the volume of bicyclists at a similar intersection three years prior (Kolb, 2013). This research project set out to explore the major question: what has encouraged people to start cycling more frequently, despite lack of improvements of cycling facilities? There are other questions that also compliment this major research question, and they are as follows:

\author{
1. What 'type' of cyclists are those that have recently begun to ride frequently for more practical purposes? \\ 2. What is the impact of geography, bicycle infrastructure and facilities in participants' decision to ride a bicycle more frequently \\ for practical purposes? \\ 3. Of those persons that currently cycle frequently for more practical purposes, is it behaviour continued from prior in life, or a \\ recently adopted behaviour? \\ 4. Did transitional life experiences have a large influence on the decision to cycle more frequently for practical purposes? \\ 5. What has most encouraged these riders to develop the skills and confidence to ride more frequently for practical purposes?
}

This study sought to answer these research questions, and in the process, generate a conceptual model to aid in the visualization of the complex theoretical interactions involved. This research utilizes a mixed-methods approach, beginning with a literature review, followed by primary data gathered from a survey, focus group and additional questionnaires. The literature involved in this research draws from the fields of public health, environmental education, behvioural psychology, transportation sociology, and sought to find intersections and connections between them all. Because of the multi-disciplinary quality of this research, a flexible research methodology such as Grounded Theory was ideal.

Grounded Theory is suited to incorporate and interpret complex phenomena (Charmaz, 2003). It is adept in conceptually dissecting socially constructed experiences (Charmaz 2006, Goulding, 1998), and can be used to clarify theories and identify opportunities for future research methodology. For these reasons, Grounded Theory was adopted as the methodological approach, which also influenced the participant selection, the coding and categorization of data, and interpretive memo-writing that were used in this research and analysis, revealing discussion and insights. 
The literature review contained three distinct sections. The first section considered the multiple benefits that cycling can offer. There are environmental benefits, due decreased congestion and pollution. There are economic benefits, also related to decreased congestion, but also because of cost savings in public infrastructure expenditures. There are health benefits to the individual, as well as broader cost savings across society. The second section of the literature review examined the connections between health and poverty, poverty and built form, and how transportation interacts all of the above. The third section of the literature review examined intention-behaviour theories, specifically regarding the strengths and weakness of the Transtheoretical Model (TTM). Prochaska, DiClemente and Norcross (1992) characterize TTM has consisting of six stages: pre-contemplation, contemplation, preparation, action, and maintenance. This is a popular framework used to plan behaviour change interventions, and in recent years, it has also been adapted to for behaviour change involving physical activity. TTM is criticized because there is a great deal of research that focuses on the change between stages, as a result in and of itself, a persistent difficulty in differentiating the stages (maintenance vs. pre-contemplation), as well as possibility of relapsing to pre-intervention behaviors. However, the conceptual model was developed over the course of this study attempts to address some of these criticisms.

The study selectively sampled 12 participants. They were all over the age of 16 , residents of Toronto, and rode a bike at least once a week. The non-probabilistic nature of this sample, as well as its small size, restricted the analysis to qualitative interpretation. The survey sought to determine several things: the demographic makeup of selective sample; establish their reasons for cycling; rank their preference of the various factors, which either encourage or discourage riding most; and to establish the 'type of cyclist' that best describes them. The question bank was designed based on Geller's Four Types of Cyclists (2006), as well as the City of Calgary Telephone Survey (2011), both of which sought to segment cycling populations into categories, such as: 'Strong and Fearless', 'Enthused and Confident', 'Interested, but concerned', and 'Not Interested at all'. In both approaches, the respondent's self-identification as a cyclist is weighted with their comfort riding with little infrastructure in poor conditions. The following sections will highlight the results from the survey.

The participant's demographic breakdown is presented here:

\begin{tabular}{|crrccc} 
& LOCATION & AGE & SEX & INCOME & \\
AR & Downtown & 28 & F & Low income & Student \\
DK & Downtown & 35 & F & N/A & NA \\
MC & Downtown & 65 & M & Middle Income & Unemployed \\
SM & Downtown & 31 & M & Upper Middle & Student \\
HC & Downtown & 46 & M & Middle Income & Tech Support \\
WB & Etobicoke & 28 & M & Low income & Self Employed \\
GG & Downtown & 29 & M & Lowest Income & Student \\
TM & Downtown & 24 & F & Lowest Income & Student \\
Dk & East York & 52 & M & Lowest Income & Messenger \\
TA & Downtown & 30 & M & Low income & Retail \\
\hline RJ & Downtown & 23 & F & Lowest Income & Student \\
RM & Downtown & 26 & M & Lowest Income & Student \\
\hline
\end{tabular}

Table 1 - Selective Sample Demographics

The participants' preferences regarding reasons for riding, things that would encourage more riding, their largest barriers to riding more, and the breakdown of 'Cyclist Types' are presented on the following page. 


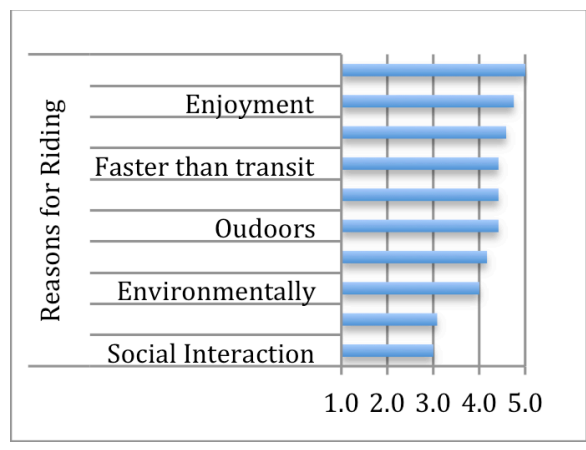

Figure 1 - Participants Reasons for Riding

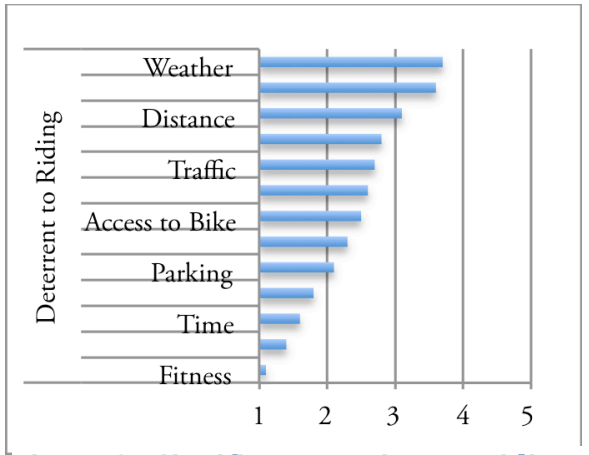

Figure 3 - Significant Barriers to Riding More

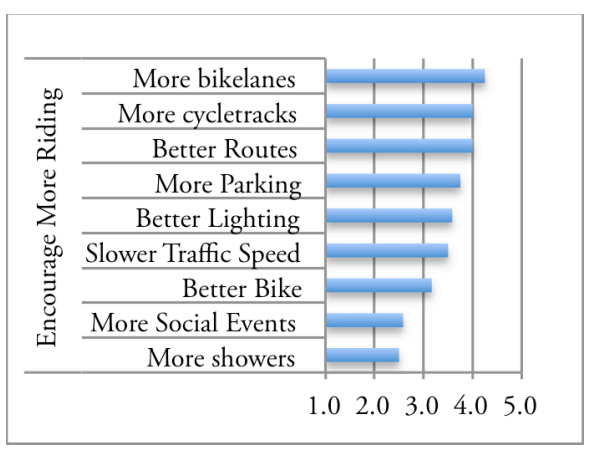

Figure 2 - Significant Motivator for Riding more.

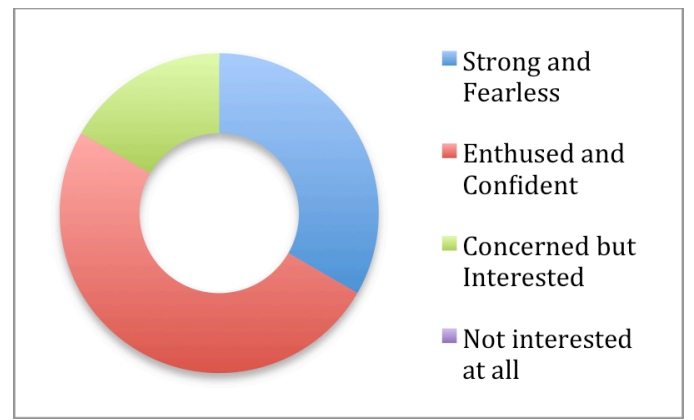

Figure 4.1 - Participants by 'Type of Cyclist'

The focus group was conducted immediately after the survey. Each focus group session was recorded using Garageband recording software, and an external microphone. Each session involved a different group of six participants, each of whom were provided with $\$ 20.00$ for their participation in the study. The audio recordings were transcribed, and the open-coding process began to draw out various ideas and concepts. Through the open coding process, theoretical categories were also developed, which helped to conceptually organize the emergent information. Interpretive and reflective memos were being written concurrently, and represent the most important part of the analysis.

These memos were organized into different categories, and clusters, and presented visually so as to capture the connections between the individual memos, their categories and clusters. This also served to illustrate the first part of the conceptual model, referred to as the psychosocial dynamic. Through further analysis, this
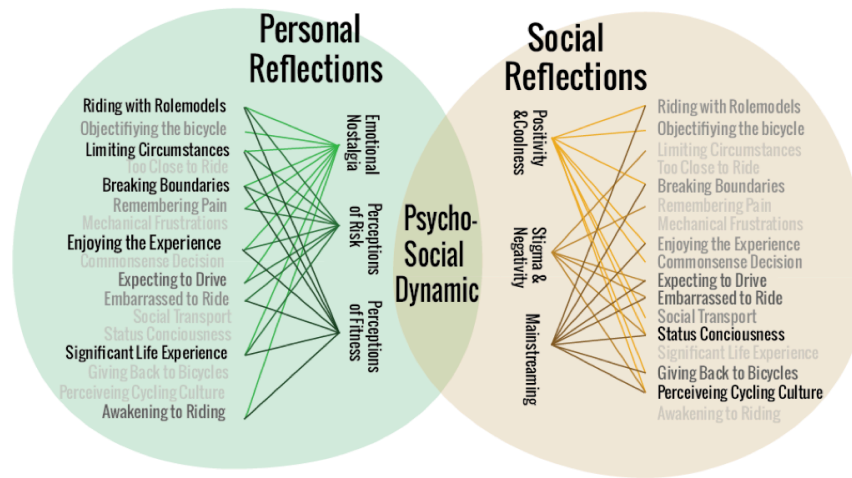

Figure 5 - The Psychosocial Dynamic conceptual model was combined in a staged manner, with Geller's Four Types of Cyclist. 
This combination results in a further progression of the conceptual model. This new iteration introduces the influence of physical and geographic variables as more concrete factor which influence the individuals decision to ride or not. As a rider becomes more strong and fearless, the influence of infrastructure becomes less important, with psychosocial factors becoming more influential. This conceptual model is useful when considering stage based behaviour change interventions, as it contextualizes the change in behaviour in a way, in which the population can be segmented and compared. The result of this combination is referred to as the staged mode choice ecosystem, as seen below.

The staged mode choice ecosystem reflects the connections and relationships that have been interpreted from literature and the focus group exercises. The largest shortcoming of this conceptual model was the absence of political and policy factors. Although very influential regarding, any mention of policy and politics did were quite rare, potentially due to having no

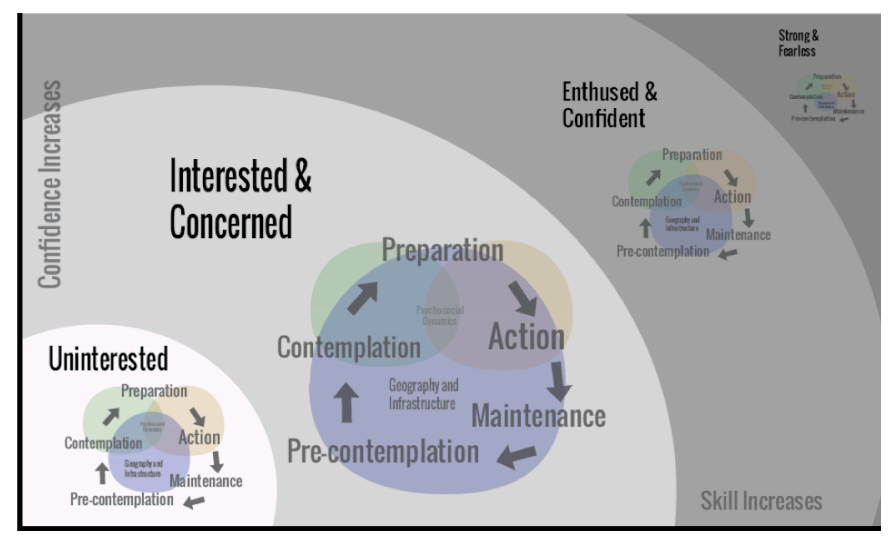
explicit prompting of questions regarding politics and policy. It is likely that having included questions about policy and politics would have generated different results. In considering the importance of policy and politics in future study, and when consulting existing literature for similar outcome, a conceptual model that accounts for the policy environment was found. James Sallis' (2006) Ecological Model stands out as being quite relevant in this regard. The Ecological Model includes many of the same psychological and sociological factors and influences that emerged Figure 9 - Staged Mode Choice Ecosystem

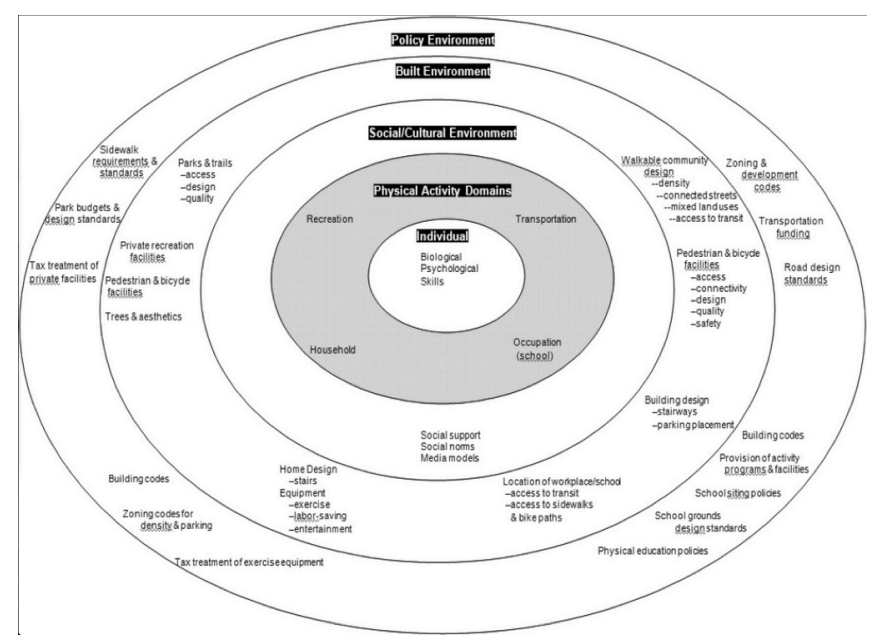

Figure 10 - Sallis (2006) Ecological Model through this study, however, it extends to higher levels by including the policy environment in the outermost circle. The Ecological Model provides a more comprehensive account of the influences on individual mode choice behaviour, and resonates with the findings of this study. The comprehensive quality of the Ecological Model, and the coherent organization of its constituent concepts, makes this an ideal conceptual model to consider in future behaviour change research.

The results of the focus group led to a theoretical sampling, through the identification of a sub-group of participants: three female university students, under the age of thirty, whom had recently adopted more frequent riding for practical more practical purposes. They were identified not only because their results where markedly different that that of their 
peers, but also because similar selections had been made in other studies. During the analysis of this theoretical sample, participant AR's experiences contrasted sharply with the other two women - despite only having recently adopted the frequent and purposeful cycling behaviour, she was classified as a 'Strong and Fearless' cyclist. Because of this difference, AR was treated as a critical case. Further exploration of her responses from the focus groups, as well as the follow-up questionnaires generated some an interesting discussion of two key concepts: Automobility, and the identity and stereotypes of the 'Normal Cyclist'. In addition to these concepts, the analysis of the critical case and the theoretical sample also provided answers to the final two research questions. The following is a summary of the research question in the order in which they were posed.

Major Research Question: Why do people start riding more frequently despite the lack of improvement to cycling infrastructure? It would seem that despite the lack of cycling infrastructure, people who are confident and skilled although not yet riding frequently for more purposeful trips, are more likely to take up cycling if there is a strong social infrastructure - which includes the ability to overcome limitations through social connections, economic resources, psychological fortitude, and seeing role models and others make similar choices.

Question 1: What 'type' of cyclists are those that have recently begun to ride frequently for more practical purposes?

Four riders are Strong and Fearless, six are Enthused and Confident and two riders are Concerned but Interested.

Despite clear divisions in survey data, focus group responses need to be coded, categorized, and compared to the survey findings before a theoretical sample can be made to advance the conceptual model.

Question 2: What is the impact of geography, bicycle infrastructure and facilities in participants' decision to ride a bicycle more frequently for practical purposes? The findings suggest that proximity is indeed a driver of cycling adoption, but only for certain types of riders - the more skilled and confident they are, the less influence distance alone exerts on their mode choice. Often that participants lived too close so some of their destinations to warrant cycling.

Question 3: Of those persons that currently cycle frequently for more practical purposes, is it behaviour continued from prior in life, or a recently adopted behaviour? All the participants had cycling experience from prior in life. Riding for practical purposes was more occasional and less common. The distinctions between utility and recreation are quantitatively driven, and the clarity in purpose of ride, especially at different points in life are not as clear. Although previous riding experience could be a predictor for the speed at which they developed skills and confidence, it would appear the most significant form of encouragement during this process was role models within the cycling community and the media.

Question 4: Did transitional life experiences have a large influence on the decision to cycle more frequently for practical purposes? Transitional life experiences, especially the phenomenon of relocation, were reported by all participants as being crucial, not only in their development as riders, but that their development as riders grew with the other events in their lives. 
Question 5: What has most encouraged these riders to develop the skills and confidence to ride more frequently for practical purposes? Although previous riding experience was a crucial factor within AR's case, the importance of role models in the process of becoming more capable and confident was also made clear. The access and support from these role models is important in phases where the potential rider is shifting from contemplation, to preparation and action.

There were several reflections that arose from these findings. As long as individual were coached toward the choice to ride, weighed against a sense of fear, it is possible that decisions to ride a bicycle will almost never be considered 'normal' in the same way that driving currently is. This implies that the growth of cycling in Toronto may not be sustainable as a common everyday form of transportation. Questions about the equality in this growth are also raised. Critics, like Horton (2013), call for radical changes of the transportation system, but it is unclear for whom these interventions would really be serving, and if changes could be made equally throughout Toronto. Although it is clear that a comprehensive and quality system of transportation alternatives needs to be developed to ensure lasting changes in urban mobility, the location and quality of that change should be considered. One of Hulchanski's (2010) most important finding in the Three Cities report was that many of the inner ring suburban neighbourhoods also have experienced decreasing average incomes since the 1970's. It is no coincidence that these inner ring neighbourhoods are also contain many of the city's most vulnerable and under-served residents. The future of urban mobility has a large role to play in the resilience and future prosperity of these neighbourhoods communities .

A Ryerson Studio project called Connecting Black Creek (Augustyn, 2013) found that Black Creek neighborhood used more active transportation modes than was expected, regarding the levels of pedestrian activity at Jane and Finch In addition to the high levels of active transportation already occurring, the other finding was that the area had a great potential to introduce cycling infrastructure, due to wide right-of-ways, and the proximity of many origins and destinations. If cycling is going to grow equitably and democratically in Toronto, the quality and character of that growth, in the inner ring suburbs especially, will be a key area of focus in the following years.

Studies on transitional life events (ie. migration), and school based programing are already underway, under the purview of organizations like the Toronto Cycling Think \& Do Tank, Cycle Toronto, Culture Link, and the Toronto District School Board. These programs were put in place in the attempts to implement the most current research relating to behaviour change, framed by transitional life and school based programming. Future study includes a follow up study on the participants in the Culture-link mentorship program, to verify if changes in behaviour extend beyond 6 months. The Bike to School Project also presents an interesting opportunity for a longitudinal study, which could contribute to the literature on the effectiveness of socially-oriented behaviour change programs. Other studies could also include the impact of community based non-profit bike repair shops, as their accessible services, and local operation could have implications for the development of sustainable and equitable cycling cultures in under-served areas of Toronto. 


\section{Introduction}

Over the ten year period from 2001 to 2011 the Toronto Bike Plan (2001), there has been little change to the cycling related infrastructure in Toronto, yet ridership has been increasing. Improvements to infrastructure (i.e. the network of bike lanes in particular) are considered to be a very important precursor for increasing ridership, but the increasing ridership in Toronto suggests that there may be other factors involved. What has encouraged people to start cycling more frequently, despite lack of significant improvements to the bicycle infrastructure?

The following related research questions will be used to investigate this issue sufficiently to development a conceptual model for future policy and planning related studies:

1. What 'type' of cyclists are those that have recently begun to ride frequently for more practical purposes?

2. What is the impact of geography, bicycle infrastructure and facilities in participants' decision to ride a bicycle more frequently for practical purposes?

3. Of those persons that currently cycle frequently for more practical purposes, is it behaviour continued from prior in life, or a recently adopted behaviour?

4. Did transitional life experiences have a large influence on the decision to cycle more frequently for practical purposes?

5. What has most encouraged these riders to develop the skills and confidence to ride more frequently for practical purposes?

This study investigated these questions through a mixed method methodology, including a literature review, the design and implementation of a survey and focus group plan and a follow-up questionnaire. To address the major research question of increased cycling ridership despite lack of significant improvements to the network of bikeways. Charmaz's interpretation of Grounded Theory (2006) was used to develop a conceptual model for future studies. This research process relied upon non-probabilistic sampling, theoretical coding and memo-writing. This investigation led to the emergence or identification of insights that have implications for policy, research, and advocacy.

\section{Context}

As Ontario's economy and population grow, Toronto will be faced with managing the complications that arise from that growth, such as congestion. In the Big Move (2008), Metrolinx predict that the population in the GTHA is expected to grow from 6.6 million to 8.6 million in 2031 (p.3). It is an additional 1 million vehicles to our already bumper-to-bumper roads and highways and 7 million more trips a day (p.3). Traffic congestion is a concern, primarily because of its economic impacts. In 2008, traffic congestion in Greater Toronto Hamilton Area (GTHA) cost \$3.3 billion, and reduced gross domestic product (GDP) by $\$ 2.7$ billion dollars, and the cost of congestion will increase to $\$ 15$ billion by 2030 (Toronto Board of Trade, 2011). This is a pressure that the City of Toronto faces with particular acuity, as it is the economic heart of the entire region (Greater Toronto Marketing Alliance, 2012). 


\section{Lack of growth in the City of Toronto's bicycle infrastructure.}

The City of Toronto's Bike Plan (2001) set out the goal of creating $495 \mathrm{~km}$ of on street bicycle lanes, as a part of a larger 1000km network, across Toronto by 2011 - but only 109.7kms were installed as of September 2009. Mayor Rob Ford came into office in 2010, the Cycling Committee was disbanded, and the on-street bike lane grid of the 2001 Bike Plan was replaced by the Mayor's Bike Plan (City of Toronto, 2011). The Mayor's Bike Plan emphasized off-road and multi-use trails as the key focus for the growth of cycling infrastructure in Toronto. This new plan has realized only modest gains since it's enactment, with only $2.4 \mathrm{~km}$ of bicycle lanes created in 2013 (Kolb, 2014). At this rate of construction, it will take approximately 158 years to complete the 2001 Bike Plan (Kolb, 2014).

\section{Growing ridership despite slow infrastructure growth.}

A recent survey conducted by Share the Road Cycling Coalition indicates that 37\% of Torontonians bicycle at least monthly and 7\% (182,000 people) are cycling daily in Toronto (Share the Road, 2012). This shows that modest numbers of cyclists across Toronto are already riding. There also evidence of widespread latency in demand considering that $68 \%$ of Ontarians stated that they would prefer to ride a bicycle more often. This is in contrast to the observed behaviour of only $5.1 \%$ of the provincial population actively riding on a regular basis, which suggests a disconnect. According to the City of Toronto's cycling survey, there is also latent demand for cycling within the city as $69 \%$ of Torontonians claim they would prefer to cycle more often (City of Toronto, 2010). In that survey, the biggest concern for $18 \%$ of all respondents (non-cyclists included) was general safety, followed by concerns about careless drivers at $15 \%$ and cyclists $15 \%$, with $15 \%$ each. This shows that the reason that Torontonians do not ride more, is related road safety or the perceived lack thereof. Yet, despite lack of investment in cycling infrastructure, more people are riding than ever before. Bicycle counts performed on College St. during afternoon peak on a weekday in the autumn revealed that the traffic volume was over $50 \%$ bikes (Kolb, 2013). More importantly, when compared to the volume of bicycles at a similar intersection three years prior, in 2010, there appears to have been a 67\% increase (Kolb, 2013).

A look at the broader context of urban transportation systems and regional traffic congestion may provide some perspective regarding the increasing number of cyclists. More people cycling in Toronto has implications for the broader region, through cost savings and decreased traffic congestion for urban transportation systems. The Ontario Ministry of Transportation, among other bodies, regards active transportation (i.e. human-powered methods such as walking, running, cycling, etc.) as one of the main strategies in reducing auto-dependent behaviour (e.g., automobility) throughout the province - which has significant benefits for reducing traffic congestion while improving health outcomes (Ontario Ministry of Transportation, 2013). The Toronto Public Health's Road to Health (2012) report points to current land use planning policies and an automobile-oriented transportation system as being linked to low levels of physical activity, such that adults 20 or older have the second lowest levels of physical activity compared with over 35 other health units in Ontario (Toronto Public Health, p.8). Furthermore, $40 \%$ of adults and 22\% of adolescents (12-17) are overweight or obese, which contributes to chronic disease in Toronto. Although these figures represent average trends in Toronto, some areas of the city experience these effects more severely than others - as not all 
neighbourhoods in Toronto are designed or serviced equally. A report by the University of Toronto's Cities Centre, Toronto's Inner Suburbs, highlighted the precarious situation for the increasing number of low-income neighbourhoods across Toronto (Cowen and Parlette, 2011). An exploration of the implications will be explored in greater detail below in the literature review.

\section{Research Questions}

This project sought to develop a conceptual model, which could potentially explain the increase in frequent and purposeful cyclists in Toronto despite of the lack of significant improvements to the network of bikeways. The central research question focuses on three main factors: recentness of adoption, frequency of riding, and trips for more practical purposes.

- Recent adoption is tied to a change in the frequency and purpose within the last three years of riding history.

- Frequent riding is defined by an average of one a bicycle trip per week over the last year, not accounting for seasonal differences.

- Riding for 'more practical purposes' refers to any bicycle trip that is not regarded by the rider as purely recreational. This includes trips to work, to school, to access services and other case where the bicycle is used as a form of transportation.

The process of seeking answers to the following research questions, also produce information that helps conceptualize the relationship between behaviour and built form, and will be referred to as the conceptual model. There will be references throughout the paper to the conceptual model, and how it is developing towards a holistic view of the dynamics of mode choice. As such, these questions form a central piece of this paper, and will be revisited throughout.

\section{What 'type' of cyclists are those that have recently begun to ride frequently for more practical purposes?}

Roger Geller published a report in 2006 that included data supporting the "four types" of cyclists categorization utilized by the Portland Office of Transportation (Geller, 2006). Cyclists can be differentiated in relation to their relationship to riding, and comfort despite the absence of infrastructure. Municipalities have begun to segment the cycling populations this way as a form of market research, so as to better understand the potential latent demand for cycling that exists in their jurisdiction, which ties into potential for growth, which can be used to support changing policies and encouraging investments in infrastructure and other bicycle facilities. The cyclist four types include;

- strong and fearless;

- enthused and confident;

- interested but concerned; and

- no way. no how.

The cyclist types are utilized to classify the participant in this project within this wider spectrum of cyclists, and potentially for comparison and/or discussion in relation to larger sample size studies. 
2. What is the impact of geography, bicycle infrastructure and facilities (i.e., built form) in participants' decision to ride a bicycle more frequently for practical purposes?

This question is informed by Toronto's most recent cycling survey (City of Toronto, 2010) Recreational cyclists were asked about the barriers they face from riding for more practical purposes:

- $42 \%$ of recreational cyclists stated that perceived 'distance' was a barrier, followed by

- $18 \%$ that claimed 'general inconvenience'.

When asked about the required changes to allow them to ride more;

- $50 \%$ stated that nothing would change their behaviour, whereas

- $19 \%$ stated that improved safety measures (bike lanes, bike paths), followed by

- $8 \%$ for other amenities, such as more bike parking would encourage them to ride for more practical purposes. Perceived distances, as well as the safety of routes, work in concert to discourage recreational riders from riding for more practical purposes.

This research question address the potential issues related to changes in geographic proximity, or more bicycle infrastructure and facilities, as the reason that participant cyclists decide to ride more frequently for practical purposes.

\section{Of those persons that currently cycle frequently for more practical purposes, is it behaviour continued from} prior in life, or a recently adopted behaviour?

There are strong links in the literature reviewed between physical activity during childhood, and physical activity in adulthood. However, it is unclear if the riding a bicycle for more practical purposes as an adult can be correlated to cycling during childhood for leisure or recreation.

\section{Did transitional life experiences have a large influence on the decision to cycle more frequently for practical purposes?}

Transitional life events are suggested as one of the preconditions for effective behaviour change (Chatterjee et al, 2013). There are a wide variety of transitional life events, which may include a paradigm shift such as relocating to an area where increased proximity to cycling infrastructure is gained, a health-related concern which provide motivation for low impact cardio exercise, or a combination of several factors. What impact to do these have on the individuals decision?

\section{What has most encouraged these riders to develop the skills and confidence to ride more frequently for practical purposes?}

If riding a bicycle was a behaviour that was adopted early in life, was it more of a family dynamic rather than a peer dynamic? Who or what encouraged it most? If riding a bicycle was a behaviour adopted more recently, was it the result of a peer dynamic, or was it more of an individual pursuit? What was the role of other types of social networks that may have contributed to adoption, such as cycling clubs, bike shops, or community bike centres? These enrich the account of the adoption process, and provide a narrative with which to compare experiences of cyclists. 


\section{Limitations}

There were several limitations to acknowledge in this study. This study is limited due the small set of data collected and resulted in limited the amount of data analyses. A more rigorous line-by-line coding process would have involved software such as Atlas.Ti or NVivo. However, the even the manual application of the Grounded Theory to this small data set was useful and appropriate as a first step in identifying future research. 


\section{Chapter 2. LITERATURE REIVEW}

Planners, transportation engineers and public health professionals have been working together to design healthier cities by creating streets and transportation systems that encourage people to be more active (i.e. active transportation).

Although urban design and physical infrastructure (i.e., built form) are the most influential factors in achieving these goals, there is a need to consider the soft variables that may compliment these efforts. These soft variables include initiatives that may shift the hearts and minds of potential adopters of active modes, to do so. This literature review explored several topics, which form the academic foundation for the research and analysis and developing theoretical model. Topics included a brief description of the multiple benefits of cycling, theories on intention-behaviour dynamics, and the intersection of health, poverty, built form and transportation.

\subsection{Benefits of Riding a Bicycle}

For some, the simple pleasure of riding a bike is enough of a reason to ride - but for others, it is not nearly enough, as there are many perceived barriers. Most notably among these barriers, is a high degree of perceived danger, compounded by a pervasive lack of well-designed bicycle infrastructure (painted and protected on-street bike lanes especially). Other barriers are less physical, and more psychological, including confidence, or even prejudice. Some people do not consider the act or riding a bike to be anything more than a form of child's play, and are prejudiced against the broader use of bicycle as a form of transportation. However, there is a wealth of literature which expounds the environmental, economic, and health benefits that result from getting more people to ride bicycles more often - not just as a phase during childhood. This section will examine some of the most persuasive evidence from each of these perspectives.

\section{Benefits to the Environment}

Considering that many municipalities are concerned with the acute environmental effects of pollution, as well as climate change - the fact that riding a bicycle pollutes much less than the alternative modes of transportation should not be ignored. The City of Toronto's Climate Change, Clean Air and Sustainable Energy Action Plan (2007) has an ambitious greenhouse emission reduction target, which aims to reduce emissions to $80 \%$ below 1990 levels, of 22 million tonnes per year by 2050 . The plan also reported that around $33 \%$ of locally generated emissions comes from motor vehicles, and recommended a sustainable transportation system to counter air pollution (City of Toronto, 2007). Getting more people to ride bicycles is a part of this strategy.

In 2011, The European Cycling Federation (ECF) calculated the greenhouse gas (GHG) footprint of a typical bicycle, with a lifespan of 8 years, ridden at distance of $2400 \mathrm{~km}$ each year was 5 grams $\mathrm{CO}_{2}$ per kilometer (Blondel et al, 2011, p.8). Riding a bicycle is a rare example of the case where the diet of the operator would have a greater impact on the environment, than the manufacture and operation of the vehicle itself. As part of the life cycle analysis, the ECF calculated the environmental impact of the additional food needed to nourish the rider. Based on European nutritional guidelines and a balance diet resulted in a GHG impact estimated at 16 grams $\mathrm{CO}_{2}$ per kilometer (p.11) for the entire life cycle. This stands in stark contrast to the same life cycle impact analysis performed for a private automobile. When 
compared for trips that compete with bicycle use (i.e., $7 \mathrm{~km}$ ), the analysis produced a $\mathrm{GHG}$ impact of $271 \mathrm{~g}$ of $\mathrm{CO}_{2}$ per kilometer (p.14). Consider that this is only the reduction of GHG on an individual basis - when multiplied, the environmental and economic benefits are striking.

\section{Benefits to the Economy}

In 2008, the Toronto Board of Trade (2013) calculated that traffic congestion in GTHA cost $\$ 3.3$ billion, and if current trends continue, the cost could reach $\$ 15$ billion by 2030 (p.5). More people riding bikes not only improves the economy through a reduction in traffic congestion, but there is more 'bang for the buck' with regards to infrastructure investment, significant cost savings, and more money in the pocket of individuals - which also creates a multiplier effect for dollars available to be spent at local businesses (Clifton et al, 2012, and 2013; Sztabinzki, 2009).

Campbell and Wittgens (2004) highlight that in urban areas, where cycling is competitive with the private automobile in terms of speed, bicycle infrastructure can accommodate 7 to 12 times more people per meter of lane per hour, with less wear on pavement. The Pedestrian and Bicycle Information Centre (PBIC) examined the cost of installation of bicycle lanes across the USA, and found that the cost varies due to location, width, road condition, signalization - yet can cost as little as $\$ 5000$ per kilometer, and is often most cost-effective when a road is being resurfaced (PBIC, 2009). The California Department of Transportation (2010) calculated that the State could sign and stripe over $2000 \mathrm{~km}$ of bike lanes for the cost of repaving around $5 \mathrm{~km}$ of an interstate highway. There are few pieces of transportation infrastructure that can move as many people, per lane per kilometer per dollar than protected bicycle lanes.

If more people ride bikes instead of drive, there could be significant cost savings for the cyclists themselves. Todd Litman at the Victoria Transport Policy Institute monetized the benefits of switching from driving to cycling (Litman, 2009). When factoring in traffic congestion reduction savings, roadway construction cost savings, vehicle cost savings, parking cost savings, air pollution reduction, energy conservational and safety improvements; a bike trip saves $\$ 1.69$ per kilometer. In 2006, it was estimated that there are over 9.29 million daily vehicle kilometers travelled within the city of Toronto at the morning peak (City of Toronto, 2014; Greater Toronto Transportation Authority, 2008). Considering that cycling is almost as fast as driving for trips under $7 \mathrm{~km}$ in urban areas, and that this distance of trip represents about $55 \%$ of all trips taken within the City (Toronto Public Health, p4.), the potential savings would be considerable. If Toronto had a 15\% percent mode shift to cycling, and assuming that the savings calculated by Litman are accurate, the shift could generate roughly $\$ 680$ million in saving monthly - \$272 each month for each of Toronto's 2.5 million residents. If all the potentially cycleable trips ( $7 \mathrm{~km}$ distance or less in urban areas is around $55 \%)$ were cycled each day, that shift could generate roughly $\$ 2.5$ billion monthly.

Much of the traffic congestion savings (i.e, gas and time wasted in traffic jams), parking cost savings, vehicle cost savings will go right to the pocket of the individuals that have opted to switch. More cyclists with more disposable income would be better for the local economy. This is a hypothesis shared by Clifton et al (2012) that posits, since cyclists need to spend less money on auto repairs, gas, insurance, and car payments, they have more disposable income, and 
thus can spend more. Sztabinski (2009) performed a two year study on the Annex neighbourhood in Toronto, and found that customers that arrived by foot, by bike or by transit, spent more on average than customers that arrive by car. This is interesting because it runs counter to the expectation of many business owners, that expected more to arrive to arrive by car than were actually observed. A conclusion of the Sztabinski study was the suggestion that investment in pedestrian and cycling infrastructure should be increased, due to the commercial benefits associated. In places where cycling is much more common and widespread, the results are similar. In Portland, Oregon, cycling related business generates significant 'main street' economic activity, accounting for more that $\$ 100$ million in local economic activity each year, and has produced 1000 jobs (Cortright, 2007)

Cycling is also good for the broader economy. In Wisconsin, the cycling industry generated $\$ 1.5$ billion in economic activity across the state from manufacturing, sales and services (Wallasper, 2010 in Toronto Public Health, 2012). In the UK, the economic activity related to cycling is estimated at $\$ 4.6$ billion CAD (Grous, 2011 in Toronto Public Health 2012). It is important to note these spending patterns are typically more local than spending on automobiles and gasoline, and that money remains in the local economy (Cortright, 2007). These environmental and economic benefits do not include the benefits to health, which are perhaps the most important reasons to encouraging a mode shift towards cycling.

\section{Benefits to Health}

The simple act of riding a bike can raise the heart rate enough so as to improve cardiovascular fitness, which contributes to better health outcomes for youth (12-17 years) and adults (Underwood and Handy, 2012). Considering youth obesity is a leading public health challenge (Heinberg and Thompson, 2009), and that driving learners permits are not granted until the age of 16 , encouraging mode shift is good strategy in this younger demographic. Beyond the ability to reduce the risk of heart disease, lower blood pressure and reduce the risk of obesity, cyclists tend to report better mental health, and higher general sense of satisfaction (Frank, Andersen, Schmid, 2004; Taylor, 2000, Fox, 1999). Detractors may consider cycling to be an inherently risky activity, and that these benefits are seen only in controlled environments. Studies have shown that despite exposure to traffic, pollution and the other risks of injury, the health benefits greatly outweigh the risks - benefit to risk ratios ranged between 9 to 1, and 96 to 1 (British Medical Association, 2012; Teschke et al, 2012; Hartog et al, 2010; Rabl and de Nazelle, 2012).

One major strategy is to invest in bicycle infrastructure to improve safety and thereby increase ridership and improve health. Gotschi (2011) compares the cost of investment in cycling infrastructure to monetized health benefits (health care cost savings, value of statistical life savings). He calculated that by 2040 in Portland, Oregon's investment of $\$ 138$ to 605 million could result in health care cost savings of $\$ 388$ to 594 million, and statistical life value saving savings of $\$ 7$ to $\$ 12$ billion (p.49). 
In Toronto, the amount of walking and cycling that occurred in 2006 was estimated to prevent 120 deaths each year. An increase in cycling mode share to $6 \%$ would prevent another 100 deaths per year - depending on how these deaths are valued, could lead to millions of savings and a higher quality of life (Toronto Public Health, p.5).

\subsection{Poverty, Health, Built Form and Transportation}

The interplay between poverty, health, built form and transportation is a central concern for all urban professionals. With urban centers across Canada continuing to grow, the challenges that face residents and municipalities in which they live are starting to shift as well. To address these challenges, a wide array of approaches and perspectives need to be utilized, so as to develop flexible and responsive ways to prevent conditions from deteriorating any further than they already have.

\section{Poverty and Health}

The effects of poverty on health have been known since the $19^{\text {th }}$ century (Sram and Ashton, 1998). Numerous reports, such as in Raphael (2002) document how "those in the lowest employment groups showed a greater likelihood of suffering from a wide range of diseases, and having a greater likelihood of death from illness or injury at every stage of the life cycle” (p.4). Similarly, Benzeval, Judge and Whitehead (1995) argue that this is because poverty can affect health in a number of ways. "Income provides the prerequisites for health, such as shelter, food, warmth, and the ability to participate in society; living in poverty can cause stress and anxiety, which can damage people's health; and low income limits peoples' choices and militates against desirable changes in behaviour" (p.xxi). Because income is distributed unequally, and income is the means of securing shelter and transportation, the patterns of settlement and the transportation used in these spaces will be similarly affected.

\section{Poverty and Built Form}

In the USA, Cawthorn (2010) highlights that "since 2000, the number of low income people in the suburbs jumped by more than 37 percent to 13.7 million-also outpacing the national growth rate of 26.5 percent.” (p.1). Furthermore, these suburban communities have also seen increased racial and income stratification as low-income workers-particularly recent immigrants that seek the low skilled jobs, and low rents outside of the urban centers. In a similar vein, David Hulchanski (2010) released the Three Cities of Toronto report, looking at income and settlement patterns from 1970 to 2005 - resulting in the influential map inserted below (map 1).

In Toronto, the inner suburban areas, referred to as the Third

City, have experienced decreases in average income by $20 \%$ or more since the 1970's (Hulchanski, p.2). The grey borders are Priority Neighbourhoods, as identified in a report by the City of Toronto United Way in 2005 (Hulchanski, p.23). This is significant because it visually demonstrates the income polarization that is taking place in Toronto, which has implications for social equity, transportation choices and health outcomes - especially amongst the most vulnerable populations in the city.

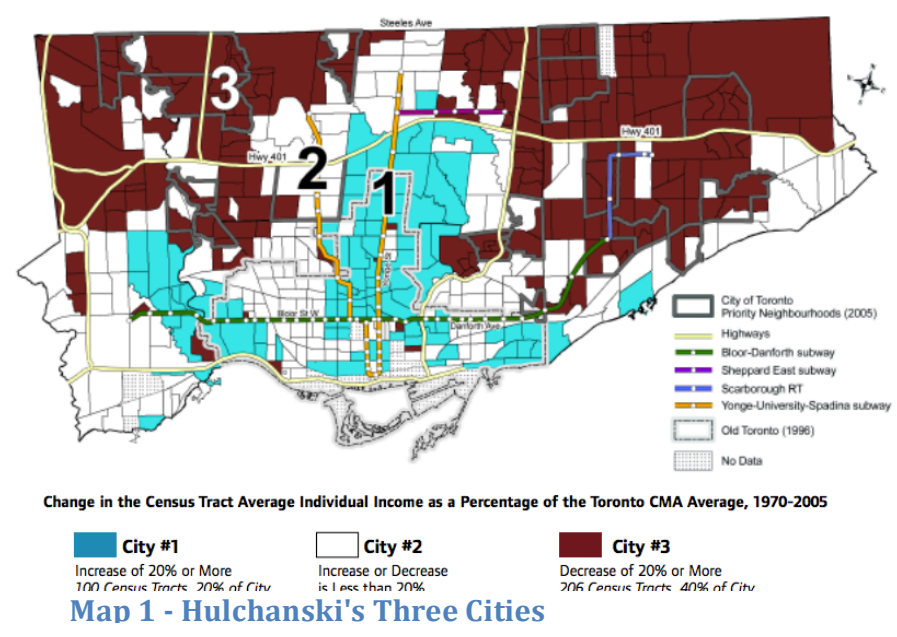




\section{Built form, Transportation and Health}

Susan Handy (1996) studied the relationship between urban built form, and pedestrian choices, as well as other forms of non-work travel behaviour in Davis, California (2011). In both studies, she found that people who lived in more physically connected spaces, chose different forms of transportation, and led less sedentary, healthier lives . Cervero and Kockleman (1997) have integrated environmental and ecological approaches into planning, in an attempt to encourage more physically active communities - resulting in the 3D's: Residential Density, Land-use Diversity, and Pedestrian Oriented Designs. The purpose was to provide urban professionals with a framework, so as to work towards building healthier communities through providing better transportation options for residents.

More recently James Sallis et al (2006) examined the cues and barriers within the physical geography (i.e., built form) of residential areas and their effects on transportation choices, and how sedentary lifestyles emerged in these areas. Due to the layout and arrangement of suburban spaces, those individuals that occupy them tend to be more sedentary because it is harder to move around without a motor vehicle (p. 300). Furthermore, it was also observed that many of these suburban neighbourhoods were locations where there were high concentrations of low-income populations, which further compounds the health and mobility issues in these areas (p. 305). Felland et al (2009) identify declines in suburban health to be a trend that has been emerging over the last decade, for reasons that relate not only to income, but also to the limited transportation options available in those contexts. In this way transportation emerges as being an integral part of the intersection between built form, health and income.

\section{Transportation: Beyond Physical Infrastructure}

As has been shown, riding a bicycle is a fun, affordable, cost effective, fast, healthy and environmentally friendly way to get around - but how can urban professionals encourage more people to ride more often? Some studies have shown that improved cycling facilities can lead to an increase in cycling trips (Martens, 2006; Wardman et al 1997). However, numerous studies have also shown that although bicycling facilities make bicycling safer (Krizeck and Roland 2005), they do no lead to more bicycling for infrequent riders (Davies et al, 2001; McClintock 1992). Furthermore, despite improvements in bicycle facilities, very few non-riders appear to have any intention of riding anyways (Dickinson et al, 2003). It is likely that the only way to get non-riders to consider cycling is through education, and changes to policy as well as investment in infrastructure - a position supported by several studies outside of North America. Australian research found that community-based social marketing programs involving education, training, bike-hire schemes, and a ride to work campaign promoting the use of existing cycle paths contributed to an increase in the use of cycle networks (Rissel, et al, 2010). In a similar fashion, Odense, Denmark implemented many creative programs in its efforts to increase bicycling, including giving bicycles to domestic workers, taking senior citizens on guided bicycle rides, and lending bicycle trailers to parents of young children. These efforts produced an $80 \%$ increase in bicycle trips between 1984 and 2002 (Troelsen, 2005).

However, in a North American context, the results are quite different. Because of a lack of political support to invest in infrastructure, some advocacy groups have needed to opt for education-based interventions in isolation - which 
Baranowski et al (1998) found to all have very modest success. Hillsdon et al (2005) produced a review of various studies that examined physical activity intervention using education based strategies, and found that the effect was very small by generally accepted standards. The combination educational with promotional measures had no effect on increasing rates of cycling (Groesz, 2007). However, this is not necessarily a condemnation of educational approaches, if focusing on targeted populations, with multi-level programming, results may be more positive results, and lasting increases ridership.

What can explain the increase in cycling in Toronto? It is unlikely that basic educational and promotional efforts have been the main factor in isolation, however if well designed and provocative, the effectiveness of these approaches could be improved. If educational experiences could create positive first experiences, or leverage positive past experiences they may be able to reinforce the programs efficacy in shifting certain people towards more frequent cycling behaviour. How these attitudes are formed, and what types of experiences are most impactful on the current attitudes are poorly understood. The following research attempts to chart some of these murky concepts, in the hope that a clearer picture of the dynamics between physical infrastructure and mode choice can be discovered.

\subsection{Intention-Behaviour Theory}

Given the environmental, economic and health benefits, it is surprising the variability in numbers of riders in North America, and how their riding behaviour changes over time. It is also surprising to see how some governments have embraced investment to attempt to shift mode-share towards cycling, where as other have done the opposite. The research questions that are explored in this paper are centered around the perspective of individuals, currently situated in an urban context, and looking at their histories of riding, their process of adoption, and the influences on their decision to cycle or not. As such the literature, which explores theories of behaviour change and the Trans-Theoretical Model (TTM) in particular, will be examined so as to connect mode choice with the theory of intention and behaviour. Recall that the major research question of this paper asks: why are people beginning to cycle more, despite a lack of improvement to the cycling infrastructure? As such, the study of behaviour change is central to this investigation.

\section{Theories of Behaviour Change}

Behaviour change is a branch of behavioural psychology, in which the role of intention and contemplation is the primary concern, both in the process of initial adoption, and sustaining changes in behaviour. A review of the behaviour change literature was conducted, and was abbreviated significantly (see Appendix A), with only the TTM being explored in detail below.

On a broad level (i.e., a summary of literature review in Appendix A), the theory of behaviour change emerged from the field of public health in the 1950's, and started to mature during the 1970's through the work of Hochbaum, Rosenstock and Kegels (Taylor et al, 2006). In the early years, it was focused on public health issues such as HIV disclosure, condom use, smoking, and alcoholism (Sheeran and Taylor, 1999; Albarracin et al, 2001). Since it's 
emergence, the interest of public health research in behaviour change has extended to examining sedentary lifestyles, and physical activity (Rhodes and Pfaeffli, 2010; Weichselbaum et al, 2013, Barwais et al, 2013). Several models were developed to account for the different elements and influences of behaviour. The Theory of Reasoned Action emerged in the 1970's (Ajzen, and Fishbein, 1980) stress the idea of how intention leads to behaviour, as conceived as a singular event (see also Integrated Behavioural Model). As theories developed and became more sophisticated, others theories came into favour, such as the TTM, which conceptualizes behaviour change as a process, either through stages or continuous cycles (see Appendix A for Social Cognitive Theory and Health Action Process Approach). The role of intention is central to the understanding of individuals as rational agents, and understanding the reasons $w h y$ they perform actions.

\section{Trans-Theoretical Model}

A closer study of TTM is part of assessing a component part of understanding how intentions relate to behaviour. The TTM was developed by Prochaska and DiClemente (1984), and is one of the most dominant behaviour change paradigms (Armitage, 2009). The basic TTM posits 5 stages (Prochaska, DiClemente, Norcross, 1992):

- pre-contemplation,

- contemplation,

- preparation,

- $\quad$ action, and

- maintenance.

Historically, most TTM research has used cross-sectional interventions in their research design, whereas longitudinal studies focusing on physical activity have become more popular in recent years (see Nigg, 2001; Plotnikoff et al, 2010; Dishman et al, 2010). These studies, Nigg in particular showed that the direction of stages, process, and development of self-efficacy all happened as expected, yet was little evidence to show that the processes were correlated with an increase in exercise. TTM was deemed to be more of a framework to understand behavior, rather than influence it. A critical assessment of TTM was undertaken, so as understand the academic discourse that surrounds the theory.

Over the past decade, TTM based interventions have attracted a great deal of criticism, especially regarding smoking cessation (Bridle et al 2005; Reisma et al, 2003; Aveyard et al, 2009, 2011) and applicability to physical activity. Adams and White (2005) developed several criticisms of using TTM based interventions with physical activity, summarized as such:

- Exercise behaviour is a complex of different behaviours, not a single behaviour such as smoking.
-Determining current stage of change is crucial to intervention delivery, yet nearly impossible to differentiate.
-Exercise behaviour is influenced by numerous external factors, not considered by TTM.
-TTM suggest that stage progression is significant outcome, despite not necessarily changing behaviour
-Stage-based interventions are complex, and require more than one level of development and evaluation. (p.240)

In addition to these specific criticisms, Robert West (2009) launched a more conceptual critique of TTM. Drawing from the conclusions that other academics have made after evaluating TTM's accuracy and productivity, he claims that 
the suggestions created by the model are "incorrect or worse than competing theories" (p. 1037), and that the entire model is based on a fundamentally naïve assumption, "that individuals typically make coherent and stable plans"(p.1037).

Although the critiques are numerous, many academics felt that it is not worth abandoning TTM. Spencer et al (2005) found that of the 31 stage-matched interventions reviewed, 25 demonstrated their success in motivating participants toward higher stages and amounts of exercise. As studies on validity continued to be performed, the literature suggested that the TTM could be applied to exercise behaviour. In Brug et al (2005), Harre argued that is it unreasonable to expect that any single study with any single intervention should produce lasting changes to behaviour over a 6 month period (p. 250). She argued that other social forces, the environmental inertia, which contributed to the initial position of inactivity, should also be considered - as they explained the tendency to revert to past behaviours (p. 251). In this way, TTM was able to recognize different stages of cognition, despite a lack of clarity on where each begins or ends, but this does not represent a critical flaw (Sandman and Weintstein, 1993) - this recognizes the dynamism of behaviour on a broad level, and should be embraced because of this, not in spite of it (Brug et al, p. 248). On a related note, despite intention not always resulting in behaviour adoption, people's intentional every day behaviour is a product of their psychological schemas about themselves and the world (p. 251). Although behaviour can be observed and measured, if the researcher seeks to understand people's intention, asking them about their intention is the only way in which it can be measured.

Aside from accepting TTM's limitations outright, some critics also suggested strategies through which the weight of these limitations might be reduced. Robert West (2009) was one such critic:

"The model needs to consider the difference between desire and value, attaching to a specific behaviour (smoking) vs. a label (being a smoker). Lasting behaviour change relies on the balance of motivational forces regarding the specific behaviour consistently favouring the alternative whenever the opportunity to engage in it arises. The model of change needs to describe and explain how it occurs. It is apparent that self-labeling plays an important role in generating this consistency (Kearney \& O'Sullivan, 2003). An individual who is committed to being a non-smoker is motivated to exercise restraint when temptation to smoke arises. A 'State of Change' model is needed which provides a coherent account of the balance of motivational forces that operate on habitual behaviours, and how these need to change for a different pattern of behaviour to emerge. It needs to consider 'state' not as a outcome, but as a characteristic (selflabel) that can stabilize a new behaviour pattern." (p.1038)

The implications of this are significant; it illustrates that even the 'simple' behaviour of smoking is wrought with concerns of social pressure, public image and identity politics. Capturing the nuanced aspects of behaviour is a concept with which TTM is still trying to adapt. With these criticisms, rebuttals, and strategies in mind, the attention will turn to the literature that explores the fascinating intersection of physical space and behaviour, and how cycling is discussed in that context.

An ontological begins to surface when looking at cycling behaviour within this context. 'Physical activities' are the focus within the existing behaviour change literature, but in the context of transportation research, the measurement of 
mode share reinforces a paradigm where only purposeful or transportation trips by bicycle are of any significance. The term physical activity seems to evoke ideas of 'recreation and leisure', more than terms like 'utilitarian cycling', which consists of more practical/purposeful trips. The act of riding a bike inherently involves both elements of physical activity (recreation and leisure) and practical purposes (i.e., purposeful) - which makes it so appealing and enjoyable. For this reason, the literature that revolves around physical activity and behaviour change can be applied to cycling. This is a small distinction that can be kept in mind as the literature review advances.

\section{Behaviour Change and Cycling}

Perkins (2004) draws close connections between the levels of physical activity in adulthood, or the likelihood to consider being active, and the levels of physical activity as children and youth - with active lifestyles becoming engrained from young age. This also echoes important observations that less active people will be less likely to choose active transport later in life (Badland and Schofield, 2006). Garcia et al (1998) shows that childhood and adolescence are ideal periods of development for fostering active lifestyles that can be maintained through life.

Turning to studies that examine cycling more specifically, there are a number of papers that examined attitudes as influences on cycling behaviour. Most simply stated, how people feel about cycling influences how often they cycle (Handy 2011). Glatersleben and Appleton (2007) found that those who contemplate cycling the least, also have the most negative attitude towards cycling. Conversely, Handy, Xing and Buehler (2010) found a strong connection between 'liking biking' with bike ownership and regular use. The thoughts, attitudes and ultimately, the behaviours of these persons are shaped by past positive experiences - a form of operant conditioning. B.F. Skinner argued that by altering the stimulus in an environment, the environment generates a change of behaviour through a new system of rewards and punishments - known as operant conditioning (Edgar, 2012).

If someone lives in a place where they feel threatened when they walk home from work, they will walk less. If someone lives in a place that feels too dangerous to ride a bike to school, they will ride less and less. The inversion of the scenario would also produce an inversion in the results - such that a positive stimulus in the environment would produce positive feedback, and more positive behaviour. Dill and Voros (2007) showed that positive attitudes were essential to bicycle commuting behaviour in Portland. Heinen, Maat, and Wee (2011) showed the same was true for the Netherlands. On a related note, Pucher et al (1999) emphasizes that the public image is related to the general attitude to bicycling in a region - which can be positive (cool) or negative (stigma), depending on the region. Handy and Underwood (2011) point out that few studies have focused on the formation of these attitudes, individually and socially.

Some of the most important strategies when considering the potential for encouraging the shift towards cycling include building cycling infrastructure and promoting positive experiences as early as possible. However, Toronto's experiences continue to raise the question: why people start cycling more frequently despite lack of improvements of bicycle infrastructure? Furthermore, how does this literature on behaviour change intersect with the complexity of 
urban development? The idea of encouraging people to cycle must be contextualized into an urban context, which incorporates considerations of urban built form (i.e., physical infrastructure, and transportation systems) and their interaction with physical activity and health outcomes. 


\section{Chapter 3. GROUNDED THEORY: METHODOLOGY \& METHODS}

Starks and Brown Trinindad (2007) compare different qualitative methods for health research, including discourse analysis, phenomenology and grounded theory. Their comparison suggests that Grounded Theory as a methodological approach, can maintaining a certain rigor and quality of research when using a mixed method approach (i.e., survey, focus group, and questionnaire). They described grounded theory as having developed through sociology, being suited to developing theories, which explain how social process evolves in different environmental contexts (p.1373). They also note that grounded theory uses coding, to probe responses, and add detail in a method that is intuitive and reproducible - so that that is suited for developing explanatory models on which to base behaviour change interventions (p.1373). The following section will answer the questions of why and what grounded theory entails, and the considerations for how to be implemented in chapter 4.

This research project utilizes a qualitative mixed methods approach because of a small sample size, a survey, and the retrospective nature of the focus group and follow-up questionnaire. This type of mixed qualitative data is appropriate for these types of inquiry, and can become more compelling when different methods are used to draw more meaning and information out of the data.

\section{Grounded Theory}

Grounded Theory is a method of creating a conceptual model, which can be used to clarify theories and identify opportunities for future research. It is lauded because it can incorporate and interpret complex phenomena (Charmaz, 2003), and is adept in conceptually dissecting socially constructed experiences (Charmaz 2006, Goulding, 1998). The logic of Grounded Theory offers a freedom from the constraints of a priori knowledge and deductive reasoning, when exploring poorly understood and under explored questions (Glaser and Strauss, 1967). Finally, it has the ability to generate theories that cross the boundaries between potentially disparate disciplines psychology, and urban planning. The following passage from Schwandt (2001) further outlines the methodology of Grounded Theory:

\footnotetext{
"Grounded theory requires a concept-indicator model of analysis, which in turn, employs the method of constant comparison. Empirical indicators from the data (actions, events, recorded or described in documents and words of respondents) are compared, searching for similarities and differences. From this process, the analyst identifies the underlying uniformities in the indicators and produces a coded category or concept. Categories are compared with more empirical indicators, and with each other to sharpen the definition and to define its properties. Theories are formed from proposing plausible relationships among concepts and sets of concepts. Tentative theories or theoretical propositions are further explored through additional instances of data. The testing of the emergent theory is guided by theoretical sampling. Theoretical sampling means that the sampling of additional incidents, activities and populations is directed by the evolving theoretical construct. Comparisons between the explanatory adequacy of the theoretical constructs and these additional empirical indicators go on continuously until theoretical saturation is reached (additional analysis contributes nothing new). In this way, the resulting theory is considered conceptually dense, and grounded in the data." (p.110-111)
}

Grounded theory uses abductive and inductive reasoning (Reichertz, 2010), and emerged from the field of sociology, most notably, through the work of Glaser and Strauss (1967). The role of the literature review as a step in grounded theory, as well as the technical procedures for coding have since changed dramatically. For Glaser, the impact of 
external theories, such as in a literature review, was a large concern. Glaser insisted that no literature was to be read until all the data had been collected in the attempt to maintain theory neutrality . Glaser's fundamentalist interpretation caused a rift with Strauss, who went on to write with Juliet Corbin. Strauss and Corbin jointly advocated for the introduction of theory and literature at the beginning of the research process, but also introducing a more structured and reiterative process of coding and analysis. They argued that the introduction of literature, and a structured analysis would 'sensitize the researcher' and develop an initial research framework more effectively (Strauss and Corbin, 1990).

Building on the theoretical foundation of Glaser, Strauss and Corbin - Cathy Charmaz developed a constructivist approach to Grounded Theory, which further increased the growing distance between modernist (Glaser) and post-modern researchers (Strauss and Corbin). Her constructivist view tries to settle the crisis in grounded theory regarding the perceived need for theoretical neutrality - She argued that theory can never be set aside, that perfect induction is impossible, and that nothing is theory neutral (Charmaz, 2006). Futher still, the interpretive interactions with the researcher also become a part of the coding process. This has implications for the whole research process, the placement of the literature review, the initial research questions, and the allowance of selective sampling and theoretical sampling, instead of more traditional forms (i.e. probabilistic sampling). The more traditional social sciences consider probabilistic sampling to be the standard, as it is directly related to the idea of representative samples, statistically significant findings, and creating compelling evidence to support or challenge various arguments and theories. Grounded Theory instead makes use of non-probabilistic sampling, with techniques and sampling methods known as selective sampling and theoretical sampling. These samples are then analyzed through open coding, theoretical coding, memo-writing and constant comparison in order to advance the conceptual modelprocesses which will be explained in the next section.

\section{Methods in Grounded Theory}

The previous section explained the questions of why and what, regarding the selection of Grounded Theory as the methodology for this study. This section will explore how Grounded Theory is operationalized, focusing on the core methods which move the research forwards, and advance the development of a conceptual model. This explanation begins with introducing the sampling methods, the coding methods, memo-writing and introducing the concept of constant comparison, as it pertains to this study of the intersection between physical infrastructure and behaviour change.

\section{Sampling Methods}

Thompson (1999) refers to selective sampling as the "tentative theoretical jumping off points from which to begin theory development" (p. 816). This means that relevant and related literature on the topic and research questions can be investigated before any data is collected, which alludes to Strauss and Corbin's idea of 'sensitizing' the researcher. After the research has begun, and coding process nears it's completion, the sampling style is narrowed in order to advance the 
developing theory. In this way, theoretical sampling seeks to identify new cases, which might provide a deeper understanding of the cases already examined through the selective sampling process (Drauker et al, 2007).

There can be a further narrowing focusing on particular participants, through the selection of a critical case. Patton (2002) describes critical cases as those examples that can make a point quite dramatically. A clue to the existence of a critical case is a statement to the effect that "if it happens there, it could happen anywhere," (p.174). However, critical cases that are singular have limited statistical generalizability, there is the potential for logical generalizability - a situation which is consistent with the rest of the data being collected in this study. These various methods of sampling draw data from more and more specific sources, taking the constituent segments of a wide variety of stories, and constructing a theory from that data, which contributes to a richer and all-encompassing narrative. With this methodology used for the analysis of the data, and the advancement of a conceptual model, perhaps a theory can emerge that will have some explanatory power when considering the central research question of why people start cycling more frequently despite lack of improvements of cycling facilities, as well as the supporting investigative question. The theoretical processes involved are covered in the next section. The methods utilized, theoretical selections and critical cases will be covered in the next chapter.

\section{Coding Methods}

Charmaz (1995) identifies a two step-coding process in data analysis, which begins with line by line, also known as open coding, followed by a process of theoretical coding, which organizes the open codes. The process of open coding involves looking for word repetitions, key words in context, missing information, and comparing and contrasting terms (Charmaz, 1995). These relationships can be 'coded', often with gerunds, so as to situate the code in a more dynamic, conceptual context (Khandkar, 2014; Calman 2014) ${ }^{1}$. According to Charmaz (2006), the next step is the theoretical coding. Theoretical coding involves identifying the relationships between the open coded pieces of data. The observed relationships between these open coded pieces of data begin to suggest categories, which can then be analyzed and compared to other open coded pieces of data and memos, further refining the conceptual model

\section{Memo Writing Method}

Memo writing is a method, which captures the researcher thoughts and reflections during the open coding and theoretical coding processes. The memo does not summarize the data - it conceptualizes the data. The researcher, at any point in time, makes memos. The spirit of the memo is that when reflecting on data, results, ideas, revelations, and especially the relationships that exist between them, the connections are recorded (Khandkar, 2014). These memos are later organized according to their own logic, to be incorporated into the research. Taking queues from Glaser, Khandkar offered the following guidelines on the memo-writing method in Grounded Theory Research:

\footnotetext{
${ }^{1}$ Both Khandkar and Calman provide resource to guide the research through the process of coding.
} 
"Keep memos separate from data; Stop coding when an idea for memo occurs, so as not to lose the thoughts; A memo can be brought to you by literally forcing it, by beginning to write about the code; When a lot of memos on different code appear similar, compare the codes for any differences that may have been missed. If the codes still seem the same, collapse to codes into one code; When you have two ideas, add two separate memos to avoid confusion.”

(Khandkar, p.3)

\section{Constant Comparison and Evolution of Categories}

Constant comparison is the underlying principle, which interconnects open coding, theoretical coding, and memo writing. It is a process which is done over and over (i.e., iterative process), as the research continues. Strauss and Corbin (1990) suggest that through this repetitive comparison, that do the categories begin to emerge (p.63). This methodical and reiterative process of constant comparison helps form emergent categories based on 'distinctness' and 'internal cohesiveness' (Orsini 2005), which provide opportunities for further analysis. The categories, in which all of the results of these other methods are sorted into, are products of the application of the principle of constant comparison. It should be noted that these methods have large impact on the research-tool design, presentation of findings, yet it is the organization of the subsequent analysis of the each sub-section that has the largest impact on the progression of the conceptual model, and thus the development of the argument. Yet, it is because the codes and data are compared back and forth, time and time again, that when coded information is introduced, the interpretations are also updated - a process that describes the principle of constant comparison. It is the process of constant comparison that enriches the interpretation and connections within the data collected.

In summary, an initial literature sensitizes the researcher, and informs the initial selective sample. The research tools, such as a survey and the focus group are tailored to target the selective sample. The results of the survey and focus group are coded and subsequently categorized, and then compared back to the literature and the memos created during that process - and theories that start to emerge can be used to develop the theoretical sample. Once the rationale for the theoretical sample has been established, the new data that is collected is coded and categorized, and compared with the previous memos and codes. This process of coding, categorization, memo writing and comparison is non linear, and repeats for every new selection of data that is made. Any conceptual model that is generated from this process is intimately linked to the information collected, the reflections of the researcher, and broader connections literature - all of which combine to create a very data-rich, conceptually-dense, grounded theory. 


\section{Chapter 4. RESEARCH METHOD}

This section is a departure from the theoretical foundations of the methodology and methods involved in Grounded Theory research, and explains the methods that were used in this study in greater detail. The details include aspects of the ethics review process, participant recruitment, the data collection tools (survey, focus group, follow up questions), the method of data collection, and the steps involved in the analysis of that data..

\section{Ethics Review}

The Ryerson Ethics Review board approved the list of questions for the survey (Appendix B) and focus group (Appendix C). The research proposed a 90-minute session, composed of a 15-minute survey and a 75-minute recorded focus group. Participants were offered a $\$ 20$ honorarium. The Ethics Review Board approved the recruitment strategy, which included scripted emails (Appendix D) and recruitment poster (Appendix E). A template of a consent form provided by the Ethics Review Board (Appendix F), and modified to state that every attempt would be made to keep their identities confidential, and that although audio recordings would be made, that the records of these recordings, as well as all other primary notes, would be securely stored until their destruction.

\section{Participant Recruitment}

The research was initiated through an initial literature review, scanning articles regarding behaviour change, physical activity and cycling. The matrix of behaviour change literature (Cohlymer, 2012) provided by the Toronto Cycling Think and Do Tank was essential during this process, in which the selective sample was created.

Grounded Theory suggested that the selective sample remain as general as possible for as long as possible, so as to maximize the diversity in data in the early stages. Handy and Underwood (2012), and Orsini (2005) had all focused on high school aged persons, and there seemed to be a lack of research on adults of university age. For this reason, persons of university age became of particular interest. To begin the recruitment, the criteria were established as follows: The age was set to 16 , as this is the lowest age possible to legally consent in research.

Posters were placed at bike racks around Ryerson University Campus, and the Ryerson Bike Room. Scripted recruitment emails were sent out to the potential participants that responded, and included the ethics approved consent form. The first potential participants to confirm a slot in the focus group schedule were admitted onto the participant roster.

\section{Data Collection Tools}

When determining which data collection tools would be the most appropriate for the mixed method approach, a range of factors were considered in. A stock variable a measurement at one instant of time, which has built up over the passing of time - whereas a flow variable is the same phenomena, measured over an interval of time, in which the effect of time can be observed (Robinson, 1982). As such, a survey was selected to take stock of participant's current attitudes and behaviours, whereas a focus group was selected to capture the same participants' development of attitudes and 
behaviours over time. The survey was designed to partly measure participant's demographic information, as well as capture a stock of their 'cycling autobiography'. The focus group was selected to try get an idea of the 'flow', that is the development, of their attitudes and behaviours over time. The technical aspects of their respective designs will be covered in the subsequent section.

\section{Data Collection Process}

The two data collection events occurred on Sunday February $16^{\text {st }}$ at 3:00pm and 6:00pm on Ryerson University Campus. When participants arrived, they were asked to fill out the consent form, following which the activities over the next 90 minutes were outlined. Participants were provided with pen and a paper copy of the survey, for which they had 15 minutes to complete. After all the participants had to complete the survey (i.e., number of questions in 15 mins), then an audio recorder was turned on, and the focus group session began (e.g. number of set questions used to illict responses).

The survey in Appendix B was used in this research project was modeled on City of Calgary Cycling Survey (2011), as carried out by HarGroup Consulting. The four categories they use are analogous to Geller's four types: Strong and Fearless, Enthused and Confident, Interested but Concerned, and Totally Uninterested. Similar segmentation analyses have been done by Transport for London, in their Analysis of Cycling Potential (2010), and other municipalities. Recall that TTM seeks to understand the intention-dynamics of one observed type of behaviour, and then understand factors that lead to the adoption of another behaviour. When this is combined with the Geller's Four Types, there is a possibility that the factors involved in helping understanding how relatively inexperienced and casual riders, are adopting behaviours and attitudes of Enthused and Confident riders. This ties right into the central research questions, and helps situate the narrative of the focus group design.

The largest theoretical influence on the survey was Geller's Types of Cyclist (2006) which sought to explore the intersection of cycling behaviours and the absence of bicycling infrastructure - and express this intersection by labeling participants as different types of rider. This is accomplished by looking at level of activity, purpose, intentions, perceptions of safety and comfort, identity, as well as barriers and motivators (see Appendix B for survey).

The focus group (Appendix C) was a semi-structured group interview that would be audio-recorded, and would take place over 75 minutes. The focus group design was informed by a few key pieces of research. Underwood and Handy (2012) used surveys and interviews to study cycling during adolescence, and the formation of their attitudes and behaviour based on positive attitudes earlier in life on the part of 50 cyclists. Underwood and Handy employed the retrospective approach, in lieu of a longitudinal study, as used by Perkins. 1Orsini (2005) looked at attitude and behaviour of adolescents that rode to high school using mixed-method research through focus groups and interviews, using a Grounded Theory approach. The Grounded Theory approach was used to explore the connections between cycling during youth, and cycling in adulthood, especially relating to positive attitudes and social dimensions of those experiences. 
After the question was posed, and the participant answered, the other participants had opportunities to interject and discuss the differences or similarities in responses. This allowed a narrative space for participants to share their experiences, and a flow of information that was much different that the data collected in the survey. The questions covered the lifetime of each participant, exploring riding attitudes and behaviours beginning around elementary school, to high school, post-secondary, and from graduation, until current day. During each period of life, the same questions were repeated: "Did you ride during ___ ? If so, how often, where did you go, and who did you ride with? If not, why not? Having a range of types of riders participating was useful because, even if someone is 'Strong and Fearless' in 2014, they may have been Interested but Concerned in 2005 - their stories of adoption and reflections on motivators/barriers, although less recent, may not be any less relevant than more recent accounts. The open coding method was used to generate the data from the focus group.

One exemplary piece of research that did this was Perkins (2004), which studied the correlation between physical activity during childhood, adolescence and young adulthood in a longitudinal survey, which was comprised of 600 respondents, over three waves since the early 1980's. He found close relationship between exercise in childhood and adolescence, and exercise in adulthood. However, because of the limitations of available resources, a longitudinal survey was not possible, and a cross sectional survey was adopted for this study.

\section{Data Analysis Process}

The surveys were collected, and a coding rubric was created, which took the responses in the survey, and allowed the responses to be entered into SPSS and Excel. Initial analysis in SPSS found that the number of participants was too small to generate any analyses of value. The values were migrated into Excel, because of a greater familiarity with that program. Measures of central tendency (mean, median, and mode) were all taken across the whole set of data, so that individual response could be weighted against the rest of the sample. Later steps involving theoretical sampling led to a sub-division of the participants, so as to be able to draw more interesting comparisons.

The focus groups were audio recorded with an external microphone, using Garageband. A transcript was created for each session. After recordings were transcribed, the process of open coding and memo writing began. Because of time constraints, a line-by-line open coding process was not used. Instead, codes were made on a broader level to reduce the amount of time needed. This process involved listening to the audio recordings several times, while taking memos. The memos where then compared to notes taken during the original transcription, prompting another listen to the audio recordings. After this, the survey was reviewed, followed by another sequence of listening to the audio recordings, reading the transcripts and writing memos. Through this process, categories emerged by which the codes and memos could be organized, which represented the first layer in the creation of the conceptual framework. Analysis for the focus group involves a discussion on related literature, and will be explored after the results. 


\section{Chapter 5. RESULTS \& ANALYSIS}

The following section will highlight the results of the survey, which was applied to the selective sample. The selective sample consists of the 12 participants in this study: they were residents of Toronto, over the age of 16 , that rode a bike at least once a week. This loose set of critieria was determined in the literature review

\section{Survey Results}

The survey sought to accomplish following:

1. Determine demographic of Selective sample;

2. Establish reasons for cycling;

3. Rank preference of the various factors, which either encourage or discourage riding most; and

4. Establish the 'type of cyclist'.

\section{Demographics of Selective Sample}

The selective sample process resulted in 13 potential participants and 12 actual participants. The following table shows some basic demographic information about the 12 actual participants.

\begin{tabular}{ccrccc} 
& LOCATION & AGE & SEX & INCOME & \\
AR & Downtown & 28 & F & Low income & Student \\
DK & Downtown & 35 & F & N/A & NA \\
MC & Downtown & 65 & M & Middle Income & Unemployed \\
SM & Downtown & 31 & M & Upper Middle & Student \\
HC & Downtown & 46 & M & Middle Income & Tech Support \\
WB & Etobicoke & 28 & M & Low income & Self Employed \\
GG & Downtown & 29 & M & Lowest Income & Student \\
TM & Downtown & 24 & F & Lowest Income & Student \\
Dk & East York & 52 & M & Lowest Income & Messenger \\
TA & Downtown & 30 & M & Low income & Retail \\
\hline RJ & Downtown & 23 & F & Lowest Income & Student \\
RM & Downtown & 26 & M & Lowest Income & Student \\
& & & & & \\
\hline
\end{tabular}

Table 2 - Demographics of Selective Sample

\section{Reasons for Cycling}

Of the twelve actual participants, only five participants wanted to ride more than they already were. Eight participants had a driver's license, and only two had a transit pass. Despite the differences in purposes of trips, there was little deviation when considering their reasons for riding. The low cost associated with frequent bike tips is one of the most important reasons the participants chose to ride, closely followed by enjoyment and health. This is unsurprising, considering the high number of low-income earners and students in the sample. When asked about their riding behaviour, there was a distinct difference between the student and non-student participants. Students' most popular trip was the ride to school, with services and fitness as the next most popular trips. For non-students, accessing services was the most popular trip, followed by trips to work and for fitness. The high proportion of students was likely to have contributed to the large number of participants in the lower income brackets, and the high regard for the low cost associated with cycling. These differences made it clear that students would be a potential aspect of the theoretical sample as the research develops. 


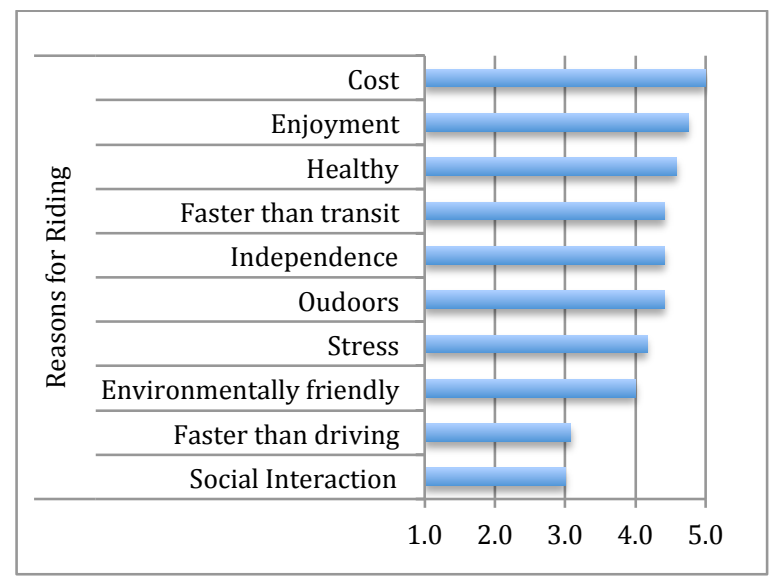

Figure 1.1 - Reasons for Riding

\section{Factors Encouraging and Discouraging Cycling (Motivators and Barriers)}

A later part of the survey asked participants to rank their preference of the various factors, which either encourage or discourage cycling most. Because of the frequency and enthusiasm of many of the participants, the factors which encouraging riding seemed to be largely more influential that the things that discouraged riding, as reflected by stronger positive responses across all participants. The top deterrents were weather, which includes road clearing in winter, and aggression from other road users, which includes private vehicles, trucks and other cyclists. Some of the least influential deterrents include fitness, confidence and image. The things that would encourage riding are unsurprising, and are touted by academics, policy makers and advocates as being necessary steps to increase ridership: More bike lanes, more cycle-tracks, a larger number or clearly market routes, and more parking at origins and destinations.

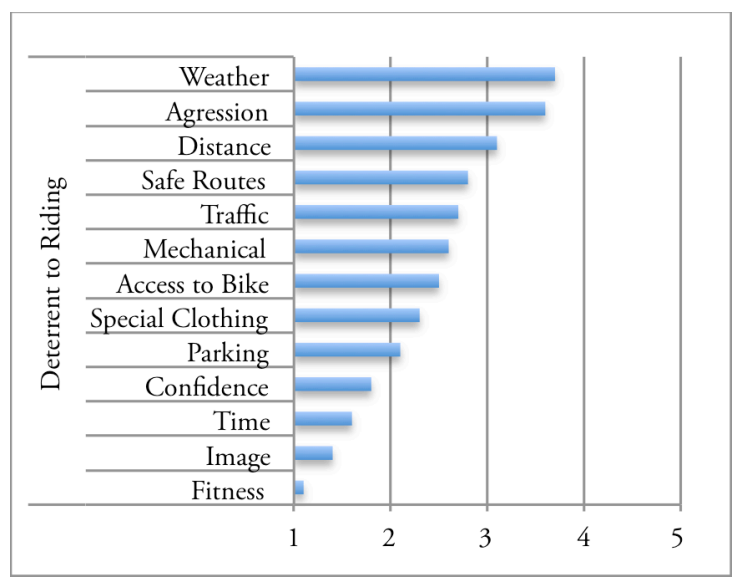

Figure 1.2 - Barriers for Riding

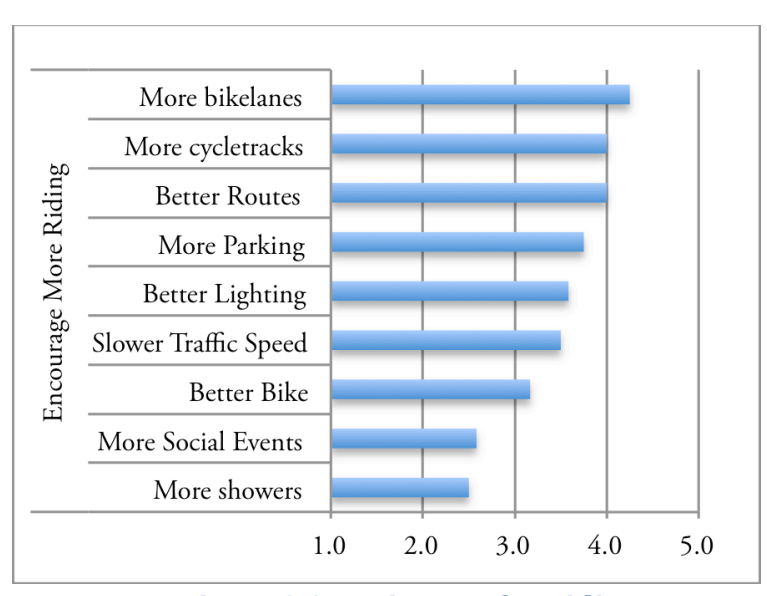

Figure 3.3 Motivators for Riding

These results are not significant at the current level of analysis - and represent what could be described as a 'common knowledge' for anyone that has ridden a bicycle around Toronto. This will serve as the attitudinal baseline, on which subgroups can be identified, and compared to other subgroups throughout the study. 


\section{Cyclist Types}

The next important analytical process was to extract the cyclist types from the data set, and understand divisions that already exist within the selected sample population. The division of each of the participants into their respective cyclist type relates directly to the third central research question: What 'type' of cyclists are those that have recently begun to ride frequently for more practical purposes? Segmenting the sample to identify individuals that may be on the cusp beginning to ride, would be even more useful if there was a better understanding of what encourages them to cross over that threshold, and begin to ride frequently. It also begins to address the major question: why certain people decide to take up riding, despite the lack of cycling infrastructure? According to the City of Calgary Survey (2011), the differentiation between each type of cyclist is driven to a large degree by the comfort thresholds regarding the absence of cycling infrastructure. The survey responses were compared with the Cyclist Types guideline, as found in the of the City of Calgary Survey. Its guidelines were adapted into excel by weighting the ranked preference responses.

1. Comfort on the busiest roads was weighted at $30 \%$.

2. Decision to ride in any weather was weighted at $20 \%$.

3. Riding when other available modes may be more convenient was weighted at $20 \%$.

4. Cycling as part of identity was weighted at $15 \%$.

5. Importance of riding a bike in their life was weighted at $15 \%$.

As seen in the weighting scheme, comfort on busy roads is the largest determinant of the 'Strong and Fearless' type. The comfort on busy roads becomes less significant in the responses, such as in the distinctions between 'Enthused and Confident' and 'Interested but Concerned' participants - a more nuanced difference may need to be calculated. Regardless of the potential lack of weighting sensitivity, the differences between these two types of cyclist within the sample were significant enough to segment the participants without issue. It should be noted that the high number of strong and fearless riders, as well as high number enthused and confident of cyclist represented in the selective sample population could be partially explained by the time of year, and the location of the posters.

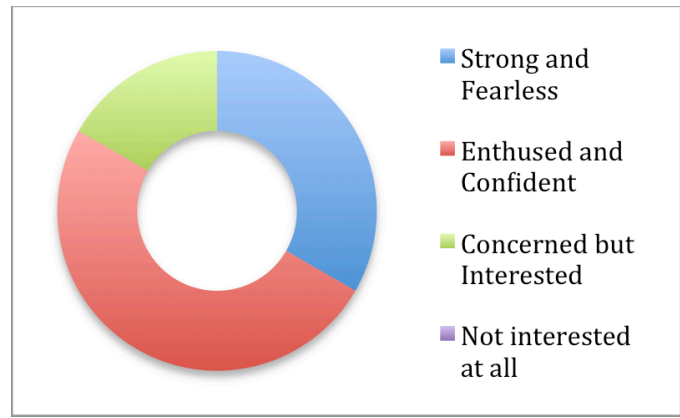

Figure 2.1 - Selective Sample

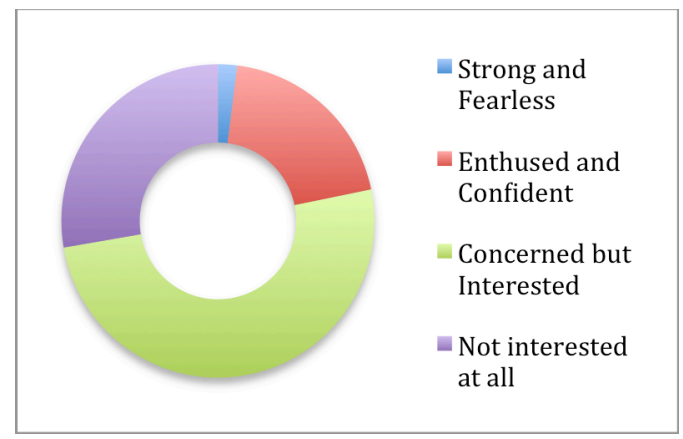

Figure 4.2 - City of Calgary Survey (2011)

The analysis of survey data reveals an answer to the question: What 'type' of cyclists are those that have recently begun to ride frequently for more practical purposes? Two riders are concerned but interested, four riders are strong and fearless, and six are enthused and confident. Despite clear divisions in survey data, focus group responses need to be coded, categorized, and compared to the survey findings before a theoretical sample can be made to advance the conceptual model. 


\section{Focus Group Results}

The focus group immediately followed the survey exercise. The voice recorder was turned on, and the list of semistructured questions was discussed around the table of participants (see Appendix C for list of semi-structured questions). After the question was posed, and the participant answered, the other participants had opportunities to interject and discuss the differences or similarities in responses. This allowed a narrative space for participants to share their experiences, and a flow of information that was much different that the data collected in the survey. The questions covered the lifetime of each participant, exploring riding attitudes and behaviours beginning around elementary school, to high school, post-secondary, and from graduation, until current day. During each period of life, the same questions were repeated: "Did you ride during ___ ? If so, how often, where did you go, and who did you ride with? If not, why not? Having a range of types of riders participating was useful because, even if someone is 'Strong and Fearless' in 2014, they may have been Interested but Concerned in 2005 - their stories of adoption and reflections on motivators/barriers, although less recent, may not be any less relevant than more recent accounts. Transcripts were created from the audio recordings. The open coding method was used to generate the data from the focus group (see Appendix G), with memos recorded concurrently, but later segregated in a different document (see Appendix H).

\section{Open Coding, Theoretical Coding and Categorization}

Open Coding is the main building block of the constant comparative method, and is applied to anything and everything, in order to sort and relate the emerging ideas from one to another. The purpose is to eventually develop or identify theoretical codes, which accounts for a large degree of variation in the data that can be used to inform the theoretical sample. This process towards discovery is guided by questions such as: What is this data studying?; what is the broader category to which this relates?; is there anything beyond what is being mentioned explicitly?; and what is happening in the data on a deeper level? The theoretical coding process began to conceptualize how these open codes may relate to each other as hypotheses to be integrated into the theory.

The limited data set involved in this research, so less sophisticated systems were used for the coding and memo writing processes: Transcripts were created from the audio recordings, codes were created on a broader than line-by-line basis, with memos recorded concurrently, but later segregated in a different document. After the open coding for each focus group was complete, they were added and compiled into single document, and condensed into an Excel sheet, and their frequency of appearance was tabulated. Orsini (2005) used a similar technique, by using the frequency with which category would appear, as justification to attribute theoretical weight to the category in question. Below is the summary table of the theoretical codes prepared as the result of open coding process. 


\begin{tabular}{|lrrr|lrrr|}
\hline Theoretical Codes & $3: 00$ & $6: 00$ & \multicolumn{1}{l}{ COMBO } & Theoretical Codes & $3: 00$ & $6: 00$ & COMBO \\
\hline Riding with Role Models & 6 & 5 & 11 & Expectation to drive & 4 & 4 & 8 \\
Objectifying the Bike & 8 & 7 & 15 & Embarrassed to ride & 4 & 4 & 8 \\
Limiting Circumstance & 11 & 9 & 20 & Social Transport & 10 & 8 & 18 \\
Too close to ride & 4 & 3 & 7 & Cycling Status & 3 & 1 & 4 \\
Breaking Boundaries & 10 & 8 & 18 & Significant Life Experience & 10 & 8 & 18 \\
Remembering Pain & 1 & 1 & 2 & Giving back & 2 & 1 & 3 \\
Mechanical Frustration & 3 & 1 & 4 & Cycling Culture & 2 & 2 & 4 \\
Enjoying the experience & 8 & 6 & 14 & Awakening & 4 & 3 & 7 \\
Common sense & 2 & 0 & 2 & & & & \\
\hline
\end{tabular}

Table 3 - Theoretical Codes from Focus Groups

\section{Memo Categorization and Memo Clustering}

As the focus group recordings were undergoing the open coding process, memos were written concurrently. As the open-codes were categorized (see table above), and memos were recorded. All of the memos were a byproduct of the coding and subsequent categorization processes, as well as thoughts that related to the survey. The large amount of memos created during these process needed to be organized into memo-categories and memo-clusters, so they could be related and compared to the theoretical codes created during the open coding. The memo-categories developed are as follows:

- Psycho-geographic nostalgia;

- Perception of risk;

- Perception of ability/fitness;

- Mainstreaming;

- Positivity and coolness; and

- Negativity and stigma.

However, the memo samples and their resultant memo-categories also revealed another possibility for conceptual clarification. The memo-categories could be grouped into broader memo-clusters, person reflections and social reflections, which help develop a structure, which assisted in the interrelation, and also allowed for a more streamlined comparison with the theoretical codes developed earlier.

The memo samples in the table below (see Appendix $\mathrm{H}$ ) has been taken right from the main document, so as to show the type of memo being recorded, and how they relate to the concepts on higher theoretical tiers. The table on the next page shows these constituent memo samples the memo-categories in which they are organized, as well as the broader memo-clusters. Memo-clusters, as expressed in the table above, consist of social reflections and personal reflections - both revolving on the act of riding a bicycle frequently. 


\begin{tabular}{|c|c|c|}
\hline Cluster & Category & Sample \\
\hline \multirow{4}{*}{ 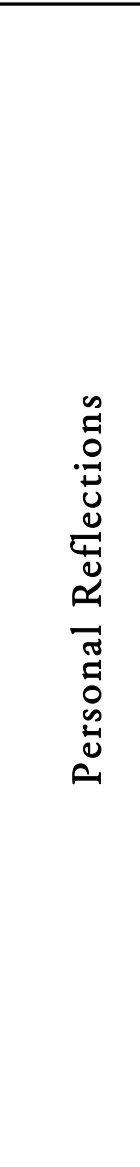 } & \multirow{2}{*}{ 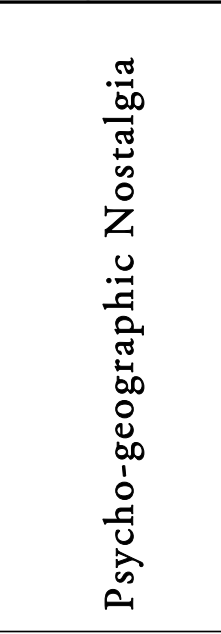 } & $\begin{array}{l}\text { HC There is a great deal of awareness about boundaries, and the physical } \\
\text { limitations that are imposed on a young rider. There is often a strong } \\
\text { connection with the sense of freedom when these boundaries are surpassed and } \\
\text { overcome. It allows for children to have moments of independence, which } \\
\text { creates space for adventure and even mischief. MC had a story about breaking a } \\
\text { speed limit, and going home to tell his father, interesting mix of pride, } \\
\text { criminality and absurdity. }\end{array}$ \\
\hline & & $\begin{array}{l}\text { TA cherishes the refreshed perception that comes with riding a bike. Being } \\
\text { able noticing the small things, like watching harrier hawks in the marsh. This } \\
\text { is used in contrast to the experience of traveling by car, how confining it feels. } \\
\text { He makes a distinction between 'traveling' and 'moving', and the interactivity } \\
\text { with surrounding that is lost when moving by car. It is likely that } \\
\text { desensitization occurs in other respects, such as towards other road users. Does } \\
\text { this tie into instances anxiety reported by other participants when using modes } \\
\text { such as transit and auto? }\end{array}$ \\
\hline & 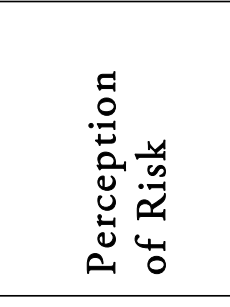 & $\begin{array}{l}\text { Consider the responsibility of different road users. Her said they trusted her, } \\
\text { but not the drivers. What determines the boundaries responsible road use, and } \\
\text { the boundaries of personal responsibility? The idea of the Other, and perceived } \\
\text { safety when sharing space with them. You never creating the danger, it is } \\
\text { always other people. There is an interesting intersection with perceptions of } \\
\text { competence, confidence and safety. In the context of thinking about tragic } \\
\text { accidents, you are someone else from other people's perspective. }\end{array}$ \\
\hline & 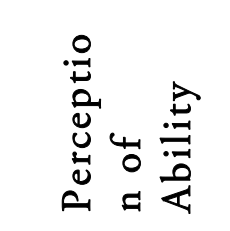 & $\begin{array}{l}\text { You realize how small distances are when you bike them. Shrinking of } \\
\text { geographic space. As you age and grow up, the sphere of accessible spaces } \\
\text { begins to expand. Revisit places later in life, and distances seem different. The } \\
\text { things that seemed too far, or too hard no longer seem to be so [x-post to } \\
\text { psycho-geography]. }\end{array}$ \\
\hline \multirow{3}{*}{ 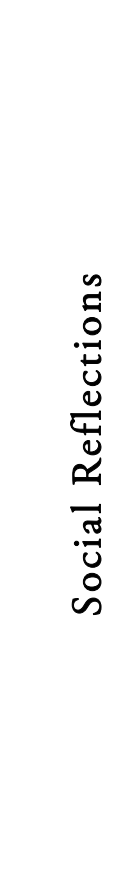 } & 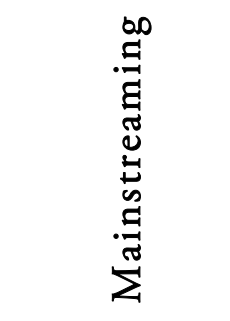 & $\begin{array}{l}\text { In some condos, you can't bring the bike in the elevator. Office buildings DT, } \\
\text { you can't bring a bike inside. "If things are not laced tight and straight, they } \\
\text { have no place in that space." What is the boundary of cycling in Toronto, and } \\
\text { how can it shift? Consider that in Amsterdam, suited lawyers ride their bikes to } \\
\text { work. Where does this division come from? Class? Is the bike a working class } \\
\text { symbol, or a white-collar hobby? Perhaps this ties into the idea of the divide } \\
\text { between recreational and utilitarian riders? }\end{array}$ \\
\hline & 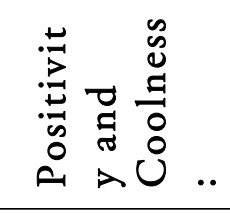 & $\begin{array}{l}\text { She watched the movie Premium Rush, and it was a formative experience for } \\
\text { her..."it looked really cool". Inspired her to ride more, but also instilled an } \\
\text { image of an ideal 'Cyclist'. What was it about premium rush that she loved? } \\
\text { What was the projection of cycling positive or negative in a wider sense? }\end{array}$ \\
\hline & Zi & $\begin{array}{l}\text { When she is referred to as a cyclist by her family it is often in the negative - } \\
\text { family members who depends on cars as their transportation and refer to her as } \\
\text { having no right to the road, being an annoyance, being reckless, and needing to } \\
\text { "grow up" and participate in transportation that they perceive to be legitimate } \\
\text { (transit, car). When remembering mode choice back in BC, tt was just a given } \\
\text { fact of life... "the roads were for cars, and you would never, when I look in } \\
\text { Toronto now, you would never see cyclists on the road - you see tractor, but } \\
\text { you never would see a bike on the road." }\end{array}$ \\
\hline
\end{tabular}


The conceptual model presented in the graphic below was created to help visualize the relationship between the theoretical codes, the memo-categories and the memo-clusters. The memo-clusters are represented by green and yellow circles. In each circle, the colored lines connect memo categories on the inside to the theoretical codes listed on the periphery. In these lists of theoretical codes, the darker texts denote the more common codes, whereas the lighter texts denote less common codes.

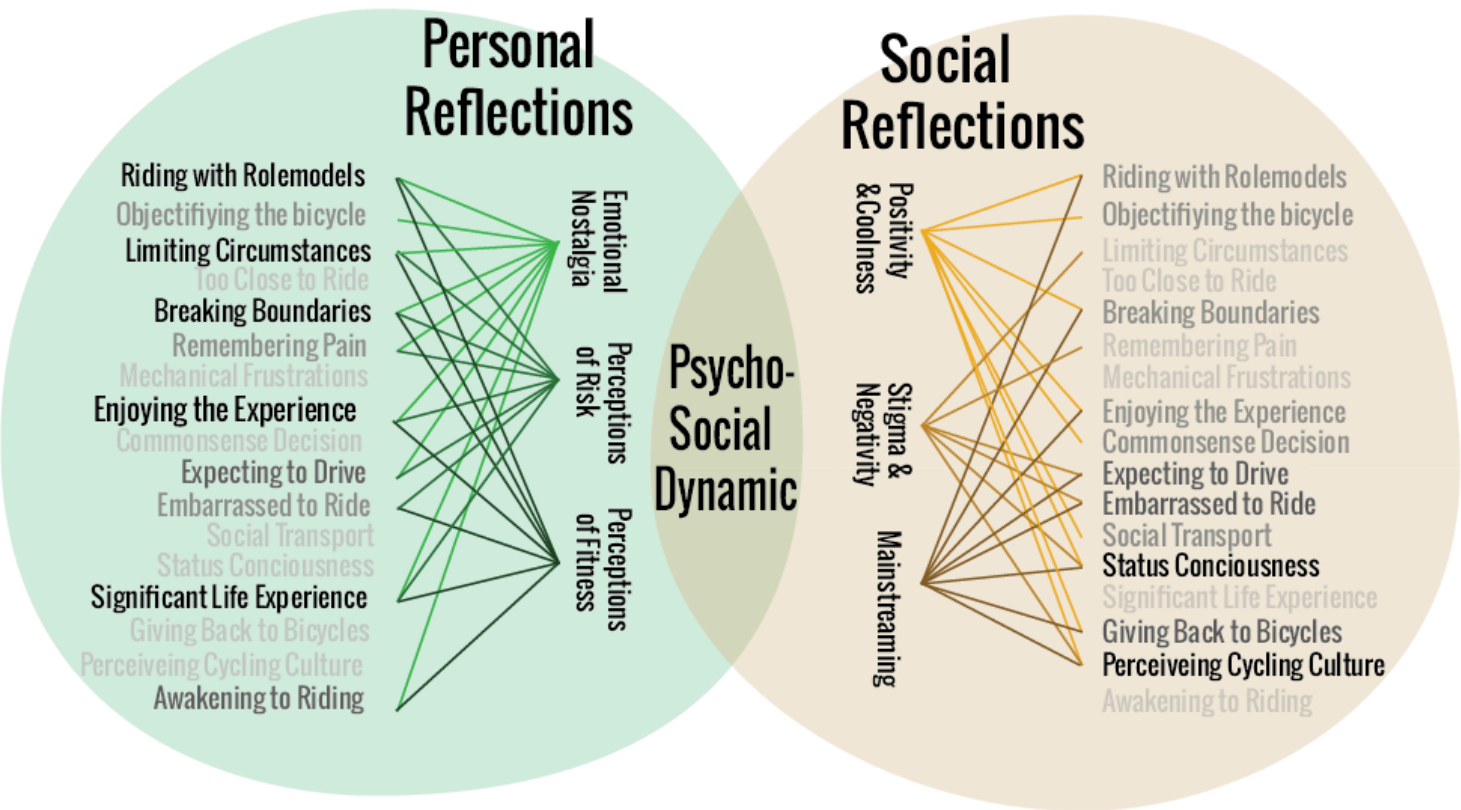

Figure 5 - The Psychosocial Dynamic (Memos Categories, Clusters and Theoretical Codes)

The circle of 'personal reflections' can be understood as an internally focused narrative, regarding one's own psychogeographic nostalgia, perceptions of risk, ability, physical limitations and so forth. The circle of 'social reflections' can be understood as an externally focused narrative, regarding ideas about one's own stigma, coolness, and what is considered mainstream.

The only feature of the conceptual model show above that has not been accounted for is the overlapping portion, which is labeled as the psychosocial dynamic. The psychosocial dynamic can simply be defined as the interrelation of social factors and individual thoughts and behaviours $\left(\mathrm{OED}_{1}, 2014\right)$. The concept of the psycho-social dynamic emerged from data collected during the focus group interviews, and it's coded interpretation - it emerged at a more conceptual a level and in a position of prominence within the foreground of the emergent theory.

It may seem like this representation omits policy, geography, and physical space. But when the transcripts and open codes from the focus groups were examined, it is apparent that geography and infrastructure have been internalized in the responses of participants. Participants did not speak about distance in terms of 'meters'. Instead, they would talk about distance in terms of 'too close' or 'too far'. These are social and psychological reflections of the physical circumstances when visualizing a more holistic view of the decision to ride, recognizing geography and physical infrastructure are external forces that need to be considered. Although the element is internalized in the responses of 
the participants, geography and infrastructure are also very tangible, and can serve as an independent variable of sorts, that can be used to explore various intersections and relationships as the conceptual model evolves.

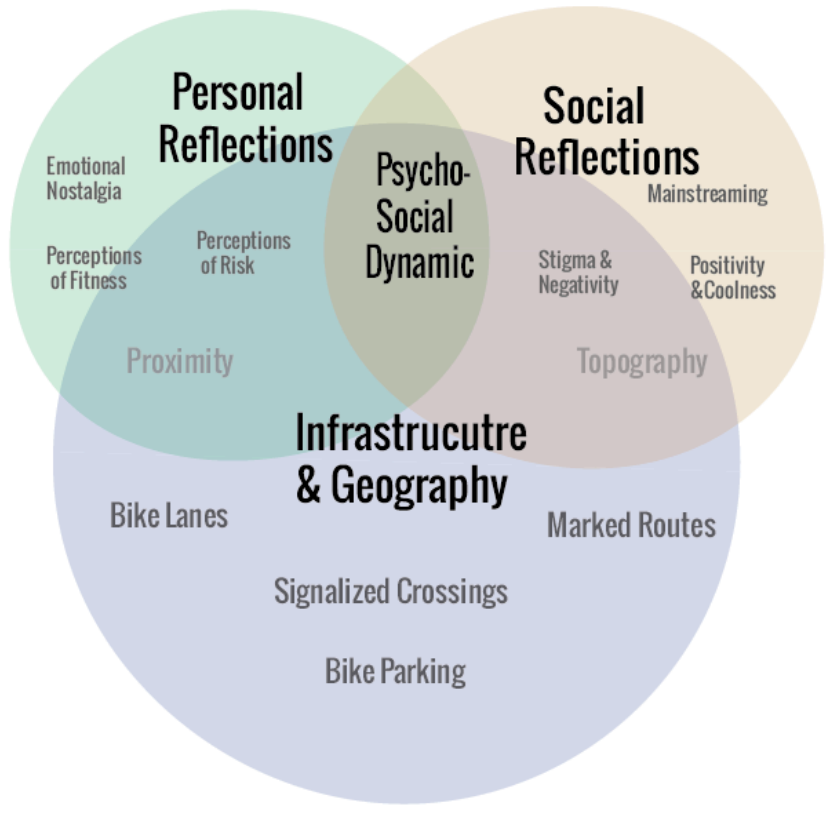

Figure 6 - Psychosocial Dynamic with Physical Factors

\section{Observations Relating to Related Research Questions}

The analysis of the focus group and survey produces some insights regarding the following question:

What is the impact of geography, bicycle infrastructure, and facilities in participants' decision to ride a bicycle more frequently for practical purposes? One discovery is that this question has two parts: The first component inquires as to how influential geographic proximity is in relation to mode choic. The second component revolves around uptake, implying a change in behaviour. So to answer this question, the focus must be on the intersection of behaviour change and proximity. However, this view is further complicated, because based on the Geller's Four Types and the responses from the focus group, it would seem that different types of cyclists have different understandings of 'too far' and 'too close' and also include implications regarding a perceived comfort despite the lack of infrastructure. The result is a more holistic decision to ride model, which the 'weight' of geography and infrastructure is not fixed.

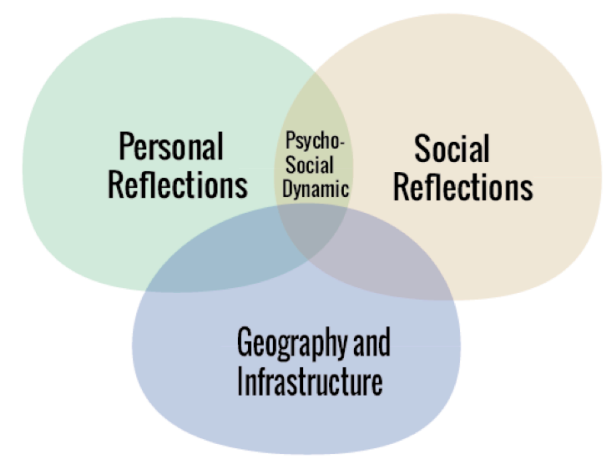

Figure 7.1 - Strong and Fearless Dynamic

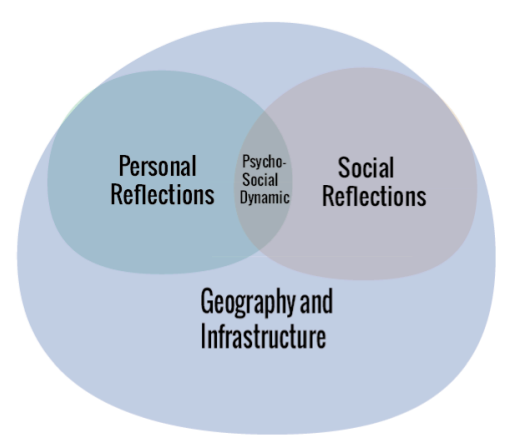

Figure 7.2 - Interested, but Concerned Dynamic 
Figure 5.1 shows an example of the dynamic for a 'Strong and Fearless' rider, where geography and infrastructure have decreased their influence on mode choice, as shown in the survey responses. Figure 5.2 shows the dynamic for an 'Interested but Concerned' rider, where geography and infrastructure exert more 'weight' on the psychosocial dynamic, perhaps overpowering any personal or social motivation to consider riding. This suggests that distance is indeed a driver of cycling adoption, but only for certain types of riders - the more experienced they are, the less influence distance experts on their mode choice. As such, an answer to the first component is easy, yet the second component of this question is more perplexing. What drives the change from someone being an interested and concerned rider to becoming a strong and fearless rider? More specifically, what would encourage an 'interested and concerned' rider to start cycling, despite no change in infrastructure and geography?

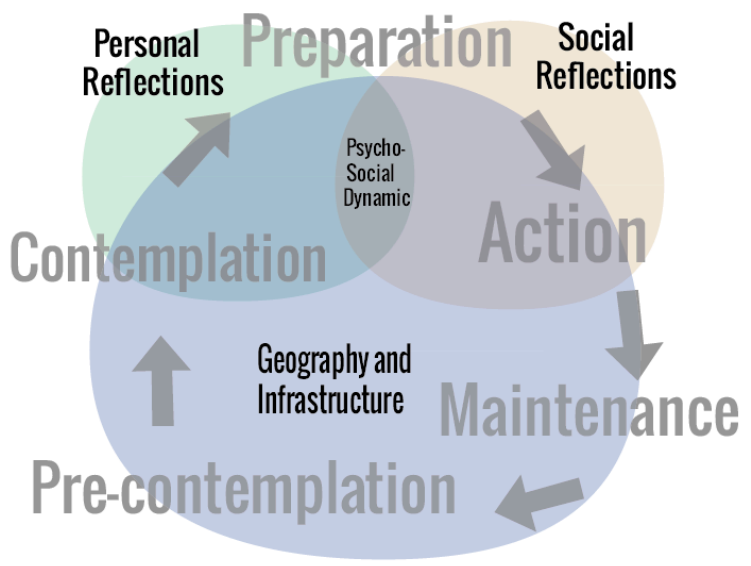

Figure 8 - TTM and the Dynamic of Mode Choice
This next question is:

Of those persons that currently cycle frequently for more practical purposes, is it behaviour continued from prior in life, or a recently adopted behaviour?

This question relates back to the idea of behaviour change and TTM. However, does any type of riding prior in one's life constitute a 'continuation' of behaviour, or must it be frequent cycling for trips to school and work that is being continued? The literature suggests that physical activity in early life, is a determinant of levels of physical activity later in life (Perkins, 2004). Recognizing this distinction means that when 'uptake' of riding is being discussed in this context, it

refers to a change in behaviour - more frequent riding, and increased trips to work and school. There is not a single case of someone beginning to ride later in life, after not having learnt to ride child. This suggests that the experience of the experience of selected. All twelve participants learnt to ride a bike as a child - around the time when they attended elementary school. It was always a family member who taught them, predominantly the parents, although siblings and cousins also were involved. During this time, almost all of the participants reported riding for fun and recreation, whereas only about half rode to school on an occasional basis. This was a trend that continued through high school, with frequency of riding continuing to decrease. It is interesting to note, that of the twelve participants, only one stopped cycling entirely during high school. This means that all of the 'uptake' of frequent cycling behaviour being captured in this study only consists of individuals with previous occasional recreational riding experience, who switched to more frequent and purposeful riding behaviours. Considering that most of the participants started to introduce frequent and purposeful riding at some point in their riding history, looking at the most recent cases of uptake was determined to be a good strategy, as their memories would be most recent. 


\section{The Staged Mode Choice Ecosystem and the Ecological Model}

The following diagram (figure 7 below) shows the staged mode choice ecosystem - the most recent expression of the conceptual model, which seeks to visualize the intersection of psycho-dynamics with infrastructure and geography. This particular articulation also integrates the different bands of grey, to represent Geller's four types of cyclist, which also reflect representing different sensitivities to infrastructure and geography indirectly. This can be measured indirectly because as the skill and confidence of the rider increase, concerns about geography and infrastructure becoming less influential in their decision to ride - with psycho-geographic factors gaining influence. This combination of different theories has some interesting implications for TTM, as well as other theories of behaviour change. The most interesting implications include rebuttals to some of the criticisms mentioned by Adam and White (2004).

The first criticism in the fashion of Adam and White is that exercise is a complex of different behaviours, and not a simple behaviour like smoking (Adams and White, 2005). This criticism is weak due to the misrepresentation of smoking as a simple less effective than was anticipated. Aveyard and Bauld (2011) performed a review of studies that treated smoking as a simple behaviour, and the results were disappointing - which lead the authors to conclude that the most effective smoking cessation interventions treated it as a complex behaviour. This relates to the next

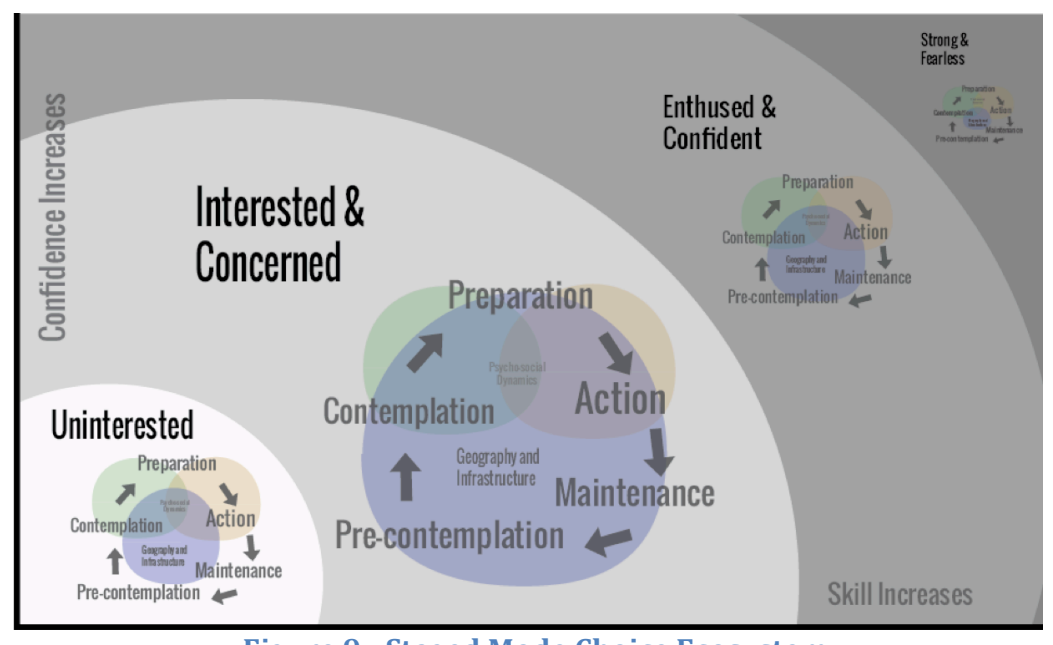

Figure 9 - Staged Mode Choice Ecosystem criticism, that exercise behaviour is influenced by numerous external factors, which is not considered by TTM (Adams and White, p.240). By contextualizing the TTM cycles within the conceptually broader 'types of cyclist', the psychosocial and infrastructural elements have been somewhat internalized within the theory. In this way, TTM does not need to consider them explicitly, as the context takes them into consideration. This relates to the next criticism: that determining the stage of change is crucial to intervention delivery (p.240). Contextualizing TTM within the cyclist types means that intervention delivery could be based on the individual's current riding behaviour, and their selfreported sensitivity to infrastructure and geography. A refined survey process can be used to differentiate these different types, and any change in behaviour would be verified through observation, or a follow-up survey. This addresses another criticism: that a progression of the TTM stages itself is considered a significant outcome (p.240). By contextualizing TTM in the cyclist types, the TTM stages recede into the background, with changes between cyclist types becoming the only metric of significance. The final criticism is that stage-based interventions require more than one level of development and evaluation (p.240) - a criticism which has continued to persist. Although the contextualized expression TTM does little to address this criticism, challenge of multi-level analysis and evaluation is 
being addressed by academics, with groups such as the Cycling Think and Do Tank continuing to research and investigate stage-based interventions and cycling uptake.

Although this hybrid theory/conceptual model may provide some novel features, there are other some concerns that should be addressed. This conceptual model is heavily weighted to individual perspective, and perhaps does not take a broad enough range of factors into account. There are many other nuanced details, which if changed, may have an influence on the individual in ways that this conceptual model does not address. Zoning codes, transport policies, subsidized equipment, healthcare policies or incentives are all external levers that are very influential in the decision to begin to ride, but their direct attribution is almost completely omitted in the conception advanced by the conceptual model. Although the Stage Mode Choice Ecosystem, as developed in this study was imperfect, it was an interesting exercise, and led to some interesting insights regarding the shortcomings of TTM.

There is another approach that seems to account for many of the things, beyond the shortcoming of the conceptual model developed within this study. James Sallis (2006) uses the Socail Ecological Model do understand the influences on Active Living (see figure 8). The inner most circle is the intrapersonal, which speaks to the psychological, with the social aspects of the psychosocial dynamic, as expressed in this study's conceptual model. The next circle is the 'perceived environment' which incorporates the ideas of comfort, accessibility, and safety. Both of these circles are subsumed by the larger circle of 'Active Living Domains', which includes active transport, occupational activities, active recreation, and household activities. All of these are set in the circle called 'Behaviour Setting", which is analogous to the 'infrastructure and geography' component of the conceptual model developed in this study. The final circle that encapsulates all of these previous circles is the policy environment. Discussion of policy was totally absent from the survey and focus group, and this explains its lack of presence in the model that emerged from this study. It is clear that Sallis' Ecological Model is more comprehensive, as it captures the multiple layers, and multitude of factors in the decisions that relate to an active life. This holistic approach is also interesting because in includes transport, recreation, occupation and household related trips as different domains of transportation behaviour, and does not treat them as being mutually exclusive. The only challenge is understanding how the ecological model could be used in the design behaviour change interventions. It has been noted that interventions need to be multi-layered so as to be effective, and the Ecological Mode provides a very clear visual of the different layers that are involved. In this way, a contextualized TTM may be useful for evaluating behaviour change interventions, whereas the Ecological Model is an important part in contextualizing the specific behaviour change intervention, and could be used to suggest complimentary interventions, so as to encourage the most uptake 


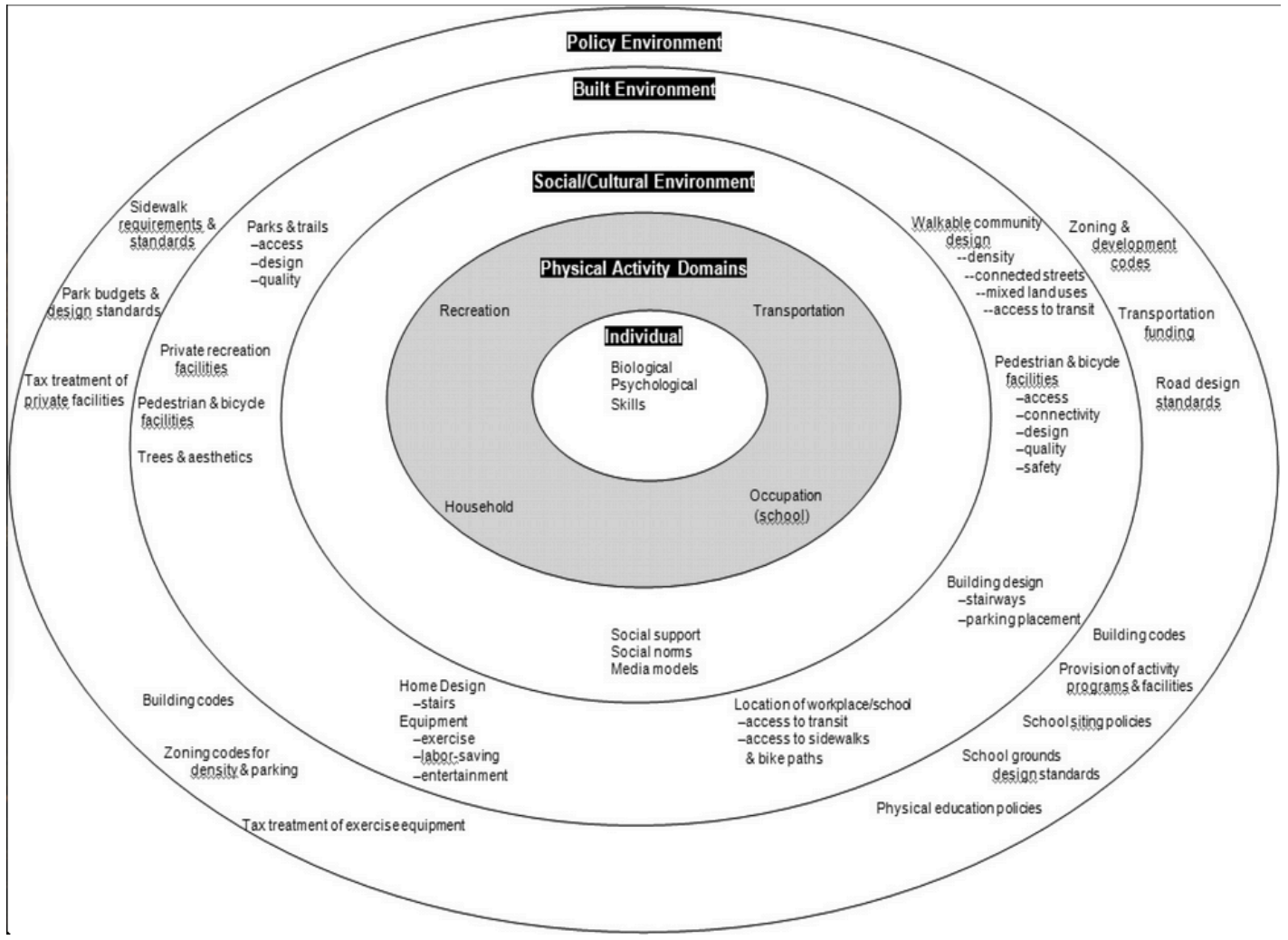

Figure 10 - Sallis (2006) Social Ecological Model 


\section{Theoretical Sampling}

In this study, the theoretical sample was identified from within the existing group of participants with similar considerations about the latent demand for cycling with women in particular. The sample was identified during the theoretical coding process, a distinct group emerged: female participants, under the age of 30) who had recently adopted frequent riding.

This theoretical sample is supported by literature that have used similar numbers, or similar characteristics on which to make the selection. Onwegbuzie and Leech (2007) recommend that when creating theoretical sample selections for quantitative analyses and comparison, that at least three cases are used so as to avoid saturation if one of only two cases is a-typical (p.245). Conveniently, three participants matched the criteria described above. Although no new participants were recruited during this phase, a four-question follow-up questionnaire was drafted and circulated to the theoretical sample group of three female participants, so as to increase the amount of data gathered (see Appendix B). The theoretical sample should highlight some differences between the rest of the population, and the particularities unique to their sub-sample. When identifying the theoretical sample, it is important to include as many potential options as possible, and thus these criteria for selecting the theoretical sample were only applied after open coding and theoretical coding had ended (Strauss and Corbin, 1990). Some examples of theoretical samples include Motl, Dishman and Saunders (2007), in which they studied the perception of physical and social environmental variables, and their effect on self-efficacy in self-reported physical activity in adolescent girls. Saunders et al (2004) compares social variables for understanding physical activity in adolescent girls. Dishman, Saunders and Motl et al (2004) explore how self-efficacy mediates the effects of school-based interventions in adolescent girls. Motl, Dishman and Ward et al (2005) begin to explore this in a time sensitive manner, looking at how self-efficacy mediates the relationship between perceived physical environments, and physical activity over one year among adolescent girls. Puscher and Buehler (2008) explain the higher ridership of women in Europe to be explained by higher levels of safety - when compared, cycling in the USA is 5.8 times more dangerous than in the Netherlands (p.504). These studies use age and gender as independent variables in the theoretical selection because females are often as a group with a large proportion of interested, yet concerned cyclists.

\section{Analysis and Discussion}

The first phase of analysis was to disaggregate the theoretical sample from the other participants, and compare their survey responses. The theoretical sample was only compared to other participants of a similar age who were university students, so as to reduce the number of variables. The small size of the theoretical sample only allowed for the data to be analyzed interpretively, with indicators of central tendency to gauge relative differences between the theoretical sample and the other sub-sample - their respective responses on a likert scale (A likert scale consists of a four or five point ranking system, where for example $1=$ strongly disagree and $5=$ strongly agree) were subtracted for each question, and any results of over one degree of difference were included in the following review. 
The young women in the theoretical sample had several noteworthy differences between their similarly aged, male university student counterparts. The young women rode less than their male counterparts; they reported riding at least once a week, as opposed to almost every day. They had also been riding frequently for a shorter period of time, reporting less than three years, as opposed to ten years or more for their male counterparts. Interestingly, these young women also placed less of an emphasis on trips to school and accessing services, whereas their male counterparts rated those as some of their most important reasons to ride. They were less likely to ride than their male counterparts if the weather is bad, and face a different set of deterrents when debating whether to ride or not: they felt limited most by a lack of confidence, and the mechanical frustrations that would affect their bike. The biggest difference, at almost two entire points on a five point scale, between the young women and their male peers was the perceived need for specialized clothing. These differences were within the realm of expectation. However, there was a difference that emerged within the theoretical sample that had not been anticipated.

The three women that formed the theoretical selection differed significantly regarding their respective cyclist type: TM was Interested, but Concerned; RJ was Enthused and Confident; whereas AR was a Strong and Fearless rider. Based on their responses from focus group, these women shared the similar motivations and limitations, and a recreational riding history - yet their current level of comfort, and self-identification as cyclists varied dramatically. Investigating the origins of these differences provided a clearer idea of the identity is shaped by larger transportation paradigms, power of this identity in an individual's decision to riding a bike.

\section{Critical Case Analysis: Participant RA}

Recall that in the mode choice ecosystem, a less confident cyclist is deterred by a lack of cycling infrastructure, the more they are considered to be strong and fearless. RA self-identifies as a Strong and Fearless cyclist, bicycle infrastructure has very little weight within her personal mode choice ecosystem. This means that psycho-social factors, such as coolness, stigma, psycho-geographic nostalgia are more likely to have a greater impact than the absence of bicycle infrastructure on her decision to ride. Her case provided an opportunity to take a closer look at both a case of recent adoption of frequent riding, and how psycho-social elements factored into her behaviour. To develop the information on the critical case of $\mathrm{AR}$, four more questions were sent to her in an attempt to learn more about her riding past and life experiences that may have contributed to her rapid uptake of frequent cycling (see Appendix I). This critical case analysis compares AR's personal experiences, and proved to be vital in drawing out subtle themes and ideas. Three key concepts that emerged from this process included Automobility, and The 'Normal Cyclist': identity and stereotype. The examination critical case also provided answers to the remaining research questions. Examining the importance of transitional life changes provided an answer to the fourth question. Examining the motivators and barriers provided insights into the fifth question. All of which provided to create a clearer idea of the major research question, regarding the lack of infrastructure, yet the decision of people to travel by bike, rather than any other mode. 


\section{Automobility}

Furness (2010) defines automobility as: "the assemblages of socio-economic, material, technological, and ideological power that not only facilitate and accelerate automobile travel, but also help to reproduce and ultimately normalize the cultural conditions in which the automobile is seen, and made to be seen, as a technological savior, a powerful status symbol, and a producer of both "modern" subjectivities and "civilized" peoples." (p.6).

AR grew up in a rural place, where automobility seems to be deeply engrained, as no alternative form of transportation, in her experience, was seriously considered. "When you turn 16, you get a driver's license. You have your birthday, and then you go get it. It was a big deal." When asked about riding to school, she responded "I don't recall anyone biking...getting your parents to drop you off was better than biking". When asked why she thought it was "uncool" to ride, to which she responded after a pause “... because - you could drive.” This captures automobility's hegemonic presence within the memories of her childhood and her adolescence.

Hegemony is an idea that is central to automobility - and the associated marginalization of other alternative forms of transportation. Hegemony is the predominance by a particular set of social or cultural ideas, or way of doing things, even to the exclusion of others $\left(\mathrm{OED}_{2}, 2014\right)$. Because of the social and ecological harms that could be tied to the social dependence on the private automobile, use of the private car is seen as a problem, with things such as cycling, walking and transit as being the alternatives. Millard-Ball and Schipper (2011) find that there is evidence that some cities have experienced a plateau or even decrease in private car use - yet in many urban areas, private car use continues to dominate as the preferred way to satisfy requirements and desires to be mobile. Kent (2013) sought to understand the motivators of automobilty. Kent recognized that simple accessibility was not the main issue; it was that perception of time - the idea of spending time versus loosing time, and the space that the car provides during that time. In a similar vein, Laurier and Dant (2012) also conclude that automobility is increasingly involves a practice of using the space of the car during travel time. - paying bills, making calls, as a central theme. The idea of automobility supports the notion that transportation practices are not simply a product of individual desires to get from A to B in the fastest time possible, in the safest way possible - but rather a complex, psycho-social phenomenon.

AR's exposure to automobility stands in contrast to the experience of her peers within the theoretical sample. Both RJ and TM occasionally rode to high school, and were unaware of any social animosity, or social alienation that may have occurred as a result of their decision to ride a bike. TM grew up in downtown Toronto, where car ownership is less common, and the accessibility of other modes including walking and transit likely softened the weight of automobility. However, it is interesting to note that the dissonance that cycling creates when confronting automobility is so powerful, there are even effects within the home between members of the same family, as will be shown in the next section. 


\section{The "Normal Cyclist": Identity and Stereotype}

Participants in the theoretical sample were asked to elaborate on their conception of a 'cyclist', if other people saw them as a cyclist, and how they felt about being labeled as such. Participants were asked to write freely, with as little editing or revision as possible. AR strongly self-identified as a cyclist, although also providing an interesting qualification:

The image that is conveyed with the word cyclist is someone who is the ultimate progressive person they are environmentally conscious, progressive in their views, comfortable in an urban environment, confident about who they are, and fearless. Much of my thoughts towards a cyclist come from my experience cycling in the context of Toronto, and it being a mode of transportation [...] I do not consider myself a full cyclist - I feel as though I am still learning. A cyclist knows how to fix their bike, change a tire, and is confident on their bike - so confident as to break rules like rolling through red lights. Being a "cyclist" is embracing the whole lifestyle that goes along with it - cycling is a part of you - it shows in how you dress and your interests - in some ways it is a person."

Radicalism in her identity became visible through her internalization of Rachel Aldred's (2010) heroic/dangerous archetype, as evidenced in her earlier responses, equating confidence with breaking the law by rolling through red lights. Another telling comment was that she referred to Premium Rush, a movie in which the protagonist and supporting cast are bike messengers, as being a formative influence on her views of coolness and cycling.

It is possible that AR's views on cycling could be partially explained by the quality of her past recreational experiences. She wrote that her recreational cycling experiences consisted of nine years of mountain biking with casual and enthusiasts in British Columbia. This is important to note that dedicated recreational cyclists, also referred to as enthusiasts, often adopt a 'lifestyle' approach to cycling, and associated behaviours - especially true with mountain biking, for various reasons. Along with this lifestyle often comes highly structured social norms, especially when encountering competitive enthusiasts - the fastest, fittest and finest riders often represent the pinnacle of what a 'cyclist' can be. It is likely that her thoughts about how other forms of cycling are structured have been shaped by the enthusiast's lifestyle approach that was carried over from her recreational riding experiences. The likelihood of this being the case hinges on her internalized idea of the identity of a cyclist, as evidenced by the statement: "I don't consider myself a full cyclist." This raised the idea of entelechy, which describes a vital principle that guides the development of a thing - the way an acorn or caterpillar 'becomes' an oak tree or a butterfly. A 'normal cyclist' is a cyclist by virtue of the simple fact that they are riding a bike, whereas a 'lifestyle cyclist' is a cyclist by virtue of how well they realize their idealized conception of what a 'full' cyclist is, whatever that may be.

If AR's idealized conception- stereotype of a 'full cyclist' was recalibrated from mountain biker, to a new identity based on the movie Premium Rush, as well as her new social circle, it may explain her desire to become a 'full' cyclist', with all the deviant, heroic and dangerous behaviours that it may entail.

AR's views stand in contrast to the responses of both RJ and TM, who wrote about improving skills to become more confident riders, as well as gaining more maintenance skills - yet neither of them frames this process as 'becoming a full cyclist'. Both RJ and TM used language such as 'conscious' and 'prepared'. They both also reported that the thought 
any impressions other had of them being a cyclist were positive, and that their riding had even encouraged others to start riding more. RA only mentioned negative associations with being called a cyclist, especially by her family, and did not mention having encouraged others to ride.

As a counterpoint, it is interesting to see how people's self perception changes when they ride a bike in a system that is not characterized by automobility. Such persons exist in Copenhagen, where cycling mode share is over $30 \%$. In an interview for the BBC, Andreas Rohl the Bicycle Program Manager for the City of Copenhagen, said:

"For people here, going on your bicycle is a bit like brushing your teeth. You don't identify as a bicyclist, you just ride on your bike, wherever you want to go" (BBC, 2009). This is Copenhagen's vision for how the bicycle fits into everyday life. There is no such thing as identifying some people as teeth-brushers, and non-teeth-brushers - it is a transportation paradigm in which only 'hardcore' motorists will insist on navigating by car. So it comes as no surprise that Copenhagen and Amsterdam have been exporting their vision of everyday cycling - and rightly so. But the extent to which cities like Toronto will attempt to emulate these changes, and their efficacy of these attempts remains to be seen.

\title{
Transitional Life Events
}

When AR moved to Toronto, her commute reached from the Scarborough Bluff area to Young and Dundas Square, at the heart of downtown. AR would occasionally ride along Kingston Road, as it provides the most direct East West route. There is a painted bike lane on Dundas, beginning at The Don River, and ending when Dundas becomes Kingston Road. According to the City of Toronto, Kingston Road has been undergoing surface repairs since 2009, creating for many disruptions to the flow of traffic, and some dangerous riding environments. Despite this long distance, on a route that only has painted bike lanes for a short segment, her riding behaviour changed dramatically.

\begin{abstract}
"My riding was always recreational, and never utilitarian... When I moved to Toronto for grad school, then it changed to work, to school and back... it has now flipped. I now cycle for everything...even for recreation, I ride around on the waterfront, ups and down few times. I'll even go on my bike to get groceries and other errands. I'll go for rides as a form of exercise." (AR, focus group)
\end{abstract}

When asked about how moving to Toronto influenced her attitudes, she responded, "everything was up in the air, I was open to doing new things." She also mentioned how economically and mentally difficult it was to drive around in Toronto, and how anxious she felt in transit. It seemed that the volatility and sense of novelty, and her idealized image of the urban cyclist, paired with her confidence and skill, allowed her to commit to riding in Toronto in a way that few others were willing to do (see Map 2 on following page). It is very likely that AR's previous riding experience with recreational mountain biking was a factor in the shift in her riding.

The literature suggests that transitional life events disrupt habit and routine, and allow individuals to challenge and adopt new patterns (Chatterjee et al, 2013). In a similar vein, Van der Waerden, Timmermans, Borgers (2003) examine the influence of key events and critical incidents on transport mode choice switching behaviour, and find similar results. 
Klockner (2004) takes a life span perspective on how single events change travel mode choice, suggests that this relationship does not weaken over time.

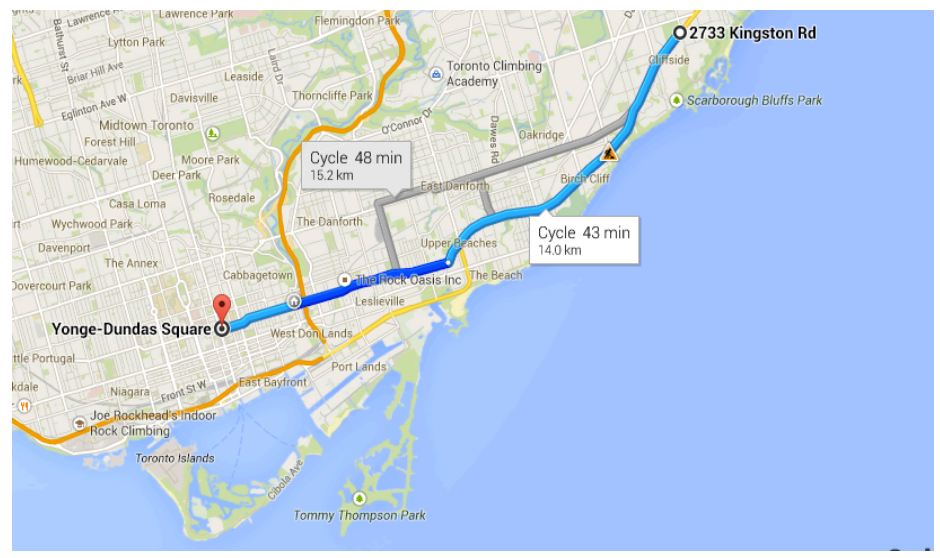

Map 2 - AR's Approximate Commute

Examining the response of the participants more generally, transitional life events were mentioned throughout their personal accounts and individual riding histories. Transitional events include: going to a new school, shift in economic circumstances, the end of a relationship, the beginning of a new one, having a child - or even moving to a different country. A common thread that tied all of those accounts together was the idea of relocation. Harms and Lanzendorf (2007) specifically study interactions between residential relocations, significant life events, and daily commute distances, and find that travel patterns become more flexible, and can often be expanded with less resistance during these times. The idea of relocation is quite dynamic, as it incorporates an interplay between new physical spaces, as well as psychological and social upheaval. The idea applies to persons that are new to a neighbourhood as in the case of TM, as much as it applies to those that are new to Canada, such as TA. This has implications for shifting recreational riders to take up more frequent and purposeful riding behaviour, as well as a critical window of opportunity for introducing people to cycling, who may never have considered it before.

\section{Motivators and Barriers}

A closer look at AR's case revealed more evidence in support of the idea that she became self-conscious of a commitment to cycle more frequently. When AR was asked about the most important factors that contributed to decision, she replied:

\footnotetext{
"With support from my peers, I was able to pick up tips and feel comfortable enough to start biking as a mode of transportation - because my peers were biking, I was able to imagine myself being a cyclist as well. The biggest factor in shaping my decision to bike as frequently as I do and the way in which I do, was having access to people with knowledge and experience in biking who encouraged me and were an example of how someone could use a bike as transportation. Without this I would not have known that biking was safe in Toronto."
}

The responses of other young women in the theoretical sample cited cost, enjoyment and being outside as their main motivators - and these motivators are no different than any of the other participants' motivators. Conversely, one of the biggest limitations cited by the women in the theoretical sample was a lack of confidence. This is a key 
opportunities for role models to influence change, due to their ability to inspire a change, despite the new riders lack of confidence.

The other aspect of this idea is the importance of role models in the process of becoming more capable and confident. But if you see another person, just as timid, and unsure as yourself, but still saddling up to ride - that is motivator. Perhaps simply seeing other people ride may be an important part of moving certain persons from pre-contemplation, towards contemplation of a first ride. Furthermore, access and support from these people is important in phases where the potential rider is shifting from contemplation, to preparation and action. The result is that people, who may doubt their abilities and skills, are inspired to set out into the streets of Toronto. This is exactly what cycling needs, yet at the same time, it is unclear if this strategy for growing cycling is sustainable.

It has already been suggested that previous riding experience had a significant influence on the increasing confidence and skill, and this is consistent with the literature. Garcia (1998) found that childhood and adolescence are key times to foster activities through life. Perkins, et al (2004) found that childhood and adolescent participation is a strong predictor of participation and physical activity in young adulthood. Pucher and Buehler (2008) also found similar results, showing that when cycling increases through adolescence, it is also likely to increase during adulthood as well. It seems that previous riding was not actively considered by the participants, because no one really mentioned their previous riding experiences, and the foundation of confidence that they had built.

\section{Major Research Question: Behaviour and Cycling Infrastructure}

Why do people start riding more frequently despite the lack of improvement to cycling infrastructure? Every time they choose to ride, they choose the freedom and enjoyment they experience from it, over the other various fears. In the case of the three young women in particular, the ability to overcome those fears appeared to have involved social connections, economic resources, psychological fortitude, and seeing others make similar choices. Knowing that others have also overcome the same barriers, and still continue to pick the bike over their fear, gave other the courage to do the same. Social connections begin at the home, with parents or siblings teaching the initial skill, which becomes a form of play and adventure that may, or may not extend to a broader group of friends. The activities within these circles of friends seems have a significant influence over their recreational, and transportation behaviours as there was a large social element that emerged. These social dynamics, during high school especially, and then into undergrad and beyond seem to have been responsible for people riding less at certain times, and more at other points in their lives. Economic circumstances also have a role to play. All of the recent adopters had the resources, in time and money, to secure a bike for their regular use. Additionally, all of these frequent adopters have experienced shifts in their individual economic circumstances that make riding a bike a wise choice, in terms of time and money - especially when compared to the other alternatives. It is precisely for these reasons that cycling is a key form of transportation for students.

Psychological fortitude was also a factor, as many of their peers in similar demographic, social and economic situations make the decision to not ride. In the case of the recent adopters, it would seem that the perceived conditions of road safety combined with a lack of infrastructure did not provide enough of a deterrent to ride. The importance of role 
models is particularly important in the critical case. Although the message in the media seemed to leave a strong impression, she also cited the encouragement and tips from key people whom also rode, as being an important source of support during her change in behaviour. It would seem that despite the lack of infrastructure, people who are confident and skilled although not yet riding frequently for more purposeful trips, are more likely to take up cycling if there is a strong social infrastructure. 


\section{Chapter 6. SUMMARY OF RESULTS \& REFLECTIONS}

\section{Research Questions and Answers}

Major Research Question: Why do people start riding more frequently despite the lack of improvement to cycling infrastructure? It would seem that despite the lack of cycling infrastructure, people who are confident and skilled although not yet riding frequently for more purposeful trips, are more likely to take up cycling if there is a strong social infrastructure - which includes the ability to overcome limitations through social connections, economic resources, psychological fortitude, and seeing role models and others make similar choices.

Question 1: What 'type' of cyclists are those that have recently begun to ride frequently for more practical purposes? Four riders are Strong and Fearless, six are Enthused and Confident and two riders are Concerned but Interested. Despite clear divisions in survey data, focus group responses need to be coded, categorized, and compared to the survey findings before a theoretical sample can be made to advance the conceptual model.

Question 2: What is the impact of geography, bicycle infrastructure and facilities in participants' decision to ride a bicycle more frequently for practical purposes? The findings suggest that proximity is indeed a driver of cycling adoption, but only for certain types of riders - the more skilled and confident they are, the less influence distance alone exerts on their mode choice. Often that participants lived too close so some of their destinations to warrant cycling.

Question 3: Of those persons that currently cycle frequently for more practical purposes, is it behaviour continued from prior in life, or a recently adopted behaviour? All the participants had cycling experience from prior in life. Riding for practical purposes was more occasional and less common. The distinctions between utility and recreation are quantitatively driven, and the clarity in purpose of ride, especially at different points in life are not as clear. Although previous riding experience could be a predictor for the speed at which they developed skills and confidence, it would appear the most significant form of encouragement during this process was role models within the cycling community and the media.

Question 4: Did transitional life experiences have a large influence on the decision to cycle more frequently for practical purposes? Transitional life experiences, especially the phenomenon of relocation, were reported by all participants as being crucial, not only in their development as riders, but that their development as riders grew with the other events in their lives.

Question 5: What has most encouraged these riders to develop the skills and confidence to ride more frequently for practical purposes? Although previous riding experience was a crucial factor within AR's case, the importance of role models in the process of becoming more capable and confident was also made clear. The access and support from these role models is important in phases where the potential rider is shifting from contemplation, to preparation and action. 


\section{Reflections}

If the answers to the research questions, although limited in generalizability, are somewhat accurate - there are interesting implications and consequences which arise from the conclusions. As long as people are being coached toward the choice to ride, weighed against a considerable sense of fear, the decision to ride will almost never be considered 'normal' in the same way that driving is - will this type of growth be sustainable in developing cycling as a common everyday form of transportation in Toronto? In this way, the growth of cycling can include concerns of sustainability and equality. Dave Horton is an academic who studies transportation sociology, shares many of these same thoughts, developed through his own research and advocacy experiences in England. The concerns that he articulates in the concluding chapter of Cycling and Sustainability (2012) resonate deeply with the thoughts that have developed the course of this study. The main concern that he shared is if the current form of growth in ridership sustainable in the sense that it "works towards a culture of 'normal' and 'everyday' cycling" (p.306). This is because the lack of infrastructure may always threaten the possibility of creating 'normal' cyclist identities, because of the risk inherent in the perception of that activity.

"Difficult and dangerous conditions for cycling have produced styles of cycling which are elite, and which can be elitist. In order to negotiate many contemporary cities by bicycle, the rider needs to be agile, fit, fast and, frequently, illegal. Across most of the planet, we have inadvertently produced a minority of people capable of negotiating a car system by bicycle." (Horton, 2014, p.1)

In this way, motivating and 'training' people to ride in the city creates a dissonance between the intended, and unintended consequences. One of the intended consequences of 'training' is that more people ride bicycles, with each new rider capturing all of the well-documented benefits that cycling can offer. Another intended consequence of training is that eventually, there will be a 'constituency' of cyclists, large enough to encourage politicians to take note, building the impetus for investment in a safer transportation system that would include cycling infrastructure. But this ties directly to the unintended consequence, in that the more people that are seen to ride on unsafe streets, could be interpreted by detractors of cycling for transportation, as evidence that improvements do not need to be made to the streets, as people already feel comfortable enough to ride. Furthermore, if the tolerance for danger was increased in the minds of the people riding, perhaps their own views regarding the urgent need for improved and safe infrastructure would be softened. This creates a situation where the pressure for safer streets could be inadvertently weakened allowing projects that perpetuate the status quo to move ahead with only token improvements, with no changes to safety. If the roads remain unsafe, the underlying perceptions of risk and associated fear of riding may persist - and cycling and will remain a deviant choice, taken by the elite few. Horton (2012) stated it as such:

"To keep cycling in an unsupportive, inhospitable environment is hard to do. In those instances where cycle training is 'successful', then, the person might become part of the cycling minority, demonstrating that 'cycle training works' and preventing the more fundamental changes required to make cycling truly accessible..."

(p. 307)

In other words, inspiring more people to ride in a system where it is perceived as being unsafe to do so can be counterproductive - because every person that starts to ride, and continues to do so, despite the infrastructure adds to a case 
that people don't need the infrastructure in order to ride. Horton continues, articulating a view that evokes Oscar Wilde's philosophical position on charity ${ }^{3}$, but instead relating to cycling advocacy:

"...Ironically, part of our collective failure to realize cycling's critical situation derives from the perseverance and ingenuity of people who continue against all the odds to cycle and to promote cycling. Together we (we include ourselves) have become so good at celebrating what is good about cycling, and at feeling optimistic for its futures, that we obscure the critical reality. So we want now, albeit briefly, to dampen enthusiasm for alternative routes to mainstream cycling, routes which do not require radical overhaul of the contemporary dominant mobility environment" (Horton, 2014, p.1)

Although it is clear that a comprehensive and quality system of transportation alternatives needs to be developed to ensure lasting changes in urban mobility, writers like Horton and Wilde call for radical overhauls of the systems they deem to be oppressive, their radical approach also raising concerns of equity and democracy. Contemporary development processes are often incremental, and involve social negotiation - which complicates Horton's apparent imperative for radical change. Toronto has a great deal of variation in demography and geography, thus the way in which people perceive the automobile, and the alternatives would vary accordingly. Like every system of transportation, the modes desired and the modes available are shaped by class, race and gender - the bicycle has its own place in this dynamic. Mapes (2009) and Wray (2008) observed that cycling's status is only changing in select areas with certain people in certain parts of the city. Echoing this, perhaps it is worth noting that the majority of participants in this study were Caucasian, likely middle class, and living in downtown Toronto. There is an interesting similarity when comparing Hulchanski's map of the Three Cities to the Cycling Think and Do Tank's map of bicycle mode share by ward.

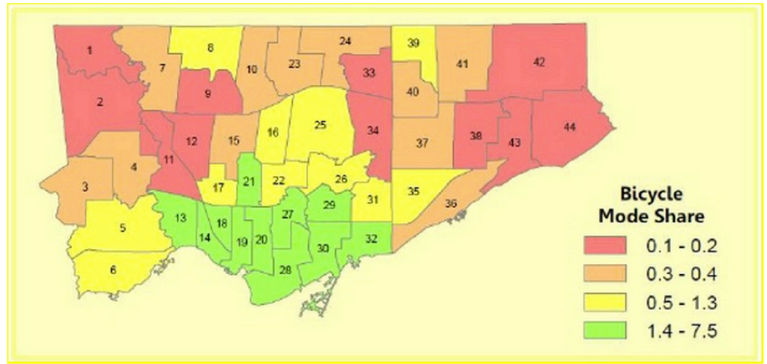

Map 4 - Ledsham's Mapping Cycling Behaviour

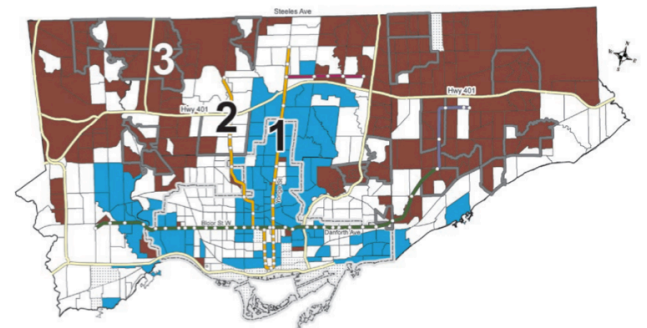

Map 3 - Hulchanski's Three Cities

The wards with the lowest mode share (Ledsham, 2013) are often located in areas that have also had declines in average income over the last 20 years (Hulchanski, 2010). One of Hulchanski's important points was that many of these areas with declining average incomes, often referred to as the inner ring suburbs, are where many priority neighbourhoods are located - areas in which many of the city's most vulnerable and under-served residents reside. These are neighbourhoods like Jane and Finch or Malvern, which are located as far as $20 \mathrm{~km}$ away from the downtown core

3 The Soul of Modern Man Under Socialism (1891). Oscar Wilde wrote that charity was an immoral response to the poverty in London. "The proper aim is to try and reconstruct society on such a basis where that poverty will be impossible. Altruistic virtues have really prevented the carrying out of this aim. Just as the worst slave owners were those who were kind to their slaves, and so prevented the horror of the system being released by those who suffered from it, and understood by those who contemplated it, so in the present state of things in England, the people who do most harm, are the people trying to do the most good." (Wilde, 1891, p1) 
(Yonge and Dundas), are served only by bus routes. Further confounding the sensitivity of these areas is the dearth of studies in these neighbourhoods, especially regarding attitudes and behaviours regarding alternative transportation. The Black Creek neighbourhood was the subject of a recent study undertaken by a group of Graduate Students from Ryerson and their advisor, which sought to develop a strategic Active Transportation plan for the neighbourhood.

The studio project, called Connecting Black Creek (Augustyn et al, 2013), analyzed the demographic composition, assessed the existing connectivity provided by the existing road network, and created suggestions for infrastructure interventions that may improve the conditions for alternative modes of transportation in the area. The initial connectivity analyses showed that there was a significant amount of origins and destinations within the neighbourhood. Although being theoretically connected, the predominance of motorized vehicles on the road, paired with decrepit and narrow sidewalks, made for hostile environments for both walking and bicycling alike. The project found that the neighbourhood was already more active than was expected, especially regarding the levels of pedestrian activity at Jane and Finch. The other finding was that the area had a great potential to introduce cycling due to wide right of ways, and many origins and destinations being within $5 \mathrm{~km}$ of each other, which has great implications for trips within the neighbourhood. However, one of the biggest limitations of the project was that members of the community were never consulted, as such, there is no sense of community support of cycling infrastructure, and how it fits within the hierarchy of the other perceived needs of the community. When the language used in the Draft Bicycle Priority Framework speaks of 'Big Gestures' expand cycling in Area 2, is contrasted to the Maturing Cycling Culture in Area 1 - what will these big gestures look like, how is cycling culture being introduced, and who is involved in the decision process? The Draft Map (figure xxx) implies that here will be a major and minor grid pattern across the city, but the questions about the consultation and strategy, and the introduction of 'cycling culture' raises many questions. If cycling is going to grow equitably and democratically in Toronto, the quality and character of that growth, in the inner ring suburbs especially, will be a key area of focus in the following years.

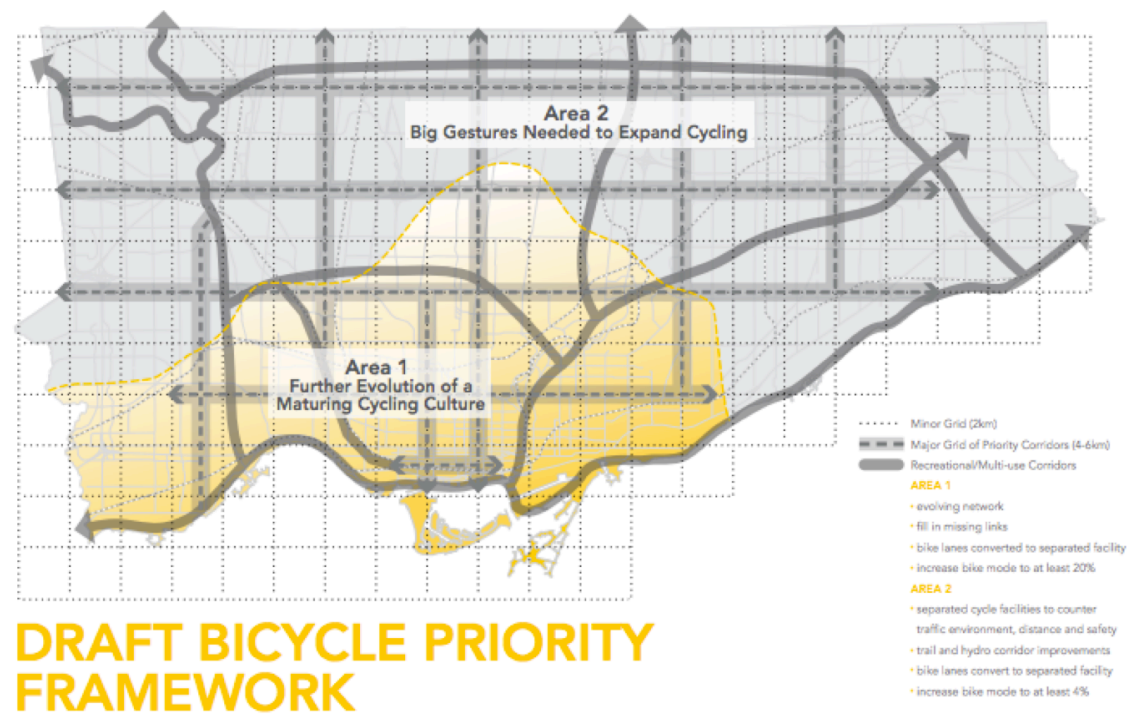




\section{Chapter. 7 NEXT STEPS}

Improvements to physical infrastructure are important for the sustainable democratization of cycling in Toronto. However, this study suggests that the short-term uptake behaviours, in certain segment of the population, are heavily influenced by psychosocial factors. Evidence shows that while respondents tend discount the importance of social norms when surveyed, it is these same social factors that seem to be incredibly influential when it comes to changing behaviour as evidenced in the focus groups, both in the theoretical sample, as well as the critical case analysis. There are segments of recent adopters, who have taken up, or continued cycling despite the stagnant or declining levels of infrastructure. But where does this socialization occur, and where could it occur that it isn't already? These are the next steps in understanding how cycling can be promoted more effectively in Toronto.

Groups such as The Cycling Think and Do Tank, Cycle Toronto, and Culture Link already have numerous research studies underway and programs in place - all of which have been combining academics and praxis in exciting ways. The Cycling Think And Do Tank have already produced numerous reports, including a behaviour change toolkit and literature review of best practices (Cohlmyer, 2012), mapped cycling behaviour in Toronto (Ledsham 2013), and most recently, a report on the economic impacts of cycling infrastructure and on street parking (Arancibia, 2014). One particularly interesting piece of research that is ongoing explores the role of cycling services and the connection and cycling behaviours. Conversely, Cycle Toronto, and other organizations such as Culture Link Settlement Services and Toronto District School Board (TDSB) are doing important work in communities and schools across the city. For example, Cycle Toronto, Culture Link, and the Cycling Think and Do Tank have created a program called Bike Host, where residents work towards welcoming new Canadians through a mentorship program, and introducing them to the possibility of cycling during their exciting transition. Another partnership with the TDSB gave rise to The Bike to School project - which has contributed to making cycling more visible in positive ways in schools around Toronto, encouraging a lifetime of cycling habits for the next generation. These are key programs because both the time spent at school, and the years getting accustomed to a new country are pivotal in shaping the foundations for future habits and behaviours, and these programs focus in on prime windows of opportunity.

Future study would ideally follow up on the participants in the culture link program, to verify if changes in behaviour extend beyond 6 months or longer. The Bike to School Project also presents an interesting opportunity for a longitudinal study, that could contribute to the literature on the effectiveness of socially oriented behaviour change programs. In a similar vein to the research done on cycling services and promotion of cycling behaviour - it would be interesting to see what the role of do-it-yourself bike shops are, especially as they tend to cater to populations that cannot afford the expensive goods and services that are sold at most bikeshops. This is significant because when considering the promotion of cycling in areas that are further removed from downtown services, and who's populations

are already economically challenged, the low-cost community driven model may be a crucial element for introducing an accessible and locally relevant cycling culture to these inner suburban areas. 


\section{Appendix A - Intention Behaviour Theory}

The Health Belief Model (HMB) was first developed in the 1950s by the U.S. Public Health Services, though the research of social psychologists Hochbaum, Rosenstock and Kegels. The HMB was developed in response to the failure of a free tuberculosis health screening program, and trying to understand how to make it more successful. The model is based on four pillars: perceived susceptibility, perceived severity, perceived benefits, and perceived barriers. As the theory developed, cues to action and self-efficacy were added by Rostock in 1988 to address more habitual behaviors, such as physical activity. This was the first expression of a formalized behavior change theory, and establishes a rough calculus as the best way to determine the factors in behavior. It was found to have a weaker explanative power when dealing with more complex decisions, such as with physical activity, which is why the model has been left at the wayside.

The Theory of Reasoned Action (TRA) was established in the mid 1970's by Fishbein and Aizen, who continue to be the stewards of this theory through it's subsequent changes, as the model responded to emergent evidence. TRA was developed for trying to account for the discrepancy between reported attitudes, and observed behavior. The theory originated when examining voluntary behavior, and suggests that a person's behavior is determined by their intention to perform the behavior and that this intention is, in turn, a function of their attitude toward the behavior and their subjective norm. That is to say that the best predictor of behavior is intention. This theory was later modified, because behavior appeared not to be $100 \%$ voluntary and under the subject's control, which resulted in the addition of Perceived Behavioral Control, which became know as the Theory of Planned Behavior (TpB). The most recent iteration, known as Reasoned Action Approach (RAA), states that attitudes towards the behavior, perceived norms, and perceived behavioral control determine people's intentions, while people's intentions predict their behaviors.

(TRA and $\mathrm{TpB}$ )

The family of behavioral calculus theories, which tend to focus on intention, also extends to the Integrated Behavioral Model (IBM). Without intention to do so, an individual is unlikely to carry out any behavior. Behavioral intention is determined by attitude, perceived norms, and personal agency (self-efficacy / perceived power). An individual needs the knowledge and skills to carry out the behavior. The behavior should be salient to the individual (that is, important to the person and at the forefront of their thoughts). There should be few or no environmental constraints that make behavioral performance difficult. With the successful experience of performing a behavior, the behavior will become habitual for the individual.

Another School of though sees behavior as a continuous process. Health Action Process Approach (HAPA) was developed as a sequence of two continuous self-regulatory processes, a goal-setting or 'motivation' phase and a goal-pursuit or 'volition' phase. The second phase is subdivided into a pre-action phase and an action phase. One can superimpose these three phases (stages) on the continuum (mediator) model as a second layer, and regard the stages as moderators. This two-layer architecture allows to switch between the continuum model and the stage model, depending on the given research question.

Social Cognitive Theory (SCT) was developed by Albert Bandura in 1956, and emphasizes the dynamic interaction between people, their behavior, and their environments. This interaction is demonstrated by the construct called 'reciprocal determinism'. This determinism is created by a interaction between personal factors, environmental factors, and behavior which are constantly influencing, and being influenced by each other. The purpose of reciprocal determinism is to consider multiple ways to change behavior; for example, targeting both knowledge and attitudes, and also making a change in the environment.

The Precaution Adoption Process Model (PAPM) identifies seven stages along the path from lack of awareness to action (Weinstein, 1988). The first is when people are 'Unaware of Issue'. Because they have never heard of a hazard or its potential precaution, they have no opinion. Persons that are 'Unengaged by Issue' know about an issue, but haven't thought about what they can do in regarding precautions or actions. Persons that are 'Undecided about Acting' are about to make a decision, and are usual engaged and have opinions formed. Persons that have 'Decided not to Act' have disengaged the process. Persons that have 'Decided to Act' have adopted a precaution. The decision to act is followed by 'Acting' and 'Maintaining', where a behavior is initiated and then sustained over time. 


\section{Appendix B - Survey}

Demographics

D1. In which part of Toronto do you currently live?

Scarborough
Etobicoke
North York
York
East York
Downtown

D2. In what year were you born?

$$
19
$$

D3. What is your sex?

$$
\text { Male [] Female [] }
$$

D4. What income groups include your annual household income, before taxes in 2012?

Less that $\$ 15,000$

$\$ 15,000$ to less than $\$ 40,000$

$\$ 40,000$ to less than $\$ 80,000$

$\$ 80,000$ to less than $\$ 120,000$

$\$ 120,000$ or more

\section{Transportation Profile}

C1. Do you currently have a vehicle license?
G/M1 [ ]
G/M2 []
Full G/M []

C2. Do you currently have a TTC pass?
Yes []
No []

C3. Do you currently own a bicycle?

Yes [] No []

C4. How often have you cycled in Toronto in the past 12 months?

Select the box that best reflects your behavior

Daily

At least once a week

Once every two weeks

Once every three or four weeks

Once or twice every two or three months

Once or twice in the past year

Unsure/don't know

C5. Which reasons for cycling applies to you? Frequently, Often, Sometimes, Rarely, Never 
Going to work

Going to school

Access services (groceries etc)

Leisure

Fitness

Competition
[] [] [] [] []

[] [] [] [] []

[] [] [] [] []

[] [] [] [] []

[] [] [] [] []

[] [] [] [] []

C6. If you cycle often, for any reason above, for how long have you been doing so?

Select the box that best reflects your behavior

Started this year

For two years

For three years

For four years

For five years

For six to nine years

For ten years or more

C7. Which of these statements best describes your current interest in cycling?

Select the box that best reflects your view

I have no interest in riding a bicycle

I already cycle as often as I want to

I cycle often, but would like to ride more

I do not cycle often, but would like to ride more

Unsure/don't know

C8. Do you with the following statements?

Select either strongly agree, somewhat agree, somewhat disagree, or strongly disagree

Riding a bike is an extremely important part of my life

I often refer to myself as a cyclist when talking to other people

I am more likely to ride a bike, even when other forms of transportation, such as public transit, are more convenient

I am willing to ride my bike in all types of bad weather, including snow

C9. Please indicated to what extent you agree or disagree with the following

Select either strongly agree, somewhat agree, somewhat disagree, or strongly disagree

I feel comfortable cycling on...

High speed roads, such as Bayview Road, Kingston Road, Lakeshore Blvd.

Main roads, such as Dundas Street, Yonge Street or Bloor Street

Busier roads without bike lanes, and are transit routes, such as Ossington or Parliament.

Busier roads with bike lanes, and are transit routes, such as College or Roncesvalles.

[] [] [] []

[] [] [] []

[] [] [] []

Residential roads with bike lanes

Paved pathways that are busy with other users (waterfront trail).

Quiet residential roads with local traffic only.

Paved pathways, that are quiet with few other users
[] [] [] []

[] [] [] []

[] [] [] []

[] [] [] []

[][][][]

C10. Rank the factors of importance in your decision to ride?

Select either Very Important, Quite Important, Fairly important, Slightly Important, Not important at all

Faster than driving

[] [] [] [] []

Faster than transit

[][][][][]

Environmentally friendly

Enjoyable 
Being outside

[] [] [] [] []

Health benefits

[] [] [] [] []

Low cost

[] [] [] [] []

Stress Reduction

[] [] [][][]

Social Interaction

[] [] [] [] []

Independence

C11. What would encourage you to ride more?

Select either Very Important, Quite Important, Fairly important, Slightly Important, Not important at all.

Bike lanes separated from traffic

[] [] [] [] []

More bike lanes on wider roads

[][][][][]

Having a bike that works

[] [] [] [] []

Social Cycling events

[] [] [] [] []

Availability of showers

[] [] [] [] []

Not having to wear a helmet

Better routes

[] [] [] [] []

More bike parking at destination

[][][][][]

Better lighting on existing routes

[] [] [] [] []

Reduced speed of traffic

[] [] [] [] []

None of the above

[] [] [] [] []

[] [] [] [] []

C12. During a time in which you did NOT cycle often, where did you live?

Select the box that best reflects your experience

Scarborough

Etobicoke

North York

York

East York

Downtown

Other:

C13. Rank the factors of importance in your decision NOT to ride?

Select either Very Important, Quite Important, Fairly important, Slightly Important, Not important at all.

Lack of a bike

Lack of confidence

[][][][][]

Lack of time

Lack of fitness

Speed and volume of traffic

Weather conditions

Need for special clothing

[] [][][] []

[] [] [] [] []

[] [] [] [] []

[] [] [] [] []

Aggression from other road users

[] [] [] [] []

Lack of bike routes

[] [] [] [] []

Live too far away

Bike does not work well

Lack of parking at home and destination

[] [] [] [] []

[] [] [] [] []

[][][][][]

Bikes are not cool

[] [] [] [] [

[] [] [] [] []

[] [] [] [] []

C14. How many times have you entered a bike shop in the last year?

Number of times entering a bike shop:

C15. How many times have you entered a bike COOP in the last year?

Number of times entering a bike COOP: 


\section{Appendix C - Focus Group Questions}

Q1. Did you ride a bike during Elementary School?

- If 'no', why not?

- If 'yes', where did you ride it, how often, and with whom?

Q2. Did you like riding?

-If 'no', why not?

-If 'yes', what encouraged you to ride?

Q3. Did you ride a bike during High School?

-If 'no', why not?

-If 'yes', where did you ride it, how often, and with whom?

Q4. Did you like riding?

-If 'no', why not?

-If 'yes', what encouraged you to ride?

Q5. Did/Do you ride a bike during your Post-Secondary studies?

- If 'no', why not?

- If 'yes', where do you ride it, how often, and with whom?

Q6. Did/DO you like riding?

-If 'no', why not?

-If 'yes', what encourages you to ride?

Q7. If you have a vehicles operator's license, how did it affect your riding?

Q8. What had the biggest influence your decision to ride more often? 


\section{Appendix D - Recruitment Email}

$\mathrm{Hi}$,

By sending me an email, you've expressed interest in gaining more information about the survey, focus group, and the $20 \$$ honorarium for participation in:

Life Cycle: Retrospective Attitudes and Behaviors regarding Cycling

This study is seeking to recruit persons that are over +16 persons who are current residents of Toronto, and that have ride a bicycle around once a week. The type of cycling of interest would occur outside, on a pedal-actuated machine, on roads, paths and trails. There will be a consent form [attached in email], a survey (15 minutes), followed by a focus group discussion about past involvement and experiences with cycling (75 minutes).

There will be two opportunities to participate. With the meeting located in room 306 in the South Bond Building on Ryerson University campus:

\section{Sunday, February $16^{\text {th }}$ at $3: 00 \mathrm{pm}$ or $6: 00 \mathrm{pm}$.}

Please send a reply to confirm that you received the message with the informed consent form, and that you meet the basic recruitment requirements. Please advise if you have a preference regarding the time slot.

I look forwards to hearing from you.

Mark Romeril, M.Pl. candidate School of Urban and Regional Planning

$3^{\text {rd }}$ Floor - 105 Bond Street 
RYERSON

UNIVERSITY
School of Urban and Regional Planning

350 Victoria Street, Toronto, Ontario, Canada M5B 2K3

Everyone Makes a Mark

\section{Are you over 16 , and ride a bicycle about once a week?}

\section{Participants needed for research on cycling attitudes and behavior.}

Participation involves the completion of a 15 minute survey, and attendance to a 75-minute focus group session regarding bicycling attitudes and behaviors. Those participating the survey and the focus group will receive an honorarium of $\$ 20.00$. Selection is made on a first come, first served basis.

\section{For more information, contact: Mark Romeril-mromeril@ryerson.ca School of Urban and Regional Planning ***Poster approved by the Ryerson University Research Ethics Board ${ }^{* * *}$}




\section{Appendix F - Consent Form}

RYERSON

UNIVERSITY
School of Urban and Regional Planning

350 Victoria Street, Toronto, Ontario,

Canada M5B 2K3

\section{Everyone Makes a Mark}

\section{CONSENT TO PARTICIPATE IN RESEARCH}

\section{Life Cycle: Retrospective Attitudes and Behaviours Regarding Cycling}

You are being invited to participate in a research study. Please read this Consent Form so that you understand what your participation will involve. Before you consent to participate, please ask any questions necessary to be sure you understand what your participation will involve.

\section{INVESTIGATORS}

This research study is being conducted by Mark Romeril at Ryerson University. The results of which will be contributing to a major research paper. This research is being conducted under the supervision of Dr. Shelagh McCartney as faculty supervisor. If you have any questions or concerns about the research, please feel free to contact:

Dr. Shelagh McCartney shelagh.mccartney@ryerson.ca 416.979.5000 ext. 2133

\section{PURPOSE OF THE STUDY}

This study is designed to assess the changes in attitudes and behaviours regarding bicycling (outdoors, on roads, paths or trails) at different ages and stages of a person's life.

\section{DESCRIPTION OF THE STUDY AND YOUR PARTICIPATION}

If you volunteer to participate in this study, you will be asked to do the following things:

A Short Survey - 15 Minutes. It will cover basic questions about age, gender, income and geography, and then conceptual questions about perceived safety and attitudes towards cycling.

Focus Group - 75 Minutes: focused group discussion. There will be 5-7 other people in attendance. The focus of this discussion will be attitudes and behaviours regarding bicycling in elementary school, high school, and in university

\section{POTENTIAL RISKS AND DISCOMFORTS}

The potential risk involved in this study is very low. Although the questions are personal in nature, they relate only to basic demographic information, and extend only so far as attitudes and behaviour around transportation. There is an opportunity to skip any question, or cease participation at any moment in the process.

\section{POTENTIAL BENEFITS TO PARTICIPANTS AND/OR TO SOCIETY}

I cannot guarantee that you will receive any benefits above and beyond the honorarium for participating in this study. Other benefits include detail about the development of cycling in Toronto, and supporting research that can be used to support advocacy for improved bicycling services and facilities in Toronto.

\section{PAYMENT FOR PARTICIPATION}

All participants will be receive an honorarium of $\$ 20$. 
RYERSON

UNIVERSITY

\section{Everyone Makes a Mark}

School of Urban and Regional Planning

350 Victoria Street, Toronto, Ontario,

Canada M5B 2K3

\section{CONFIDENTIALITY}

Because the survey and focus group are being conducted subsequently, your identities will be known to the researcher, and the other participants. Because of this, anonymity can not be guaranteed. For publication, your name will not be used, and any citations will remain unattributed to seek to maintain as much anonymity as possible. However, it cannot be guaranteed that the other participants in the focus group will do so. The session will be audio recorded. The original recordings, as well as the transcripts will be stored on a password secured computer for up to one year after the session is held, after which, they will be deleted. Only the principal investigator, Mark Romeril, and MRP supervisor Shelagh McCartney will have access to these recordings. Confidentiality will be maintained to the extent of law.

\section{VOLUNTARY PARTICIPATION AND WITHDRAWAL}

Participation in this study is voluntary. You can choose whether to be in this study or not. If you volunteer to be in this study, you may withdraw at any time without consequences of any kind. If you choose to withdraw from this study you may also choose to withdraw your data from the study. You may also choose not to answer any question(s) and still remain in the study. Your choice of whether or not to participate will not influence your future relations with Ryerson University.

\section{QUESTIONS ABOUT THE STUDY}

If you have any questions about the research now, please ask. If you have questions later about the research, you may contact:

Mark Romeril

mromeril@ryerson.ca

This study has been reviewed by the Ryerson University Research Ethics Board. If you have questions regarding your rights as a research participant in this study, please contact:

Toni Fletcher, Research Ethics Coordinator

Research Ethics Board

Office of the Vice President, Research and Innovation

Ryerson University

350 Victoria Street

Toronto, Ontario M5B 2K3

416-979-5042 or toni.fletcher@ryerson.ca

Your signature below indicates that you understand that the focus group discussions will be audio recorded, and that you give your consent to be recorded. 


\section{Appendix G - Categorized Open Coding}

Bikes: ride or use?

Limiting circumstances

Better than alternative

Too close to ride

Too far to ride

Breaking boundaries

Enjoying the experience

Remembering pain/fear

Mechanical depreciation

Object attachment

Beginning to Drive

Expectation to Drive

Geographic Stigma

Embarrassed to Ride

Difference in Age

Focusing on other things get to a friends house

Social Transport

Rising in Cycling Status

Riding with role models

SLE

Noticing the little things
- Use, ride, ride, ride

- fences, roads, train tracks, big hills, fast highways. pervasiveness of cars, and bus routes to school. The roads were unsafe for riding. Sometimes PT was TOO good, and cycling didn't make sense. Bad weather often gets cited, that and winter climates.

- intersected with coolness. Walking is slow, transit is terrible, cars are expensive and slow.

- This was one of the most common examples for elementary school. The catchment area are much smaller for elementary schools, and HSs tend to be less dense

- this was the most common thing that happened in high school. Many people where

bussing, or transit was excellent. This was a

- going beyond the parks, going all the way to a place where only previously

driven...overcoming these boundaries, going further than walking. The older you get, the less distance seems to matter. Getting distance from watchful eyes... buying cigarettes and alcohol. Some people moved out so they could ride more.

- It is a rush, going down hills, going as fast as you can, racing other people. Blake street

hill. Riding on trails and like a MTB. Key fun experiences. Never had a day and hated the ride, just tired of getting wet. Earlier in life, most of the riding was recreational. Riding to school was occasional, and it was done mostly for fun

- first crashes, early in the riding experience. The older, the more vivid. Sliding under a car, covered with scratches.

- Not being able to ride due to poor repair.

- feeling protective of bikes, even when not owned

- small town. The culture of the place. Coming of age. In some places, delayed until 18

- this hints at cultural expectations. So pervasive, you drive to ride your bike!

- when in a place like Scarborough, they look at you differently, there is a sense of not belonging, they think you are crazy. This is geographically particular, the respondent even talked about an explicit car culture.

- shame, and no one talks about it. Recreation is the only socially acceptable outlet. There are times when respondents felt embarrassed for other users.

- the 70's were a different age.

-partying, driving, opposite sex. Bikes are just a way to

-if others walk, you walk. If others ride, you ride. Other people around riding, latent cycling culture. Recreational riding helped bridge that gap, as rec riding is very social. Friends started to get into it, motivated increase in own behavior. Interactions with others grow knowledge and confidence. A good way to meet significant others.

- Noticing that other people that were deemed cool, were beginning to ride. Within the city, the status was starting to rise with the younger demo. Many indifference to the coolness. BMX and MTB was cool, but people were largely indifferent.

- from the people who initially teach to ride. To circle of friends. The others with high social status.

-Moved to Toronto, moved closer to DT, Moved to Canada, moved to a new part of DT, started school, went traveling, moved to a better city, broke up with a SO, needed a job. Moving away from home. Realizing you didn't need a car.

- harrier hawks in the marshes. Beautiful people walking around. The weather, the condition of the road. The sounds around you, the glint of the light off buildings 


\title{
Appendix H - Categorized Memos
}

\section{Focus Groups}

\author{
Psycho-geography of riding \\ Emotional nostalgia \\ Perceptions of risk \\ Perceptions of Fitness \\ Social influences \\ Mainstreaming \\ Stigma \\ Coolness
}

\section{Psycho-geography of Riding}

$\{$ MEMO $\}$ relative velocity...the speed which you pass through a space determines what you can appreciate. KD talked about the benefits of walking, where as AT realizes the same thing with walking. Its all about relative speed

MEMO noticing the small things... harrier hawks in the marsh.

$\{\mathrm{MEMO}\}$ you realize how small distances are when you bike them.....shrinking of geographic space.

$\{\mathrm{MEMO}\}$ there is a great deal of awareness about boundaries, and the physical limitations that are imposed on a young rider. There is often a strong connection with the sense of freedom when these boundaries are surpassed and overcome. It allows for children to have moments of independence, which creates space for adventure and even mischief

This ties into an emotional Nostalgia

\section{Emotional Nostalgia}

$\{\mathrm{MEMO}\}-\mathrm{MR}$ recalls the I remember getting it for the first time, then riding to the end of my street. Eventually, I was able to head out to the park. we would ride around in circles around the track, trying to go as fast as possible.

There was a steep hill...we'd take turns riding down it as fast as we could. Then ride around the outside...one day, the challenge was to ride the other way around the track...I could barely climb the hills, I fell off my bike it was so hard. I recall the feeling of achievement that I felt, being able pull my self over the crest.

$\{\mathrm{MEMO}\}$ its interesting how often possession, and feelings of ownership come into this. Sometimes the bikes are borrowed, other times they are given as gifts, and later, they are purchased and made. IT is interesting to note the intensity of the bond that some feel with their bicycle. There was a sense of ownership and responsibility that comes with the object.

\section{Perceptions of Risk}

$\{M E M O\}$ it's interesting to note the views on helmets, and how some gravitate to wards them, and others do not. Helmet use is probably correlated to perceptions of risk, and projections of that perceived risk.

$\{\mathrm{MEMO}\}$ it is normal no not wear a helmet in Paris, because there is an image that cycling is safe, and because it is a safe activity, why are helmets needed? This is the expression of the activity of cycling. IT is just a normal thing for people to ride their bikes. Just a normal everyday thing...this is cycling culture in the most purest form, when advocacy is no longer needed from outside public institutions, because they have embraced it so fully.

$\{\mathrm{MEMO}\}$ they all use helmets in TO, despite having a history of not wearing a helmet in other places. I was as afraid of other cyclists and pedestrians...its about the head hitting the concrete, and it's a precaution.

$\{\mathrm{MEMO}\}$ the responsibility of different road users. They said they trusted her, but not the drivers. What is it that makes the onus on responsible road use? The idea of the other, and perceived safety. It is never you that is creating danger, it is always other people. There is an interesting intersection with perceptions of competence, confidence and safety. In the context of thinking about tragic accidents, you are always other peoples 'someone else'

\section{Perceptions of Fitness}

$\{\mathrm{MEMO}\} \mathrm{BW}$ this was an interesting case because he only rode recreationally, never to school and stopped riding when he was about 11 years old. Because of this, he was more likely to be physically active later in life, but he then began to do so in a very enthusiastic way?

\{MEMO $\}$ Danish people don't consider riding a bike exercise. When people were asked "People here can easily be riding back and forth $5 \mathrm{~km}$ per day, and if you ask them on a questionnaire if they are physically active, they will say 
'No, I don't do any exercise'," says Ledgaard Holm. For many here, she says, it's not a choice of activity, but your mode of transport. http://www.theguardian.com/cities/bike-blog $/ 2014 / \mathrm{mar} / 04 /$ cycling-cities-search-bike-friendly-metropolis.

\section{Social Influence}

$\{M E M O\}$ the social dynamics of riding are quite interesting, in the sense that no one is directly motivated to ride by social interactions, but it was the intersections and possibilities of meeting others, of being more accessibly, and more easily accessed. There are stories of courting the opposite sex, and persons that one may be attracted to through bikes. Contrast the response in the survey with the recorded interview. It is interesting that social factors rank so lowly in their decisions to ride, but remain central to the processes of adoption.

shape our views about who rides bikes. Humanization and a PR campaign

$\{M E M O\}$ this interesting because there are strong social influences, that are clearly influencing people's desire to ride more... what is it about watching peer's ride that inspires them to ride more? Each person that influenced them tended to be demonstrating a different type of cycling behavior, that was modeled by the participant in question. Although social interaction is low on the reasons to ride, it is high up on the influences on riding behavior. Across the board, the social queues were hugely influential.

$\{M E M O\}$ what is it about bikes and attraction. There is something interesting, the last 2 of my three significant relationships had cycling involved in some way.

\section{Stigma and Embarrassment}

$\{M E M O\}$ when she talked about the Trials riders... and how they were only seen, and not heard, and that they didn't even talk about it. She was almost embarrassed for them.

$\{M E M O\}$ this is an interesting response, because the tone made it seem like a no- brainer. Its interesting that despite height recreational use, there was such a blindness to riding a bike in a more utilitarian capacity. The tone of this comments still sticks with me. IT was just a given "the roads were for cars, and you would never, when I look in Toronto now, you would never see cyclists on the road - you see tractor, but you never would see a bike on the road"

\section{Mainstreaming (cycling culture)}

$\{$ MEMO\}[cycling culture] what is cycling culture...mainstream, or subculture? What does it look like, and how do you know?

$\{$ MEMO she watched the movie premium rush, and it was a formative experience for her...it looked really cool. Inspired her to ride more. What was it about premium rush that she loved? What was the projection of cycling culture $\{\mathrm{MEMO}\}$ portrayal of riding bikes in media, how does that shape our own attitudes?

A lot of condos, you can't bring the bike's in the elevator. Office buildings DT, you cant bring a bike inside. If things are not laced tight and straight, they have no place. What is the boundary of cycling...in Amsterdam...suited lawyers ride their bikes. Where does this division come from?

$\{M E M O\}$ education and enforcement. There is a sea change that is needed, to communicate that the road is for everybody..."I don't think I'll live long enough to see it happen, but it is worthwhile that we should hope."

\section{Coolness}

It brings up an image... do sometimes people do something because it fits an image that they want to express. Its is a form of presentation. Bike specific clothing and whatnot.

\{NOTE\} KD brings up the idea of coolness, but it only really comes up in a very passive way. The image of cycling does not seem like a less than conscious phenomenon. Although all behaviors are greatly guided by peer interaction with peers. And does not seem like anything particularly noteworthy.

$\{\mathrm{MEMO}\}$ are bikes trendy? What is the trend? For all kinds of reasons... is it cool to take care of the planet. Its more affordable... it is also convenient. Bike are more bike friendly.

\section{Analysis}

Although riding a bike is a transportation choice, it is also a consumer choice. Like many other consumer choices there are many non-rational and emotional factors that come into play. Rational factors include, distance, weather and existence of adequate bicycle facilities. Non-rational factors include a powerful nostalgia, social influences revolving around self-perception and self-awareness, and expressions of a desired image. Understanding how these factors interact with the more rational factors is important to developing a strategy's to market cycling more effectively. 
And this ties back into the Transtheoretical model. Campaigns for increased cycling (Prochaska et al, 2008; P. Hyllenius et al, 2009; Merseyside LTP Support Unit, 2010).

There was a Danish study that sought to understand the effectiveness of bicycle marketing messages. It collected responses about general risk and experienced self risk, Experience (enjoyment), Image and Appearance, and the values associated with the pictures. There is an interesting gap between perceived risk, and experienced self-risk. The most central opinion is enjoyment, a finding shared by this study. This speaks for focusing on positive aspects and leave out negative safety issues when marketing cycling. This is not big news for marketing people but still a challenge to be overcome in some Danish campaigns. If one focuses on appearance and image - which can also be claimed to be of relevance from a marketing point of view - picture impacts point in other directions than is the case for experience (enjoyment). This is indeed the case for opinions on values related to the different pictures. Here, a picture of a cyclist wearing a helmet scores higher on all values - even on comfort - than a picture of the same cyclist without a helmet. (Thomas Kragg, 2013)

If one focuses on appearance and image - which can also be claimed to be of relevance from a marketing point of view picture impacts point in other directions than is the case for experience (enjoyment). This is indeed the case for opinions on values related to the different pictures. Here, a picture of a cyclist wearing a helmet scores higher on all values - even on comfort - than a picture of the same cyclist without a helmet.

Perhaps this is why BIXI is an interesting program to follow... how many new riders are created by BIXI? 


\section{Appendix I - Additional Questions Theoretical Sample}

Hi 'participants name here',

Thank you, I appreciate your time at this busy time of the year.

These questions are closely related to the topics of conversation during the focus group and survey, but allow for more reflection. I suggest reading through all the questions before beginning. I seek only descriptive and candid recounting of these moments and processes. Please take as much, or as little space as you need.

1.1 Can you remember, at any point in the last five years or so, a moment of 'awakening' to the possibilities of riding a bike more consistently or intentionally than you had done in the past?

1.2 More specifically, what was the context of the 'moment' when you made a conscious or concerted effort to ride as frequently as you do today? What was the biggest factor shaping your decision?

2. What is the image that is conveyed with the word 'cyclist', and how do you relate to it? Do you think you are described as a 'cyclist' when talked about by other people? In what ways is this positive, in what ways is this negative?

3. Aside from improving physical infrastructure, such as cycle-tracks, on street bike lanes, and more bike parking - what would encourage people, like yourself (ie. university-age female) to ride more often?

Best,

Mark Romeril 


\section{WORKS CITED}

Adams, J and White, M. (2005) Why don't stage-based activity promotion interventions work? Health Education research. July 14. Ajzen, I., Fishbein, M. (1980) Understanding attitudes and Predicting Social Behaviour. Englewood Cliffs, Prentice-hall.

Aldred, R. 2010 .'On the outside’: constructing cycling citizenship. Social \& Cultural Geography. Vol. 11, No.1 , pp.35-52.

Albarracín, D. Johnson, B., Bein, M., Muellerleile, P. (2001) Theories of Reasoned Action and Planned Behavior as Models of Condom Use: A Meta-Analysis. Centre for Health Intervention and Prevention. Accessed at: http://digitalcommons.uconn.edu/chip_docs/8/

Arancibia, D (2014) Cyclists, Bike Lanes and On-street Parking: Economic Impacts. University of Toronto: Toronto Cycling Think \& Do Tank.

Armitage, CJ.(2009) Is there Utility in the Transtheoretical Model? British Journal of Health Psychology. Vol.14, Pt. 2, pp. $195-210$.

Aveyard, P., Massey, L., Parsons A., Manaseki, S., Griffin, C. (2009) The effect of transtheoretical model based interventions on smoking cessation. Social Science Methodology. Vol. 68 Iss. 3, pp. 397-403.

Aveyard P., Bauld, L, (2011) Incentives for Promoting Smoking Cessation: What We Still Do Not Know. The Chochrane Library Cochrane Database System April 13, Vol 3. ED000027 Accessed at: http://www.thecochranelibrary.com/details/editorial/1052523/Incentives-for-promoting-smoking-cessation-what-we-still-do-notknow.html

Badland, H., Schofield, G. (2006). Perceptions of replacing car journeys with non-motorized travel: Exploring relationships in a crosssectional adult population sample. Preventive Medicine, Vol. 43, No. 3, pp. 222-225.

Baranowski, T.C., Anderson , Carmack, C. (1998) Mediating variable framework in physical activity interventions: How are we doing? How might we do better? American Journal of Preventive Medicine. Vol. 15, pp. 266-297.

Barwais, F., Cuddihy, T., Tomson, L. (2013) Physical activity, sedentary behavior and total wellness changes among sedentary adults: a 4-week randomized controlled trial. Health and Quality of Life Outcomes. Vol. 11, pp.183. Accessed at doi:10.1186/1477-7525-11183

BBC (2009) 'Cycling is like brushing your teeth'. One-Minute World News. Thursday August $27^{\text {th }}$. Accessed at: http://news.bbc.co.uk/2/hi/europe/8223520.stm

Benzeval, M. , K. Judge \& M. Whitehead (1995), Tackling Inequalities in Health: An Agenda for Action, Kings Fund, London.

Blondel, B; Mispelon, C; Ferguson, J. (2011) Cycle More Often 2 Cool Down The Planet: Quantifying CO2 Savings of Cycling. European $\backslash$ Cyclists Federation. Brussels. Accessed at http://www.ecf.com/wpcontent/uploads/ECF_BROCHURE_EN_planche.pdf

Böhm, S., Jones, C., Land, C., Paterson, M. (2006) Part One Conceptualizing Automobility: Introduction: Impossibilities of automobility. The Sociological Review. Vol. 54, pp. 1-16

British Medical Association (2012) Healthy Transport = Healthy Lives. London. Accessed at: file:///Users/markromeril/Downloads/healthytransporthealthylives\%20.pdf

Bridle, C., Riemsma, RP,. Pattenden, J., Sowden, AJ., Mather, L., Watt, IS., Walker, A. (2005)Systematic review of the effectiveness of health behavior interventions based on the transtheoretical model. Psychology Health. Vol. 20, pp.283-301.

Brug, J., Conner, M., Harré, N., Kremers, S., McKellar, S., \& Whitelaw, S. (2005). The Transtheoretical Model and stages of change: A critique. Health Education Research, Vol. 20, No. 2, pp. 244-258.

Campbell, R., \& Wittgen, M. (2004) The business case for active transportation: the economic benefit of walking and cycling. B.E.S.T. Better Environmentally Sound Transportation. Third Wave Cycling. Accessed at: http://thridwavecycling.com/pdf/at_business_case.pdf

California Department of Transportation (2010) Federal Economic Stimulus Transportation Projects. http://www.dot.ca.gov/Recovery/documents/federaleconomicstimulustransportationprojects.pdf

Calman, L. (2006), What is Grounded Theory? The University of Manchester. [Accessed on April 12 $2^{\text {th }}, 2014$ ] Accessed at: http://www.methods.manchester.ac.uk/events/whatis/gt.pdf

Cawthorne, A. (2010) Trouble in the Suburbs: Poverty Rises in Areas Outside Cities. Center for American Progress. Accessed at: http://www.americanprogress.org/issues/poverty/news/2010/10/27/8457/trouble-in-the-suburbs/

Cervero, R., \& Kockelman, K. (1997) Travel Demand and the 3Ds: Density, Diversity and Design. Transportation Research Part D: Transport and Environment, Vol. 2, Iss. 3, pp. 199-219.

Charmaz, K. (1995). "Between positivism and postmodernism: Implications for methods". Studies in Symbolic Interaction. Vol. 17, pp. 43-72.

Charmaz, K. (2003). "Qualitative interviewing and grounded theory analysis". In: Holstein, J.A. \& Gubrium, J.F. (eds.), Inside Interviewing: New Lenses, New Concerns, pp. 311-330. London: Sage.

Charmaz, K. (2006). Constructing grounded theory: A practice guide through qualitative analysis. Thousand Oaks, CA: Sage.

Chatterjee, K., Sherwin, H., Jain, J. and Christiensen, J. Marsh, S (2013) a conceptual model to explain turningpoints in bicycle behaviour: application to bicycle use. Transporation Research Board. Vol 2322, pp.82-90.

City of Toronto (2011) Bikeway Network - 2011 Update. City of Toronto Staff Report. June $9^{\text {th }}, 2011$. Reference number: P:|2011\Cluster|B।TRAITIM\pw11004tim

City of Calgary (2011) Cycling Strategy Research - Public Telephone Survey. Prepared By HarGroup Management Consultants Inc.

City of Toronto (2010) City of Toronto Cycling Study: Tracking Report 1999-2009. Prepared by Ipsos Reid.

City of Toronto (2014) Appendix 7: Post-Construction Congestion Cost Calculation. Toronto Public Works and Infrastructure, February. Accessed at : http://www.toronto.ca/legdocs/mmis/2014/pw/bgrd/backgroundfile-67176.pdf 
City of Toronto (2007) Change is in the Air: Climate Change, Clean Air and Sustainable Energy Action Plan: Moving from framework to action. Phase 1. Toronto: Toronto Energy Efficiency Office. Accessed at http://www1.toronto.ca/City\%20Of\%20Toronto/Environment $\% 20$ and $\% 20$ Energy/Programs $\% 20$ for $\% 20$ Residents/Files/pdf/C/cle an_air_action_plan.pdf

Clarke, K. (2013) Father of bike courier who died after altercation with former Ontario AG Michael Bryant seeking justice for 'Al'. National Post, May 23. Accessed at: http://news.nationalpost.com/2013/05/23/father-of-bike-courier-who-died-after-altercationwith-former-ontario-ag-michael-bryant-seeking-justice-for-al/

Clifton, K., Muhs, C., Morrissey, S., Morrisey, T., Currans, K., Ritter, C (2012) Consumer Behaviour and Travel Mode Choices The Oregon Transportation and Research Consortium (OTREC) http://kellyjclifton.com/Research/EconImpactsofBicycling/OTRECReport-ConsBehavTravelChoices_Nov2012.pdf

Clifton, K., Currans, K.M., Muhs, C., Ritter, C., Morissey, S., Roughton, C. (2013) Consumer Behaviour and travel choices: a focus on cyclists and pedestrians. Oregon transportation research and education consortium. Portland, OR.

Cohlmeyer (2012) A Tool Kit to Accelerate the Adoption of Cycling for Transport. University of Toronto: Toronto Cycling Think \& Do Tank.

Augustyn, R., Fletcher, V., Guliani, Luyt, G., Reeder, J., Romeril, M., Rowshan, D., Sadoway, M., Thibeault, F.,(2013) Connecting Black Creek: A Strategic Active Transportation Plan [Supervised by Dr. Shelagh McCartney]. Ryerson University. Toronto.

Consiglio, A (2012) Road-rage cabbie who hit cyclist jailed 2 years. Toronto Star, October $2^{\text {nd }}$. Accessed at: http://www.thestar.com/news/crime/2012/10/02/roadrage_cabbie_who_hit_cyclist_jailed_2_years.html

Cortright, J. (2007) Portland's Green Dividend. CEO's For Cities [Accessed on April 12 ${ }^{\text {th }}, 2014$ ] Accessed at: http://www.ceosforcities.org/city-dividends/green/special-reports/portland/

Cowen, D and Parlette, V. (2011) Toronto's Inner Suburbs: investing in Social Infrastructure in Scarborough. University of Toronto Cities Centre. Accessed at http://neighbourhoodchange.ca/wp-content/uploads/2011/06/Cowen-2011-Social-Infrastructure-inScarborough-N-Change.pdf

Culley, T. (2001) The Immortal Class: Bike Messengers and the Cult of Human Power. Random House: Chicago

Davies, D., Gray, S., Gardner, G. ,Harland, G. (2001) A quantitative study of the attitudes of individuals to cycling. TRL Report. No.481.

Dickinson, J., Kingham, S., Copsey, S. and Pearlman Hougie, D. (2003) Employer travel plans, cycling and gender: will travel plan measures improve the outlook for cycling to work in the UK? Transportation Research D: Transport and Environment, Vol. 8, No. 1, pp. 53-67.

DiClemente, CC., Prochaska, J.O., Fairhurst, SK, Velicer, W.F., Velasquez, M.M., Rossi, J.S. (1991) the process of smoking cessation: and analysis of precontemplation, contemplation and preparation stages of change. Journal of Consulting and Clinical Psychology, Vol. 59, pp.295-305.

Dill, J., \& Voros, K. (2007) Factors Affecting Bicycling Demand: Initial Survey Findings from the Portland, Oregon Region. Transportation Research Record: Journal of the Transportation Research Board. No. 2031, pp. 9-17.

Dishman, R. Jackson, A., Bray, M. (2010) Annals of Behavioural Medicine. Vol. 40, Iss. 2, pp. 164-175.

Dishman, R., Motl, R., Saunders, R., et al (2004) Self-efficacy partially mediates the effect of a school-based intervention among adolescent girls. Journal of Preventative Medicine. Vol. 38, pp. 628-636.

Drauker, C., Martsolf, D., Ross, R et al. (2007) Theoretical sampling and categorical development in grounded theory. Qualitative Health Research. Vol. 17,1137-48.

Dunn, A., Garcia, M., Marcus, B., Kampert, J., Kohl, H., Blair, S. (1998) Six-month physical activity and fitness changes in Project Active, a randomized trial. Medical Science Sports Exercise. Vol. 30, No. 7, pp. 1076-83.

Edgar, D. (2012) Learning Theories and Historical Events Affecting Instructional Design in Education Recitation Literacy Toward Extraction Literacy Practices. SAGE Open. (Oct) Vol. 2 No.4, pp. 1-9.

Felland, L., Lauer, J., Cunningham, P.(2009) Suburban poverty and the health care safety net. Res Brief Vol. 13, July, pp.1-12 Fox, K.R. (1999) The Influence of Physical Activity on Mental Well-Being. Public Health Nutrition. Vol. 2, Sup. 3a, pp. $411-8$.

Frank L., Andresen M., Schmid T. (2004) Obesity relationships with community design, physical activity, and time spent in cars. American Journal of Preventive Medicine. Vol. 27, Iss. 2, pp. 87-96.

Frank, L. Engelky, P., Schmid, T. (2003) Health and Community Design: the impact of built environment on physical activity. Washington Island

Forkes, J. Smith, L.N. (2010) Bike Lanes, on-street parking and business. Year 2 Report. A Study of Bloor Street in Toronto's Bloor West Village: Toronto, Clean Air Partnership.

Fincham, B. (2006) Messengers and the Road to Freedom. The Sociological Review. Vol. 54. Pp. 208-222.

Fishbein, M., \& Ajzen, I. (2010). Predicting and changing behavior: The Reasoned Action Approach. New York: Taylor \& Francis.

Furness, Z. (2010) One Less Car: Bicycling and the Politics of Automobility. Philadelphia: Temple University Press.

Gatersleben, B., Haddad, H. (2010) Who is the typical bicyclist? Transportation Research, Part F, Vol. 13, pp. 41-48.

Geller, R. (2006) Four Types of Cyclist. Portland Office of Transportation. [Accessed on April 12 ${ }^{\text {th }}, 2014$ ] Accessed at: https://www.portlandoregon.gov/transportation/article/237507

Glaser, B., \& Strauss, A. (1967). The discovery of grounded theory. Chicago: Aldine.

Glaser, B., Strauss, A. (1967). The discovery of grounded theory: Strategies of qualitative research. Piscataway, NJ: Aldine Transactions.

Gatersleben, B \& Appleton. K. M. (2007) Contemplating cycling to work: Attitudes and perceptions in different stages of change. Transportation Research. Vol 41, p. 302-312. 
Gotschi, T. (2010) Costs and Benefits of Bicycling Investment in Portland, Oregon. Journal of Physical Activity and Health. Vol 8 January Supplemental. pp.49-58. Accessed at: http://journals.humankinetics.com/jpah-supplements-special-issues/jpah-volume-8-supplement-january/costs-and-benefits-ofbicycling-investments-in-portland-oregon

Goulding, C. (1998) "Grounded Theory: The Missing Methodology on the Interpretivist Agenda" Qualitative Market Research: An International Journal. Vol. 1, Iss. 1, pp. 50-57.

Greater Toronto Marketing Alliance (2012) Invest in the Greater Toronto Area: Financial Services Sector Overview. Toronto. Accessed at: http://greatertoronto.org/wp-content/uploads/2012/10/Invest-in-the-GTA-Fiancial-Services.pdf

Greater Toronto Transportation Authority (2008) Final Report: Metrolinx: Costs of Road Congestion in the GTHA: Impact and Cost Benefit of the Metrolix Draft Regional Transportation Plan. Toronto: HDR. Accessed at http://www.metrolinx.com/en/regionalplanning/costsofcongestion/ISP_08-015_Cost_of_Congestion_report_1128081.pdf

Groesz, L.(2007) A conceptual evaluation of school-based utilitarian exercise model. Austin: University of Texas.

Handy, S. (1996) Understanding the link between urban form and non-work travel behaviour. Journal of Planning Education Research. Vol. 15, pp. 183-98.

Handy, S. (2011) The Davis Bicycle Studies: Why do I bicycle but my neighbor doesn't? Fall ACCESS \#39. pp.16-21

Handy, S; Xing, M; Buehler, P (2010). Factors associated with bike ownership and use: a study of six small US cities. Transportation. Vol. 37, pp.967-985

Harms, S., \& M. Lanzendorf, (2007). From university to working life: Impact of a critical life event on travel mode choice. Paper presented at 7th Biannual Conference on Environmental Psychology, Bayreuth, September 9-12, 2007.

Hartog, JJ., Boogaard, Nijland, H., Hoek (2010) Do the health benefits of cycling outweigh the risks? Environmental Health Perspectives. Vol. 118 Iss.8, pp.1109-1116.

Heinen, E. Maat, K., \& van Wee, B. (2012) The effect of work-related factors on the bicycle commute mode choice in the Netherlands. Transportation. Published online $11^{\text {th }}$ April.

Heinberg, L., Thompson, J., (2009) Obesity in youth : causes, consequences, and cures. American Psychological Association: Washington.

Hillsdon, M., Foster, C., Thorogood, M. (2005) Interventions for promoting physical activity. Cochrane Database of Systematic Reviews. pp. 1.

Horton, D., Parkin, J. (2012) Towards a Revolution in Cycling - Dave Horton, John Parkin (pp. 303 - 3252012 book in Ed Parkin, J. Cycling and Sustainability. Emerald Group Publishing: London.

Horton, D. (2014) Draft of Towards a Revolution in Cycling. Thinking About Cycling. [Accessed on: April 12 $\left.{ }^{\text {th }}, 2014\right]$ Accessed at: http://thinkingaboutcycling.com/towards-a-revolution-in-cycling/

Hulchanski, D. (2010) The Three Cities Within Toronto: Income Polarization Among Toronto's Neighbourhoods, $1970-2005$. University of Toronto Cities Centre.

Kent (2013) Private Car Use As Resistance to Alternative Transport: Automobility's Interminable Appeal. University of New South Wales. Accessed at: http://www.be.unsw.edu.au/sites/default/files/SOAC\%20PhD_0.pdf

Klockner, C. (2004) How Single Events Change Travel Mode Choice - A life Span Perspective. Paper presented at the Third Annual Conference on Traffic and Transport Psychology, Nottingham, UK.

Khandkar, S. (2014) Open Coding. University of Calgary Computer Science Resources. Accessed At http://pages.cpsc.ucalgary.ca/-saul/wiki/uploads/CPSC681/open-coding.pdf

Kolb, J (2013) Cycle Toronto Observes more bikes that cars on College Street. Cycle Toronto. December Accessed at http://cycleto.ca/news/2013/12/13/cycle-toronto-observes-more-bikes-cars-college-street

Kolb, J (2014) Toronto adds zero protected bike lanes, little paint, in 2013. Cycle Toronto December Accessed at http://cycleto.ca/news/2013/12/18/toronto-adds-zero-protected-bike-lanes-little-paint-2013

Krizek, K., Roland, R. (2005)What is at the end of the road? Understanding discontinuities of on-street bicycle lanes in urban settings. Transportation Research part D10, pp.55-68.

Laurier, E., \& Dant, T. (2012). What else we do while driving: towards the driverless car. In M. Grieco, \& J. Urry (Eds.), Mobilities: new perspectives on transport and society . (pp. 223-244). Farnham: Ashgate.

Ledsham, T., Liu, G., Watt, E., Katie, W. (2012) Mapping Cycling Behaviour in Toronto. University of Toronto: Toronto Cycling Think \& Do Tank.

Litman, T (2009) Transportation Cost and Benefit Analysis: Techniques, Estimates and Implications. Victoria: Victoria Transportation Policy Institute. Accessed at http://vtpi.org/tca/

Mapes, J. (2009) Pedaling Revolution: How Cyclists are Changing American Cities. Corvallis: Oregon State

Martens, P. (2006) Sustainability: Science or Fiction. Sustainability: Science, Practice, and Policy. Online Journal. Spring, Vol. 2, Iss.1, pp.36-41.

McClintock, H. (1992) 'The significance of the bicycle in urban transport' in McClintock (ed.) The Bicycle and City Traffic. Belhaven Press. London.

Metrolinx (2008) The Big Move: Transforming Transportation in the Greater Toronto and Hamilton Area. Ontario.

Motl, M., Dishman, R., Ward, D., et al (2005) Perceived physical environmental and physical activity across one year among adolescent girls: self-efficacy as a possible mediator? Journal of Adolescent Health. Vol. 37, pp. 403-408.

Motl, R., Dishman, R., Saunders, R,. Dowda, M., Pate, R. (2007) Perceptions of physical and social environment variables and selfefficacy as correlates of self-reported physical activity among adolescent girls. Journal of Pediatric Psychology. Vol. 32, Iss. 1, pp.612. 
Nigg, C. (2001). Explaining adolescent exercise behavior change: A longitudinal application of the transtheoretical model. Annals of Behavioral Medicine, Vol. 23, pp. 11-20.

Ontario Ministry of Transportation (2013) \#CycleON: Ontario's Cycling Strategy. Accessed at: http://www.mto.gov.on.ca/english/pubs/cycling-guide/pdfs/MTO-CycleON-EN.pdf

Orsini, S. (2005) Fun, Fast, and Fit: Influences and Motivators for Teenagers who cycle to school. Thesis portion of Masters of Environmental Education and Communication. Royal Roads University. Contact Author for access.

$\left(O E D_{1}\right)$ Oxford English Dictionary (online ed.).(2014). Phsychosocial. [accessed on: April 12 ${ }^{\text {th }}, 2014$ ] Accessed at: http://www.oed.com/view/Entry/153937?redirectedFrom=psychosocial\#eid

$\left(\mathrm{OED}_{2}\right)$ Oxford English Dictionary (online ed.).(2014). Hegemony. [accessed on: April 12 ${ }^{\text {th }}, 2014$ ] Accessed at: http://www.oed.com/view/Entry/85471?redirectedFrom=hegemony\#eid

$\left(\mathrm{OED}_{3}\right)$ Oxford English Dictionary (online ed.).(2014). Cyclist. [accessed on : April 12 ${ }^{\text {th }}$, 2014] Accessed at: http://www.oed.com/view/Entry/46521?rskey=q4WFqO\&result=1\&isAdvanced=false\#eid

Onwuegbuzie, A., \& Leech, N.(2007) An Array of Qualitative Data Analysis Tools: A Call for Data Analysis Triangulation School Psychology Quarterly. Vol. 22, No. 4, pp. 557-584.

Patton, M.(2002). Qualitative research \& evaluation methods (3rd ed.). Thousand Oaks: Sage.

(PBIC) Pedestrian and Bicycle Information Center, WalkingIngo.com, "Bicycle Lanes" retrieved on April 1", 2014 Accessed from: http://wwwwalkinginfo.org/engineering/roadway-bicycle.cfm

Perkins, D. (2004) Childhood and Adolescent Sports Participation as Predictors of Participation in Sports and Physical Fitness Activities During Young Adulthood. Youth Society. Vol. 35, no. 4, pp. 495-520.

Prochaska, JO., DiClemente, CC., Norcross, JC.(1992). In search of how people change. Applications to addictive behaviours. American Psychology. Vol. 47, pp. 1102.

Prochaska, J.O., DiClemente, C.C. (1984) The Transtheorecial Appraoch: crossing traditional boundaries of therapy. Homewood.Dow Jones Irwin.

Plotnikoff, R.C., Lippke, S., Johnson, S.T., Courney, K.S. (2010) Physical activity and stages of change: a longitudinal test in types 1 and 2 diabetes samples. Annals of Behavioural Medicine. Vol. 40, Iss. 2, pp.138-49.

Pucher, J., \& Buehler, R.(2008) Making Cycling Irresistible: lessons from the Netherlands, Denmark and Germany. Transport Reviews. Vol. 28, pp. 495-528.

Pucher, J., Komanoff, C., Schimek (1999) Bicycling Renaissance in North America? Recent Trends and alternative policies to promote bicycling. Transportation Research. Vol. 30, pp. 22

Raphael, D. (2002) Poverty, Income Inequality, and Health in Canada. School of Health Policy and Management. The CSJ Foundation for Research and Education. Toronto. Accessed at: http://www.povertyandhumanrights.org/docs/incomeHealth.pdf

Reichertz, J. (2010) Abduction: The logic of discovery in grounded theory. Forum: Qualitative social research. Vol.11, Iss. 1, art 13.

Rhodes D., R., Pfaeffli, L. (2010) Mediators of physical activity behaviour change among adult non-clinical populations: a review update. International Journal of Behavioral Nutrition and Physical Activity. Vol. 37

Rabl, A., \& De Nazelle, A. (2012) Benefits of shift from car to active transport. Transport policy. Volume 19, Issue 1, pp. 121-131. Accessed at: http://www.sciencedirect.com/science/article/pii/S0967070X11001119

Riemsma, RP., Pattenden, J., Bridle, C., Sowden, AJ., Mather, L., Watt, IS., Walker, A.(2003)Systematic review of the effectiveness of stage based interventions to promote smoking cessation. British Medical Journal. Vol. 326, Iss. 7400, pp. 1175-7.

Rissel C.E., Wen, L et al (2010) The effectiveness of community-based cycling promotion: findings from the cycling connecting communities project in Sydney, Australia. International Journal of Behavioural Nutrition and Physical Activity. pp. 8.

Sallis, J., Cervero, R., Ascher, W., Henderson, K., Kraft, M., Kerr, J. (2006) An Ecological Approach to Creating more Physically Active Communities. Annual Review of Public Health. Vol.27, pp. 297-322.

Sandman, P., Weinstein, N. (1993) Predictors of home radon testing and implications for testing promotion programs. Health Education Quarterly. Vol. 20, pp. 1-20.

Saunders, R., Motl, R,. Dowda, M., Dishman, R, Pate, R. (2004) Comparison of social variables for understanding physical activity in adolescent girls. American Journal of Health and Behaviour. Vol. 28, Iss. 5, pp. 426-436.

Schwandt, T. A. (2001). Dictionary of qualitative inquiry ( $2^{\text {nd }}$ ed.). Thousand Oaks, CA: Sage.

Share the Road (2012) Provincial Bicycling Organization Releases Polling Data highlighting Support for Active Transportation in Metrolinx's The Big Move. Burlington Accessed at http://www.sharetheroad.ca/files/Media_Release__OBS_Metrolinx__FINAL.pdf

Sheeran, P. (2002) Intention-behaviour relations: A conceptual and empirical review. In European Review of Social Psychology. Edited by Hewstone M, Stroebe W. Chichester, UK: John Wiley \& Sons: pp.1-36.

Sheeran, P.,\& Taylor, S. (1999). Predicting intentions to use condoms: A meta-analysis and comparison of the theories of reasoned action and planned behavior. Journal of Applied Social Psychology, Vol. 29, pp.1624-1675.

Spencer, L., Pagell, F., \& Adams, T.(2005). Applying the transtheoretical model to cancer screening behavior: A review of Literature. American Journal of Health Behavior. Vol. 29, No.1, pp. 36-56 .

Sram, J., \&Ashton, I. (1998). Millennium Report to Sir Edwin Chadwick. British Medical Journal. Vol. 317, pp. $592-596$.

Starks, H \& Brown, S. (2007) Choose Your Method: A Comparison of Phenomenology, Discourse Analysis, and Grounded Theory Qualitative Health Research. Vol 17: pp.1372 - 1383

Stein, S. (1996) "Image, Identity and Conflict Resolution," in Managing Global Chaos, eds. Crocker, C., Hampson, F., Aall, P. Washington: United States Institute of Peace Press, pp 93-111.

Strauss, A., \& Corbin, J. (1990). Basics of qualitative research. Newbury Park: Sage. 
Sztabinski, F. (2009) Bike Lanes, On-Street Parking and Business :A Study of Bloor Street in Toronto's Annex Neighbourhood. Toronto: Clean Air Partnership. Accessed at http://www.cleanairpartnership.org/pdf/bike-lanes-parking.pdf

Taylor, D., Bury, M., Campling, N. et al (2006) A Review of the use of the Health Belief Model (HBM), the Theory of Reasoned Action (TRA), the Theory of Planned Behaviour (TPB) and the Trans-Theoretical Model (TTM) to study and predict health related behaviour change. London: National Institute for Clinical Excellence (NICE)

Taylor, A.H. (2000) Physical activity, anxiety and stress in: Biddle S, Fox, K.R., Boutcher, S.H., editors. Physical Activity and Psychological Well-being. Routledge. p. 10-45.

Teschke, K. Raynods, C. Ries, F. Gouge, B. Einters, M. (2012) Bicycling: Health Risk or Benefit? University of British Columbia Medical Journal. Vol 3, Iss. 2, pp. 6-11 Accessed at: http://ubcmj.com/pdf/ubcmj_3_2_2012_6-11.pdf

Thompson, C. (1999) Pearls, Pith and Provocation: Qualitative Research Into Nurse Decision Making: Factors for Consideration in Theoretical Sampling. Qualitative Health Research, Vol. 9 No. 6, pp. 815-828.

Toronto Regional Board of Trade (2013) A Green light to moving the Toronto Region: Paying for Public Transit Expansion. Toronto. Accessed at: http://www.bot.com/Content/NavigationMenu/Policy/TransportationCampaign/DiscussionPaper_AGreenLight_March18_2013.p $\underline{\mathrm{df}}$

Transportation Alternatives (2012) East Village Shopper Study. New York City. Accessed at http://transalt.org/files/news/reports/2012/EVSS_Final.pdf

Troelsen, J. (2005) Transport and Health: Odense - the national cycling city of Denmark 1999-2002. Ugeskrift for Laeger. Vol. 167, pp. 1164-6.

Toronto Board of Trade (2011) Reaching Top Speed: Infrastructure - Unleasing Ontario's ability to Grow. Accessed at: http://www.bot.com/advocacy/Documents/VoteOntario2011/Reaching_Top_Speed.pdf

Toronto Public Health (2012) The Road to Health: Improving Walking and Cycling in Toronto. City of Toronto, April 2012 Accessed at: http://www.toronto.ca/health/hphe/pdf/roadtohealth.pdf

Underwood, S., \& Handy, S. (2012) Adolescent Attitudes Towards Active Transportation: Bicycling in Youth in Retrospect from Adulthood . Institute of Transportation Studies, University of California, Davis, Research Report UCD-ITS-RR-12-14

United Way (2014) 13 Priority Neighbourhoods Map. Toronto. Accessed at: http://www.unitedwaytoronto.com/whatWeDo/neighbourhoodsMap.php

Urry, J. (2007) Mobilities. London: Polity

Van der Waerden, P., Timmermans, H., Borgers, A. (2003) The Influence of Key Events and Critical Incidents on Transport mode choice switching behaviour: a descriptive analysis. Presented at 10th International Conference on Travel Behaviour Research. Lucerne, 10-15. August 2003

Velicer, W. F, Prochaska, J. O., Fava, J. L., Norman, G. J., Redding, C. A.(1998) Smoking cessation and stress management: Applications of the Transtheoretical Model of behavior change. Homeostasis, Vol. 38, pp. 216-233.

Wardman, M., Hatfield, R., Page, M. (1997) The UK national cycling strategy: can improved facilities meet targets? Transport Policy. Vol. 4, pp. 123-133.

Weichselbaum, E., Hooper, B., Buttriss, J., Theobald, C., Sgarabottolo, V., Combris, P., Strigler, F. et al (2013) Behaviour change initiatives to promote a healthy diet and physical activity in European countries. Nutrition Foundation Nutrition Bulletin. Vol. 38, pp. 85-99.

Weinstein, N.D. (2007) Misleading tests of health behaviour theories. Annals of Behavioural Medicine. Vol. 33, pp.1-10.

West, R. (2009) Time for a change: putting the Transtheoretical (Stages of Change) Model to rest. Addiction. Vol. 100, Iss. 8, pp.

$1036-9$.

Wilde, O (1891) The Soul of Modern Man under socialism. Project Gutenberg. August, 1997 [EBook \#1017], Updated May 21 st, 2003. [Accessed April 12 ${ }^{\text {th }}, 2014$ ] Accessed at: http://www.gutenberg.org/ebooks/1017

Wilson, R.A. (1995) Ecological Autobiography. Environmental Education Research, Vol.1 Iss. 3, pp.305-314.

Wray, J. (2008) Pedal Power: The Quiet Rise of the Bicycle in American Public Life. Paradigm Publishers: Boulder 